\title{
Constructing Narrowband Thermally Activated Delayed \\ Fluorescence Materials with Emission Maxima Beyond 560 nm Based on Frontier Molecular Orbital Engineering
}

Xinliang Cai, ${ }^{\text {a }}$ Yincai Xu, ${ }^{\text {a }}$ Qingyang Wang, ${ }^{a}$ Chenglong Li, ${ }^{\mathrm{a}, *}$ and Yue Wang,,${ }^{\mathrm{a}, \mathrm{b}, *}$

${ }^{a}$ X. Cai, Y. Xu, Q. Wang, C. Li and Y. Wang

State Key Laboratory of Supramolecular Structure and Materials

College of Chemistry, Jilin University, Changchun 130012, P. R. China

${ }^{\mathrm{b}}$ Y. Wang

Jihua Laboratory, 28 Huandao South Road, Foshan 528200, Guangdong Province, P. R. China.

Authors to whom correspondence should be addressed:

chenglongli@jlu.edu.cn (C. Li); yuewang@jlu.edu.cn (Y. Wang)

Keywords: high color purity, multiple resonance, thermally activated delayed fluorescence

\begin{abstract}
The development of purely organic materials with narrowband emission in long wavelength region beyond $560 \mathrm{~nm}$ still remains a great challenge. Herein, we present a modification approach of multiple resonance (MR) skeleton with electron donor based on frontier molecular orbital engineering (FMOE), resulting in significant red-shift emission of target molecules. Subsequently, the parent MR skeleton is functionalized by boron esterification reaction and changed into a universal building block, namely, the key intermediate BN-Bpin, for molecular structure optimizations. BN-Bpin has been employed to construct a series of highly efficient thermally activated delayed fluorescence (TADF) materials with high color purity through one-step Suzuki coupling reaction. The target molecule perfectly integrates the inherent advantages of MR skeleton and spatial separation typical donor-acceptor (D-A) structure. The results demonstrate that the ingenious modulation of the acceptor is an effective approach to achieve bathochromic emission and narrowband emission simultaneously.
\end{abstract}


The development of purely organic thermally activated delayed fluorescence (TADF) materials has attracted wide attention because they can repopulate electrogenerated dark triplet exciton into bright singlet exciton through reverse intersystem crossing (RISC) process, and thus achieve highly efficient conversion of electric energy to light. ${ }^{[1]}$ Generally, in order to obtain an efficient RISC process, it is necessary to reduce the singlet-triplet energy splitting $\left(\Delta E_{\mathrm{ST}}\right)$ between the lowest singlet $\left(\mathrm{S}_{1}\right)$ state and the lowest triplet $\left(T_{1}\right)$ state, which can be realized by minimizing the overlap between the highest occupied molecular orbital (HOMO) and the lowest unoccupied molecular orbital (LUMO). ${ }^{[2]}$ The often adopted strategy for achieving small $\Delta E_{\mathrm{ST}}$ is to construct intramolecular charge transfer (ICT) configuration based on the spatial separation typical donor-acceptor (D-A) molecular skeleton. However, this kind molecular design strategy can inevitably increase the vibrational coupling between the ground state $\left(\mathrm{S}_{0}\right)$ and $\mathrm{S}_{1}$ state, as well as the structural relaxation of the $\mathrm{S}_{1}$ state, leading to significant Stokes shift and broad emission spectra. ${ }^{[3]}$ The broadband emission means poor color purity, so it cannot meet the need of wide color gamut display that is important for images to accurately reproduce the true colors of the objects. ${ }^{[4]}$ Although the required color purity can be realized by cutting off the margin region of original broadband electroluminescence (EL) using an optical apparatus (e.g., color filter or optical microcavity), the disadvantage is that these treatments greatly depresses the actual efficiency of organic light-emitting diodes (OLEDs) and increase cost. ${ }^{[5]}$ However, it must be highlighted that the most outstanding advantage of D-A structure is that the emission maxima can be flexibly and widely adjusted within the region of visible light spectrum.

Recently, multiple resonance (MR) induced TADF materials based on B-Ncontaining molecules have shown great potential in the preparation of efficient OLEDs with high color purity. ${ }^{[6]}$ The MR-TADF molecule is composed of a rigid skeleton with alternative arrangement of HOMO and LUMO (Scheme 1a), which holds the exclusive excitonic characteristics such as large extinction coefficients, ideal oscillator strength $(f)$, narrow full-width at half-maximum (FWHM), and high photoluminescence quantum yield (PLQY). Up to now, the research and development of MR-TADF 
emitters with blue and green colors has made tremendous progress, while the narrowband TADF emitters in long wavelength region, especially with emission maximum wavelength over $560 \mathrm{~nm}$, are still scarce. To pursue wide color gamut and full-color displays that satisfy the requirements of the National Television System Committee (NTSC), not only ultrapure blue and green emitters, but also ultrapure red ones are required. Therefore, it is critical to further explore emitters with narrowband emission in long wavelength region from the strategic perspective of academic research and commercial application.

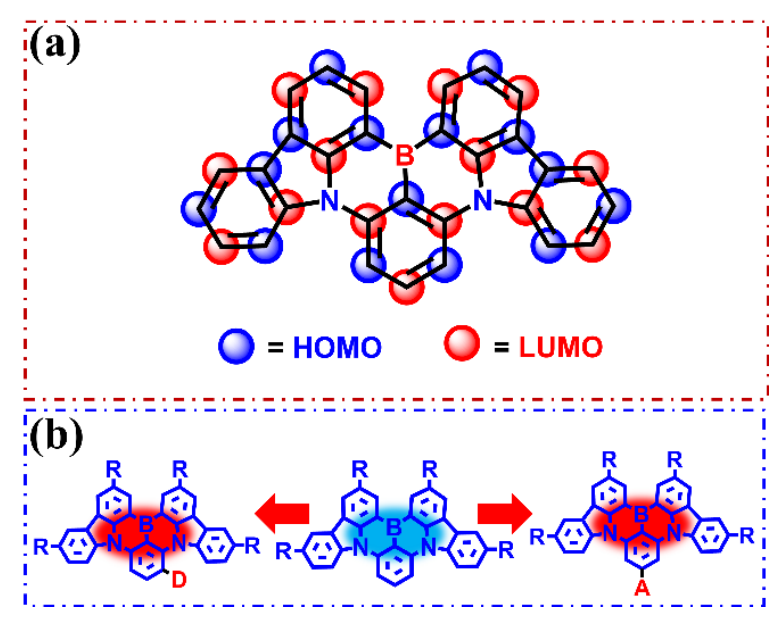

Scheme 1. a) MR skeleton. b) Diagram sketch of attaching auxiliary donor or acceptor onto MR skeleton.

In the early research, we proposed an efficient and unique molecular design strategy of frontier molecular orbital engineering (FMOE) to successfully construct green emitters by using 1,3-bis(carbazol-9-yl)benzene based MR parent molecule DtCzB. ${ }^{[6 \mathrm{k}]}$ Due to the complementary resonance effect, the electron density populations for HOMO and LUMO orbitals adopt an alternate distribution on the atoms of molecular conjugated framework. It has been proved that the red-shift emission of MR molecules can be induced by the extension of peripheral conjugation, such as the substitution of DtCzB with $p$-tert-butylphenyl. ${ }^{[6 j]}$ In addition, when an auxiliary electron donor moiety is attached to the HOMO localized on the meta-carbon position of the B-substituted phenyl-ring, it can directly participate in the distribution of HOMO and improve the HOMO energy level resulting emission ed-shift. According to FMOE strategy, upon 
attaching a strong electron acceptor to para-carbon position of the B-substituted phenyl-ring, conceptually, the LUMO energy level of the target molecule should decrease conspicuously, while the HOMO energy level should display slight change compared with the parent molecule, leading to bathochromic emission. The acceptor substituents have limited influence on MR effect of MR core, thus the small FWHM of the target molecule can be well maintained. Moreover, the multifarious electron withdrawing groups (EWGs) can be attached to MR skeleton, which can combine the intrinsic advantages of D-A structure, thus providing an effective approach to flexibly adjust the emission spectrum in long wavelength region.

In this context, we focused on the molecular design strategy based on FMOE to construct highly efficient MR-TADF materials in long wavelength region. First, by combining the auxiliary donor " and conjugation extension strategies, the electron donating groups (EDGs) 4,4'-di-tert-butyldiphenylamine and 4,4'bis(phenylisopropyl)diphenylamine were used to replace tert-butyl in $\mathrm{DtCzB}$, resulting in significant red-shift emission. Second, through boron esterification reaction, the parent MR skeleton was changed into a universal building block for further modification, namely, a critical intermediate BN-Bpin. Then, a variety of EWGs containing pyrimidine and 1,3,5-triazine derivatives were attached to MR skeleton through one-step Suzuki coupling reaction. The band gaps of the target molecules were suppressed again and the emission maxima were further red-shifted. As a result, a series of unique narrowband TADF materials with high PLQYs and emission maxima beyond $560 \mathrm{~nm}$ have been constructed. The influence of the acceptor substitution on photophysical properties has been studied. 


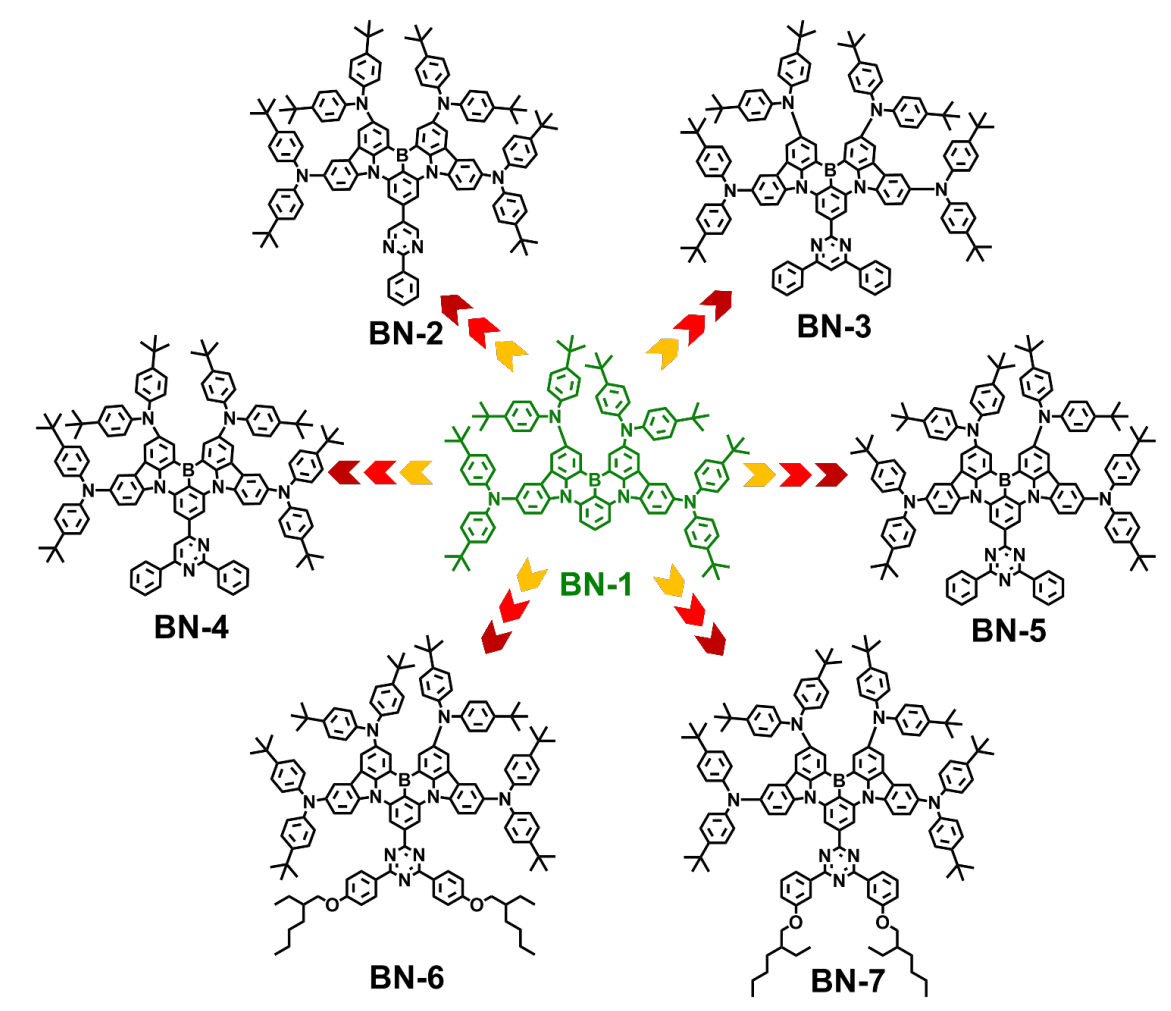

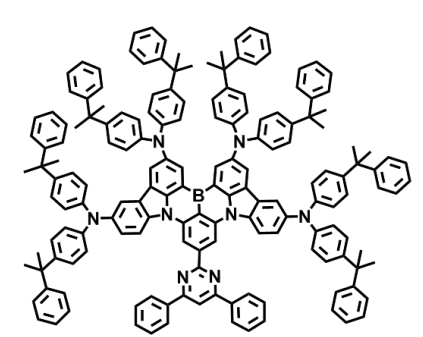

$\mathrm{BN}-10$

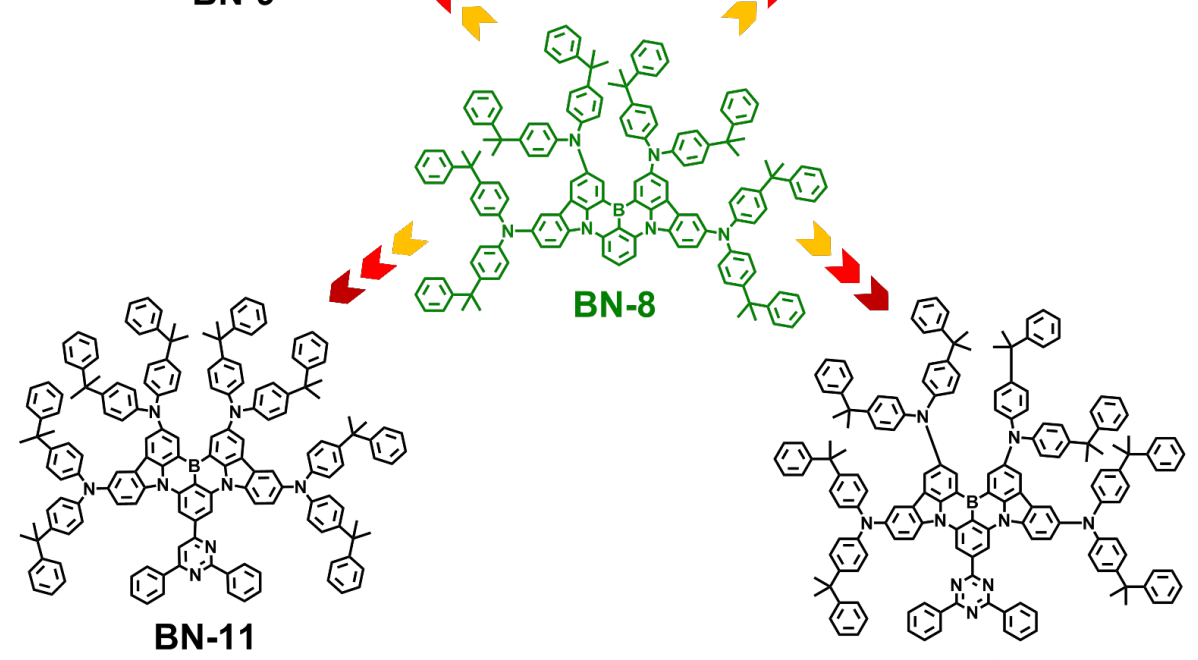

$\mathrm{BN}-12$

Figure 1. Chemical structures of BN-1-BN-12. 
The parent molecules $\mathrm{BN}-1$ and $\mathrm{BN}-8$ were synthesized through one-pot tandem lithiation-borylation-annulation reaction from corresponding intermediates 9,9'-(2bromo-1,3-phenylene)bis $\left(N^{3}, N^{3}, N^{6}, N^{6}\right.$-tetrakis(4-(tert-butyl)phenyl)-9H-carbazole3,6-diamine) and 9,9'-(2-bromo-1,3-phenylene)bis $\left(N^{3}, N^{3}, N^{6}, N^{6}\right.$-tetrakis(4-(2phenylpropan-2-yl)phenyl)-9H-carbazole-3,6-diamine). These intermediates were synthesized through a simple nucleophilic substitution reaction from commercially available starting materials, 2-bromo-1,3-difluorobenzene, $N^{3}, N^{3}, N^{6}, N^{6}$-tetrakis(4(tert-butyl)phenyl)-9H-carbazole-3,6-diamine and $\quad N^{3}, N^{3}, N^{6}, N^{6}$-tetrakis(4-(2phenylpropan-2-yl)phenyl)-9H-carbazole-3,6-diamine. Starting from the parent molecules $\mathrm{BN}-1$ and $\mathrm{BN}-8$, a series of target compounds attached with strong acceptors were successfully prepared in good yields via a two-step reaction, including boron esterification and Suzuki cross-coupling. The critical step for obtaining the target compounds was the successful synthesis of precursor BN-Bpin. In the presence of catalytic amounts di-mu-methoxobis(1,5-cyclooctadiene)diiridium(I) $\left(\left[\operatorname{Ir}(\mathrm{COD})\left(\mathrm{OCH}_{3}\right)\right]_{2}\right) \quad(1 \%$ molar stoichiometric ratio) and 4,4'-di-tert-butyl-2,2'bipyridine (dtbpy) ( $2 \%$ molar stoichiometric ratio), which are commercially available, the intermediate BN-Bpin can be easily obtained via parent molecules and bis(pinacolato)diboron with high yield. The target compounds were purified by column chromatography, and then recrystallized with dichloromethane/methanol to give highly pure samples. The preparation processes are robust and thus allow us to manufacture the target compounds with large scale, possessing the prospect of industrialization. The synthetic procedures of the compounds are illustrated in Supporting Information, the corresponding NMR spectra are presented in Figures S1-S14, and the mass spectra are recorded in Figures S15-S28.

To investigate the distributions of frontier molecular orbitals, the ground-state $\left(\mathrm{S}_{0}\right)$ geometries of representative $\mathrm{BN}-1, \mathrm{BN}-5, \mathrm{BN}-8$ and $\mathrm{BN}-12$ were optimized by using density functional theory (DFT). The HOMO and LUMO distributions, energy band gaps ( $\left.E_{\text {gaps }}\right)$ and electrostatic potential (ESP) distributions are shown in Figure 2. The LUMOs of BN-1 and BN-8 are approximately identical to that of DtCzB, which predominantly localized on the boron atom and the carbon atoms at its ortho/para 
positions in the vicinity of DtCzB moiety; whereas the HOMOs of $\mathrm{BN}-1$ and $\mathrm{BN}-8$ are mainly distributed on the nitrogen atoms and the carbon atoms at its ortho/para positions in DtCzB moiety, and some extend to the EDGs, namely, 4,4'-di-tertbutyldiphenylamine and 4,4'-bis(phenylisopropyl)diphenylamine. The enhancement of donor in $\mathrm{BN}-1$ and $\mathrm{BN}-8$ leads to narrower HOMO-LUMO energy gap, suggesting redshift emission. The HOMOs of $\mathrm{BN}-2$ to $\mathrm{BN}-7$ and $\mathrm{BN}-8$ to $\mathrm{BN}-12$ are approximately identical to those of the parent molecule $\mathrm{BN}-1$ and $\mathrm{BN}-8$, respectively, which are mainly distributed on the nitrogen and carbon atoms at the ortho/para positions. The LUMOs, however, are predominantly localized on the boron and carbon atoms at the ortho/para positions, and partially extend to the peripheral pyrimidine or 1,3,5-triazine moiety. As a result, by attaching strong auxiliary electron acceptor onto the para-carbon position of B-substituted phenyl-ring, MR and D-A complex type ICT molecules with TADF characteristic are formed. For this class composite molecules, the excited state energy can be reduced by lowering LUMO energy level, resulting in long wavelength emission. Moreover, these frontier molecular orbital distributions make it possible to preserve narrow FWHMs owing to the restricted influence of acceptor substitution on MR property of the parent BN skeleton. The ESP distributions analysis (Figure 2) shows that the introduction of pyrimidine and 1,3,5-triazine on the para-carbon position of the B-substituted phenyl ring disperses the electron density and refrains from condensed and localized LUMO population, thus enhancing the ICT strength and generating red-shift emission. 


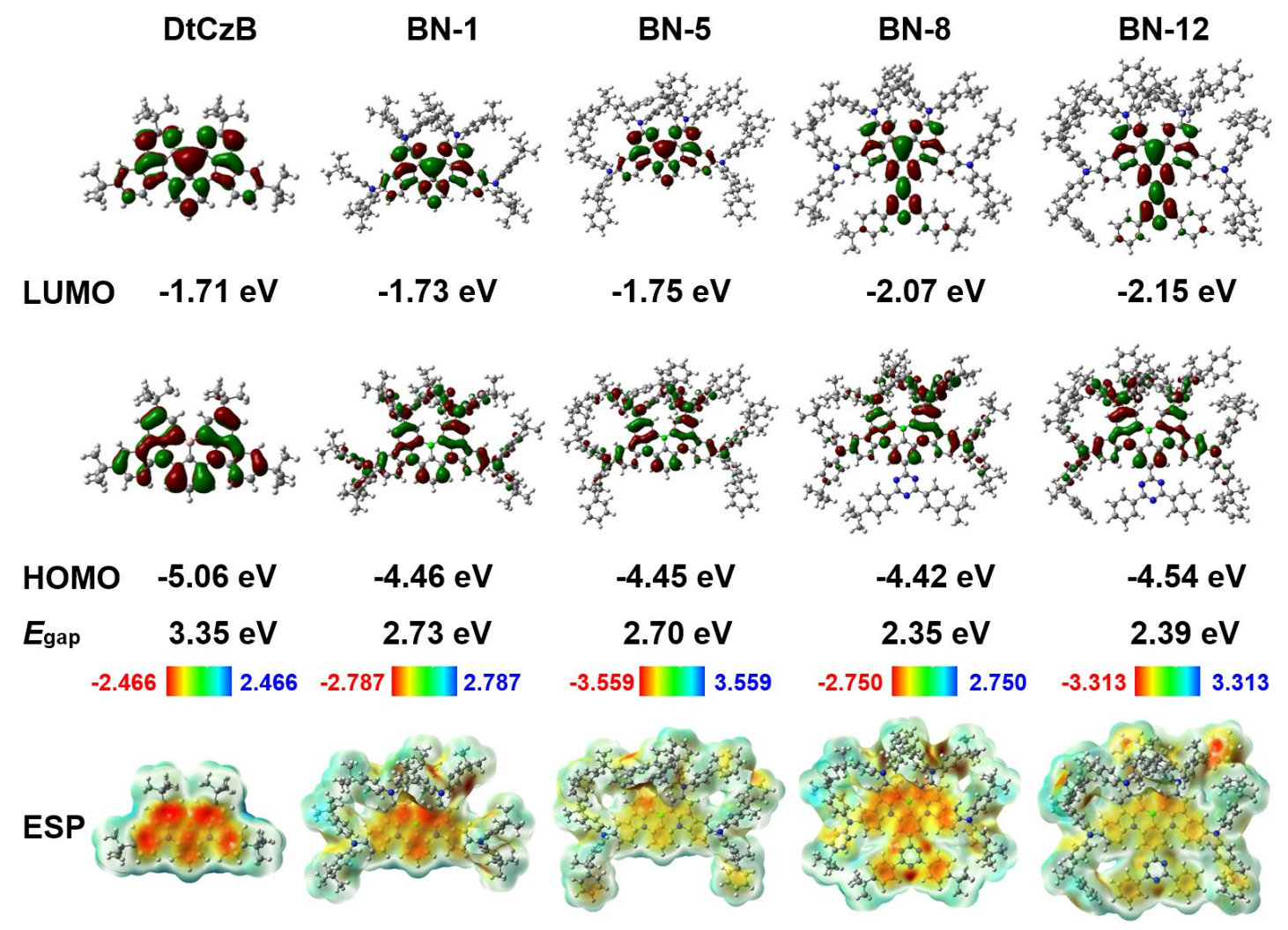

Figure 2. Calculated HOMO and LUMO distributions, energy band gaps and molecular surface electrostatic potential in $\mathrm{S}_{0}$ geometries of the investigated compounds (measuring scale $\times 10^{-2}$, red and blue indicate negative and positive electrostatic potential, respectively).

The photophysical properties of BN-1 to BN-12 including ultraviolet-visible (UVvis) absorption and photoluminescence (PL) spectra were recorded in dilute toluene solution $\left(1 \times 10^{-5} \mathrm{M}\right)$. As shown in Figures 3-6 and Table 1, the electronic absorption spectra display intense absorption bands at 537, 550, 562, 567, 584, 575, 581, 534, 548, 562, 564 and $581 \mathrm{~nm}$ for BN-1, BN-2, BN-3, BN-4, BN-5, BN-6, BN-7, BN-8, BN-9, $\mathrm{BN}-10, \mathrm{BN}-11$ and $\mathrm{BN}-12$, respectively, which correspond to the ICT absorption transitions. They all exhibit vivid fluorescence with emission maxima at 566, 586, 598, $612,627,618,629,567,585,595,608$ and $624 \mathrm{~nm}$, respectively. The existence of rigid core skeletons contribute to a minor excited state structural relaxation, impelling small Stokes shifts of 29, 36, 36, 45, 43, 43, 48, 33, 37, 33, 44 and $43 \mathrm{~nm}$, and narrow FWHMs of 34, 44, 38, 41, 47, 45, 47, 34, 40, 35, 43 and 46 nm, respectively. For BN-1 and BN8 , the emission maximum generates large bathochromic shifts of 85 and $86 \mathrm{~nm}$ compared with that of $\mathrm{DtCzB}(481 \mathrm{~nm})$, respectively. It should be noted that the 
electronically inert moieties tert-butyl and 2-phenylpropan-2-yl do not participate in the frontier molecular orbital distributions and have no contribution to the emission, so the PL spectral profiles are virtually identical. The introduction of 2-phenylpropan-2yl can greatly improve its solubility, which is conducive to the solution-processing optoelectronic devices. On the other hand, due to the large steric hindrance effect of 2phenylpropan-2-yl, the intermolecular distance between the luminophores of the adjacent molecules can be increased, and their orbital overlaps can be reduced, which, are the prerequisite of effective intermolecular electron exchange interactions. Therefore, it can be expected that the concentration quenching can be effectively inhibited. In order to construct narrowband emission materials in longer wavelength emission region, strong acceptor pyrimidine was attached onto para-carbon position of B-substituted phenyl-ring of $\mathrm{BN}-1$ and $\mathrm{BN}-8$. Meanwhile, the effect of isomer substitution on photophysical properties of MR-type TADF materials was further studied. 2-phenylpyrimidine, 4,6-diphenylpyrimidine and 2,4-diphenylpyrimidine were linked to $\mathrm{BN}-1$ and $\mathrm{BN}-8$, respectively. Due to the formation of intramolecular hydrogen bonds $(\mathrm{C}-\mathrm{H} \cdots \mathrm{N})$, the conjugation of the whole molecular plane is gradually enhanced, and the emission is gradually induced red-shift. To further push forward the emission to longer wavelength region, another class of 1,3,5-triazine deriviteves based acceptors with stronger electron withdrawing ability was selected to replace pyrimidine group. Consequently, the ICT state can be significantly increased, and the emission can be further red-shift as anticipated. BN-5 and BN-12 exhibit intense red emission peaking at 627 and $624 \mathrm{~nm}$, resepctively. Given the solubility of BN-12 is relatively better than that of BN-5, the development of new strategy to improve the solubility of BN-5 is therefore highly desirable. Generally, the introduction of alkyl chain has the following three advantages: 1) increase the solubility of the compound, beneficial to spin coating; 2) control electronic structure and modulate emitting color, especially the involvement of alkoxyl chain can lead to the red-shift of emission; 3) increase sterical hindrance or molecular distortion, and reduce molecular aggregation and concentration quenching. Taking the above merits into consideration, BN-1 was respectively grafted with alkoxyl chain 2,4-bis(4-((2-ethylhexyl)oxy)phenyl)-1,3,5-triazine and 2,4-bis(3- 
((2-ethylhexyl)oxy)phenyl)-1,3,5-triazine to regulate the solubility and electronic structure. As a result, the solubility of BN-6 and BN-7 becomes exceedingly good. Compared with $\mathrm{BN}-5, \mathrm{BN}-6$ exhibits hypsochromic emission, this is because the substitution of 4-((2-ethylhexyl)oxyl donor unit in para-position weakens the electron withdrawing ability of triazine. For BN-7, the emission is almost the same as BN-5, which is because the substitution of 3-((2-ethylhexyl)oxyl unit in meta-position is not conjugated with triazine and does not weaken the electron withdrawing ability of triazine.

(a)

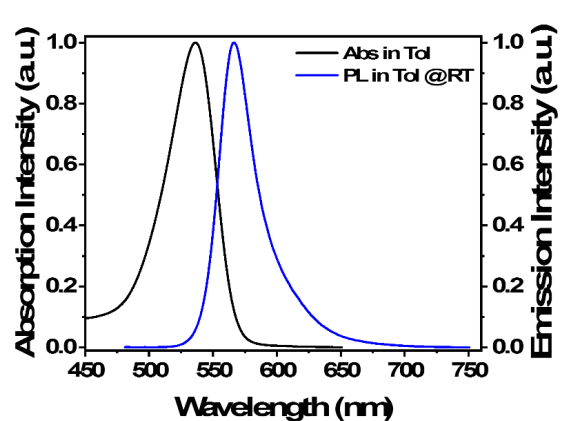

(c)

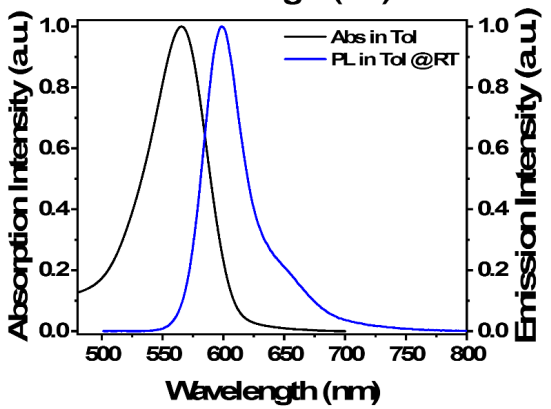

(b)

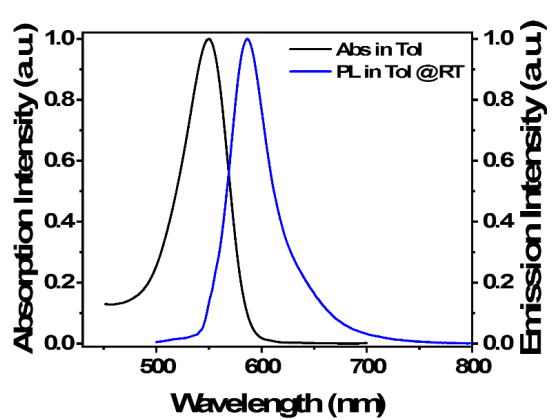

(d)

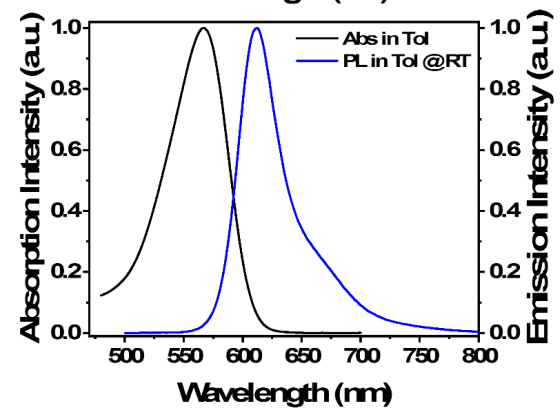

Figure 3. Normalized UV-vis absorption and fluorescence spectra of BN-1 (a), BN-2 (b), BN-3 (c) and BN-4 (d) measured in toluene solution $\left(1 \times 10^{-5} \mathrm{M}, 298 \mathrm{~K}\right)$. 
(a)

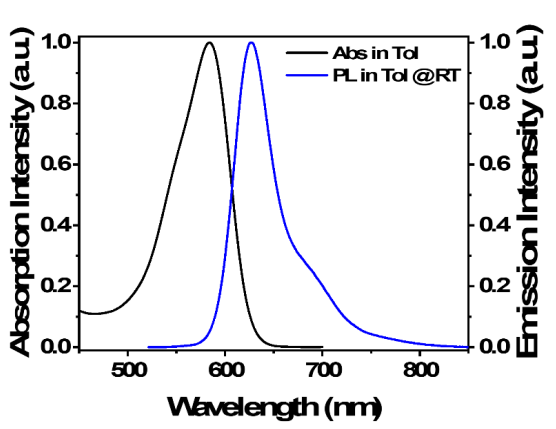

(c)

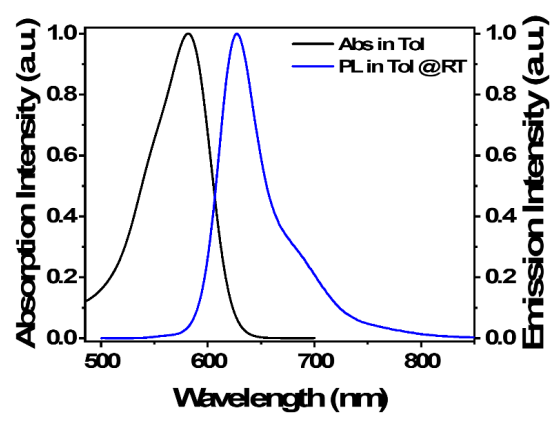

(b)

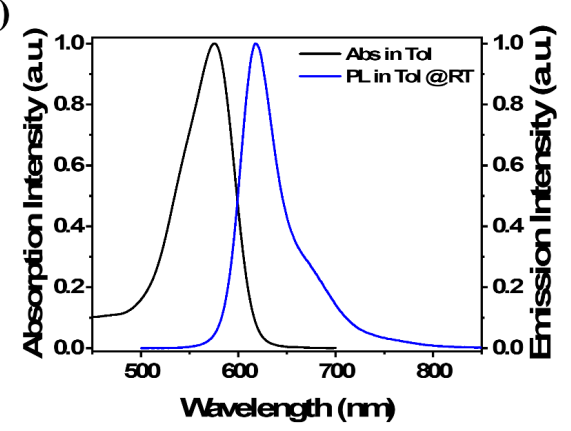

(d)

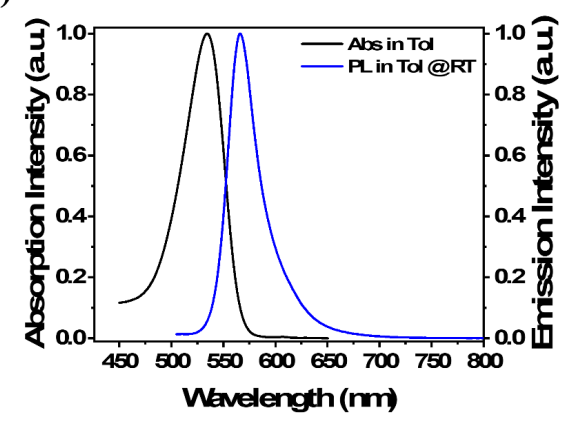

Figure 4. Normalized UV-vis absorption and fluorescence spectra of BN-5 (a), BN-6 (b), BN-7 (c) and BN-8 (d) measured in toluene solution $\left(1 \times 10^{-5} \mathrm{M}, 298 \mathrm{~K}\right)$.

(a)

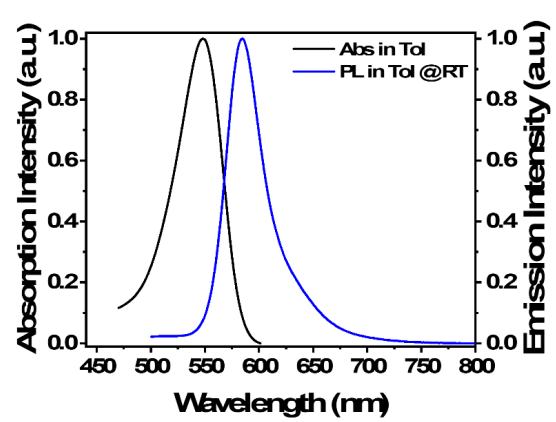

(c)

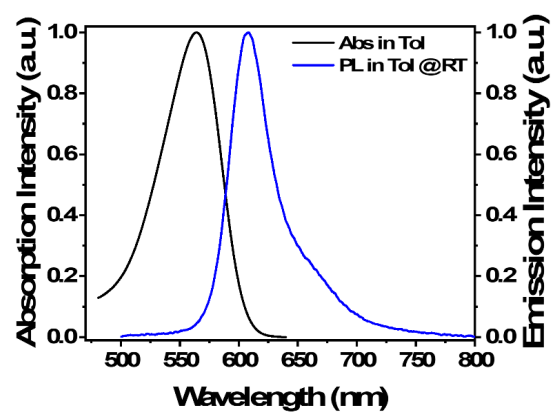

(b)

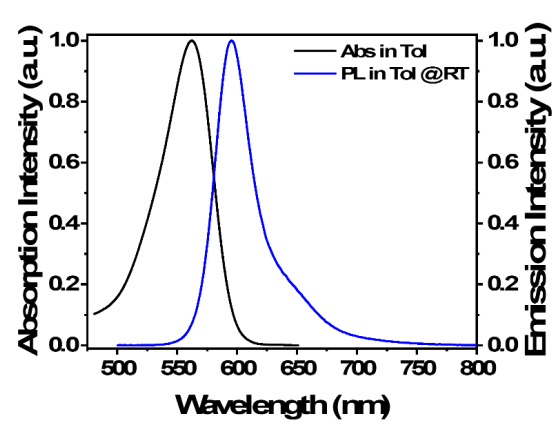

(d)

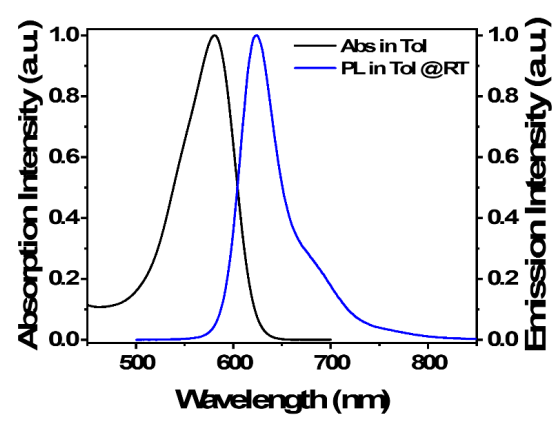

Figure 6. Normalized UV-vis absorption and fluorescence spectra of BN-9 (a), BN-10 (b), BN-11 (c) and BN-12 (d) measured in toluene solution $\left(1 \times 10^{-5} \mathrm{M}, 298 \mathrm{~K}\right)$. 
Table 1. Summary of the photophysical properties of the investigated compounds.

\begin{tabular}{lllllllllll}
\hline compound & $\begin{array}{l}\lambda_{\mathrm{abs}^{\mathrm{a}}{ }^{\mathrm{a}}} \\
{[\mathrm{nm}]}\end{array}$ & $\begin{array}{l}\lambda_{\mathrm{em}}{ }^{\mathrm{b})} \\
{[\mathrm{nm}]}\end{array}$ & $\begin{array}{l}\mathrm{FWHM}^{\mathrm{c})} \\
{[\mathrm{nm}]}\end{array}$ & $\begin{array}{l}E_{\mathrm{S1}}{ }^{\mathrm{d})} \\
{[\mathrm{eV}]}\end{array}$ & $\begin{array}{l}E_{\mathrm{T} 1}{ }^{\mathrm{e})} \\
{[\mathrm{eV}]}\end{array}$ & $\begin{array}{l}\Delta E_{\mathrm{ST}^{\mathrm{f}}} \\
{[\mathrm{eV}]}\end{array}$ & $\begin{array}{l}E_{\mathrm{g}} \mathrm{g}^{\mathrm{g}} \\
{[\mathrm{eV}]}\end{array}$ & $\begin{array}{l}\mathrm{HOMO}^{\mathrm{h})} \\
{[\mathrm{eV}]}\end{array}$ & $\begin{array}{l}\text { LUMO }^{\mathrm{i})} \\
{[\mathrm{eV}]}\end{array}$ & $\begin{array}{l}\Phi_{\mathrm{PL}^{\mathrm{j}}}{ }^{2} \\
{[\%]}\end{array}$ \\
\hline BN-1 & 537 & 566 & 34 & 2.40 & 2.29 & 0.11 & 2.18 & -4.86 & -2.68 & 95 \\
BN-2 & 550 & 586 & 44 & 2.36 & 2.28 & 0.08 & 2.11 & -4.86 & -2.75 & 96 \\
BN-3 & 562 & 598 & 38 & 2.29 & 2.21 & 0.08 & 2.04 & -4.87 & -2.83 & 96 \\
BN-4 & 567 & 612 & 41 & 2.25 & 2.19 & 0.06 & 2.04 & -4.88 & -2.84 & 96 \\
BN-5 & 584 & 627 & 47 & 2.25 & 2.20 & 0.05 & 1.98 & -4.86 & -2.88 & 95 \\
BN-6 & 575 & 618 & 45 & 2.19 & 2.13 & 0.06 & 2.01 & -4.90 & -2.89 & 94 \\
BN-7 & 581 & 629 & 47 & 2.24 & 2.15 & 0.09 & 1.99 & -4.90 & -2.91 & 94 \\
BN-8 & 534 & 567 & 34 & 2.35 & 2.32 & 0.03 & 2.19 & -4.89 & -2.70 & 95 \\
BN-9 & 548 & 585 & 40 & 2.27 & 2.24 & 0.03 & 2.11 & -4.88 & -2.77 & 96 \\
BN-10 & 562 & 595 & 35 & 2.28 & 2.16 & 0.12 & 2.07 & -4.90 & -2.83 & 96 \\
BN-11 & 564 & 608 & 43 & 2.26 & 2.17 & 0.09 & 1.93 & -4.89 & -2.96 & 95 \\
BN-12 & 581 & 624 & 46 & 2.15 & 2.08 & 0.07 & 1.99 & -4.88 & -2.89 & 94 \\
\hline
\end{tabular}

a) Peak wavelength of the lowest energy absorption band. ${ }^{\text {b) }}$ Peak wavelength of the PL spectrum in toluene $\left(1 \times 10^{-5} \mathrm{M}, 298 \mathrm{~K}\right) .{ }^{\mathrm{c})}$ Full width at half maximum. ${ }^{\mathrm{d})}$ Singlet energy estimated from the onset of the fluorescence spectrum in toluene $\left(1 \times 10^{-5} \mathrm{M}\right.$, $77 \mathrm{~K}) .{ }^{\text {e) }}$ Triplet energy estimated from the onset of the phosphorescence spectrum in a frozen toluene matrix $\left(1 \times 10^{-5} \mathrm{M}, 77 \mathrm{~K}\right) .{ }^{\mathrm{f}}{ }^{\mathrm{f}} \Delta E_{\mathrm{ST}}=E_{\mathrm{S} 1}-E_{\mathrm{T} 1 .}{ }^{\mathrm{g})}$ Optical band gap estimated from the absorption edge of the UV-vis spectrum. ${ }^{\text {h) }}$ Determined from cyclic voltammetry using the formula: $E_{\mathrm{HOMO}}=-\left(E_{\mathrm{Ox}}+4.8\right) \mathrm{eV}{ }^{\mathrm{i}}{ }$ Determined from formula: $E_{\text {LUMO }}=E_{\text {HOMO }}+E_{\mathrm{g}}{ }^{\mathrm{j}}{ }^{\mathrm{j}}$ Absolute photoluminescence quantum yield measured with an integer-sphere system in $\mathrm{N}_{2}$-bubbling toluene.

To study the electrochemical properties of the investigated compounds, the cyclic voltammetry $(\mathrm{CV})$ measurements were carried out. Based on the oxidation onset potentials (Figures S29-S31), the HOMO energy levels are determined to be -4.86, $4.86,-4.87,-4.88,-4.86,-4.90,-4.90,-4.89,-4.88,-4.90,-4.89$ and $-4.88 \mathrm{eV}$ for $\mathrm{BN}-1$, BN-2, BN-3, BN-4, BN-5, BN-6, BN-7, BN-8, BN-9, BN-10, BN-11 and BN-12, respectively. The LUMO energy levels estimated by the optical bandgaps and the values are $-2.68,-2.75,-2.83,-2.84,-2.88,-2.89,-2.91,-2.70,-2.77,-2.83,-2.96$ and $2.89 \mathrm{eV}$, respectively. Compared with DtCzB (HOMO: $-5.40 \mathrm{eV}$, LUMO: $-2.61 \mathrm{eV}$ ), the similar LUMO energy levels of $\mathrm{BN}-1$ and $\mathrm{BN}-5$, and the obviously increased HOMO energy levels resemble well with the to the trend of theoretical calculation, indicating the subsequent red-shift emission. In addition, Compared with the parent molecules $\mathrm{BN}-1$ and $\mathrm{BN}-5$, their derivatives linked with EWGs have homologous 
HOMO energy levels of and decreased LUMO energy levels, showing the definite bathochromic emission.

The absolute PLQYs of BN-1, BN-2, BN-3, BN-4, BN-5, BN-6, BN-7, BN-8, BN9, BN-10, BN-11 and BN-12 measured with an integer-sphere system in oxygen-free toluene solution are as high as $95 \%, 96 \%, 96 \%, 96 \%, 95 \%, 94 \%, 94 \%, 95 \%, 96 \%, 96 \%$, $95 \%$ and $94 \%$, respectively. Combined with the onsets of the low-temperature fluorescence and phosphorescence spectra at $77 \mathrm{~K}$ (Figures S32-S34), the $\Delta E_{\mathrm{ST}}$ values were estimated to be $0.11,0.08,0.08,0.06,0.05,0.06,0.09,0.03,0.03,0.12,0.09$ and $0.07 \mathrm{eV}$, respectively. Such small $\Delta E_{\mathrm{ST}}$ values can promote the exciton upconversion from $T_{1}$ to $S_{1}$, which leads to TADF characteristics. To gain deeper insight into the photophysical property, the representative compounds $\mathrm{BN}-1, \mathrm{BN}-5, \mathrm{BN}-8$ and $\mathrm{BN}-12$ in the doped thin films with $m \mathrm{CP}(1,3-\mathrm{di}(9 H$-carbazol-9-yl)benzene) as host were studied. In order to guarantee the effective energy transfer from the host to the emitter and suppress the bimolecular collision in the rigid matrix, the investigated compounds in the films were doped with $3 \mathrm{wt} \%$ doping concentration. Compared with the emission in low polar toluene solution, the doped $\mathrm{BN}-1, \mathrm{BN}-5, \mathrm{BN}-8$, and $\mathrm{BN}-12$ thin films show slightly red-shift emission (Figure S35), peaking at 573, 629, 573 and $629 \mathrm{~nm}$, respectively, with FWHM of 51, 58, 43 and 54nm, respectively. BN-1 and BN-8, BN5 and $\mathrm{BN}-12$ show the identical emission maximum, but the FWHM decreased respectively. This may be due to the weakening of intermolecular interactions caused by the large steric hindrance effect of 2-phenylpropane-2-yl. The transient PL decay spectra of the doped films show biexponential decays, which are composed of a prompt fluorescence decay with lifetime in the nanosecond regime and a delayed fluorescence component with lifetime in the microsecond regime (Figure S36). The existence of delay component shows that triplet excitons can be converted up to recursive $\mathrm{S}_{1} \rightarrow \mathrm{S}_{0}$ transitions, evidencing typical TADF characteristic. In summary, these properties of MR-TADF materials have tremendous advantages for the preparation of highly efficient OLED with perfect color purity. The application of these compounds in optoelectronic devices are ongoing in our laboratory. 
In conclusion, by modifying the periphery of MR skeleton with electron donor and attaching pyrimidine and 1,3,5-triazine derivatives-based acceptors onto MR framework based on FMOE, we have developed a series of unique narrowband TADF materials with high luminous efficiency in long wavelength region beyond $560 \mathrm{~nm}$. The ingenious adjustment of acceptor is an effective approach to achieve bathochromic emission and narrowband emission simultaneously. We provide a flexible approach to construct emissive materials with desired color purity in long wavelength region. The key to these excellent results lies in the perfect combination of intrinsic advantages of MR skeleton and D-A structure. This approach provides a platform for exploring a wide range of MR molecules, which accelerates the development of narrowband materials in the future.

\section{Acknowledgements}

This work was supported by the National Natural Science Foundation of China (21935005), the National Key R\&D Program of China (2020YFA0714601) and Program for JLU Science and Technology Innovative Research Team (2019TD-33).

\section{Conflict of Interest}

The authors declare no conflict of interest.

\section{References}

[1] a) H. Uoyama, K. Goushi, K. Shizu, H. Nomura, C. Adachi, Nature 2012, 492, 234;

b) C. W. Tang, S. A. VanSlyke, Appl. Phys. Lett. 1987, 51, 913.

[2] a) Y. Tao, K. Yuan, T. Chen, P. Xu, H. Li, R. Chen, C. Zheng, L. Zhang, W. Huang, Adv. Mater. 2014, 26, 7931; b) P. L. Dos Santos, J. S. Ward, D. G. Congrave, A. S. Batsanov, J. Eng, J. E. Stacey, T. J. Penfold, A. P. Monkman, M. R. Bryce, Adv. Sci. 2018, 5, 1700989; c) K. Wu, T. Zhang, Z. Wang, L. Wang, L. Zhan, S. Gong, C. Zhong, Z. H. Lu, S. Zhang, C. Yang, J. Am. Chem. Soc. 2018, 140, 8877; d) X.-K. Chen, Y. Tsuchiya, Y. Ishikawa, C. Zhong, C. Adachi, J.-L. Brédas, Adv. Mater. 2017, 29, 1702767; e) I. S. Park, K. Matsuo, N. Aizawa, T. Yasuda, Adv. Funct. Mater. 2018, 28, 1802031; f) P. Rajamalli, N. Senthilkumar, P. Gandeepan, P. Y. Huang, M. J. Huang, C. Z. Ren - Wu, C. Y. Yang, M. J. Chiu, L. K. Chu, H. W. Lin, C. H. Cheng, J. Am. Chem. Soc. 2016, 138, 628. 
[3] F. Santoro, A. Lami, R. Improta, J. Bloino, V. Barone, J. Chem. Phys. 2008, 128, 224311.

[4] a) X. Li, Y. Z. Shi, K. Wang, M. Zhang, C. J. Zheng, D. M. Sun, G. L. Dai, X. C. Fan, D. Q. Wang, W. Liu, Y. Q. Li, J. Yu, X. M. Ou, C. Adachi, X. H. Zhang, ACS Appl. Mater. Interfaces 2019, 11, 13472; b) Y. Yuan, X. Tang, X. Y. Du, Y. Hu, Y. J. Yu, Z. Q. Jiang, L. S. Liao, S. T. Lee, Adv. Opt. Mater. 2019, 7, 1801536; c) D. Hall, S. M. Suresh, P. L. dos Santos, E. Duda, S. Bagnich, A. Pershin, P. Rajamalli, D. B. Cordes, A. M. Z. Slawin, D. Beljonne, A. Köhler, I. D. W. Samuel, Y. Olivier, E. Zysman - Colman, Adv. Opt. Mater. 2020, 8, 1901627.

[5] a) T.-Y. Cho, C.-L. Lin, C.-C. Wu, Appl. Phys. Lett. 2006, 88, 111106; b) D. Poitras, C.-C. Kuo, C. Py, Opt. Express 2008, 16, 8003; c) N. Takada, T. Tsutsui, S. Saito, Appl. Phys. Lett. 1993, 63, 2032.

[6] a) T. Hatakeyama, K. Shiren, K. Nakajima, S. Nomura, S. Nakatsuka, K. Kinoshita, J. Ni, Y. Ono, T. Ikuta, Adv. Mater. 2016, 28, 2777; b) Y. Kondo, K. Yoshiura, S. Kitera, H. Nishi, S. Oda, H. Gotoh, Y. Sasada, M. Yanai, T. Hatakeyama, Nat. Photonics 2019, 13, 678; c) S. H. Han, J. H. Jeong, J. W. Yoo, J. Y. Lee, J. Mater. Chem. C 2019, 7, 3082; d) K. H. Lee, J. Y. Lee, J. Mater. Chem. C 2019, 7, 8562; e) J. A. Knoller, G. Meng, X. Wang, D. Hall, A. Pershin, D. Beljonne, Y. Olivier, S. Laschat, E. ZysmanColman, S. Wang, Angew. Chem. Int. Ed. 2020, 59, 3156; f) S. Oda, B. Kawakami, R. Kawasumi, R. Okita, T. Hatakeyama, Org. Lett. 2019, 21, 9311; g) K. Matsui, S. Oda, K. Yoshiura, K. Nakajima, N. Yasuda, T. Hatakeyama, J. Am. Chem. Soc. 2018, 140, 1195; h) S. Nakatsuka, H. Gotoh, K. Kinoshita, N. Yasuda, T. Hatakeyama, Angew. Chem. Int. Ed. 2017, 56, 5087; i) Y. Zhang, D. Zhang, J. Wei, Z. Liu, Y. Lu, L. Duan, Angew. Chem. Int. Ed. 2019, 58, 16912; j) Y. Xu, Z. Cheng, Z. Li, B. Liang, J. Wang, J. Wei, Z. Zhang, Y. Wang, Adv. Opt. Mater. 2020, 8, 1902142; k) Y. Xu, C. Li, Z. Li, Q. Wang, X. Cai, J. Wei, Y. Wang, Angew. Chem. Int. Ed. 2020, 59, 17442; 1) Y. Zhang, D. Zhang, J. Wei, X. Hong, Y. Lu, D. Hu, G. Li, Z. Liu, Y. Chen, L. Duan, Angew. Chem. Int. Ed. 2020, 59, 17499; m) N. Ikeda, S. Oda, R. Matsumoto, M. Yoshioka, D. Fukushima, K. Yoshiura, N. Yasuda, T. Hatakeyama, Adv. Mater. 2020, 32, 2004072; n) M. Yang, I. S. Park, T. Yasuda, J. Am. Chem. Soc. 2020, 142, 19468; o) S. Oda, W. 
Kumano, T. Hama, R. Kawasumi, K. Yoshiura, T. Hatakeyama, Angew. Chem. Int. Ed. 2021, 60, 2882.

[7] Y. Xu, C. Li, Z. Li, J. Wang, J. Xue, Q. Wang, X. Cai, Y. Wang, DOI: 10.26434/chemrxiv.14050712.

\section{Table of contents}

Based on modifing multiple resonance (MR) skeleton with electron donor, and attaching pyrimidine and 1,3,5-triazine derivative acceptors onto MR framework, a series of highly efficient narrowband thermally activated delayed fluorescence (TADF) materials with emission maxima beyond $560 \mathrm{~nm}$ have been developed.

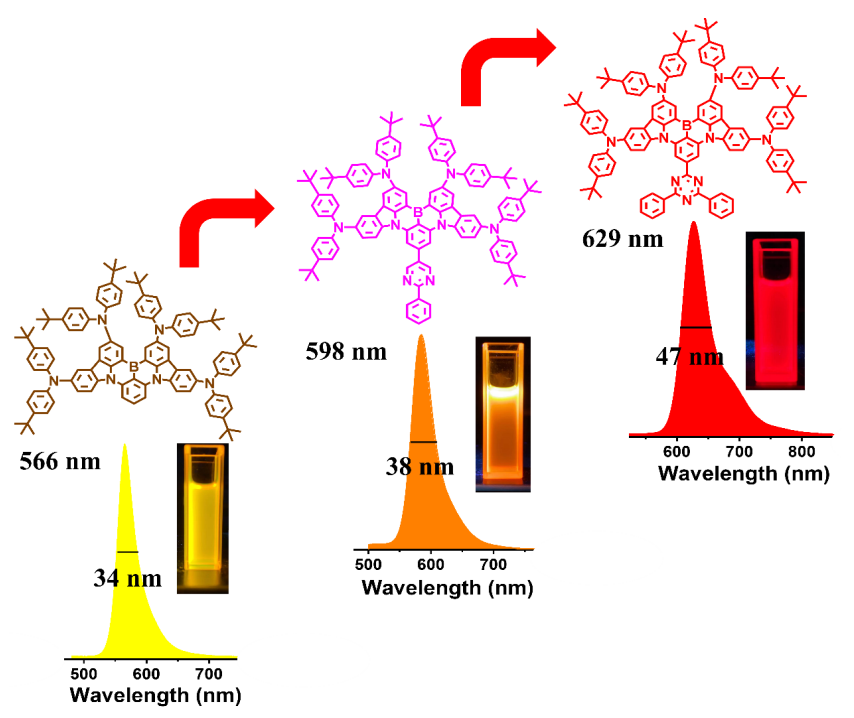




\section{Supporting Information}

General Information: Thermo Fisher ITQ1100 GC/MS and Kratos AXIMA-CFR Kompact MALDI mass spectrometer were employed to measure the mass spectra. Flash EA 1112 spectrometer were used to perform the elemental analyses. Bruker AVANCE III $500 \mathrm{MHz}$ spectrometers were selected to measure the ${ }^{1} \mathrm{H}$ spectra with tetramethylsilane (TMS) as the internal standard. Shimadzu RF-5301 PC spectrometer and Shimadzu UV-2550 spectrophotometer were adopted to record the PL emission spectra and UV-Vis absorption, respectively. The fluorescence and phosphorescent spectra taken at liquid nitrogen temperature $(77 \mathrm{~K})$ were recorded by Ocean Optics QE Pro with a 365 nm Ocean Optics LLS excitation source. Edinburgh FLS920 steady state fluorimeter equipping with an integrating sphere was employed to measure the absolute fluorescence quantum yields of solutions. BAS 100W Bioanalytical electrochemical work station was used to measure the electrochemical property with platinum disk as working electrode, platinum wire as auxiliary electrode, a porous glass wick $\mathrm{Ag} / \mathrm{Ag}^{+}$as pseudo reference electrode and ferrocene/ferrocenium as the internal standard. And 0.1 $\mathrm{M}$ solution of $\mathrm{n}-\mathrm{Bu}_{4} \mathrm{NPF}_{6}$ which was the supporting electrolyte was utilized to measure the oxidation potentials (in anhydrous $\mathrm{CH}_{2} \mathrm{Cl}_{2}$ ) at a scan rate of $100 \mathrm{mV} \mathrm{s}^{-1}$. FLS980 fluorescence lifetime measurement system with $365 \mathrm{~nm}$ LED excitation source was selected to investigate the transient PL decay.

Theoretical Calculations Method: The ground state geometries of gas state were fully optimized by B3LYP method including Grimme's dispersion correction with 6- 
$31 \mathrm{G}(\mathrm{d}, \mathrm{p})$ basis set using Gaussian 09 software package. ${ }^{[1-5]}$ The HOMO and LUMO were visualized with Gaussview 5.0.

Synthesis of Materials: All reagents were purchased from Energy Chemical Co. and/or $J \& K$ scientific Ltd. Co. and immediately used without further purification. Synthesis Procedure was showed below in detail. .

\section{Synthesis of BN-1 to BN-12}

\section{3,6-dibromo-9-tosyl-9H-carbazole (1)}

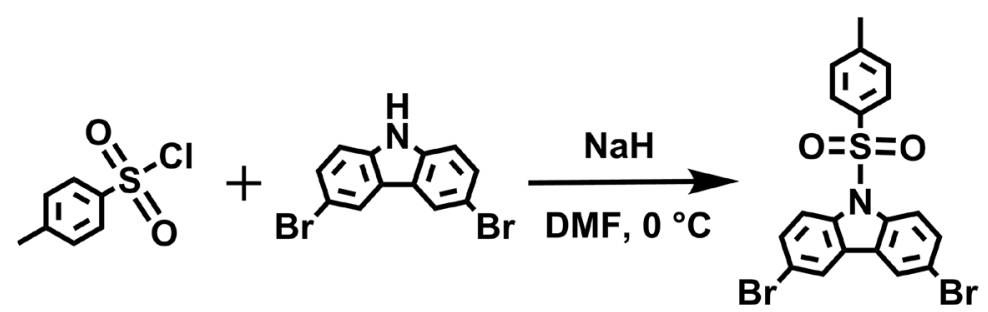

$\mathrm{NaH}(360 \mathrm{mg}, 15 \mathrm{mmol})$ was slowly added to the mixture of 3,6-dibromo- $9 H$ carbazole $(3.25 \mathrm{~g}, 10 \mathrm{mmol})$ and $\mathrm{DMF}(100 \mathrm{ml})$ under nitrogen atmosphere at $0{ }^{\circ} \mathrm{C}$ for 30 minutes. Subsequently, 4-methylbenzenesulfonyl chloride $(2.01 \mathrm{~g}, 11 \mathrm{mmol})$ was slowly poured into the reaction mixture under high flow of nitrogen and the reaction continued at $0{ }^{\circ} \mathrm{C}$ for 4 hours. Finally, the reaction mixture was poured into water and stirred for 30 minutes to obtain the suspension, which was filtered to give a white solid of 3,6-dibromo-9-tosyl-9H-carbazole (4.5 g, 94\%). ${ }^{1} \mathrm{H}$ NMR (500 MHz, Chloroformd) $\delta 8.19(\mathrm{~d}, J=8.8 \mathrm{~Hz}, 2 \mathrm{H}), 7.97(\mathrm{~d}, J=2.0 \mathrm{~Hz}, 2 \mathrm{H}), 7.67-7.57(\mathrm{~m}, 4 \mathrm{H}), 7.13(\mathrm{~d}, J$ $=8.1 \mathrm{~Hz}, 2 \mathrm{H}), 2.29$ (s, 3H). ESI-MS (M): m/z: 479.53 [M]+ (calcd: 479.19). Anal. Calcd for $\mathrm{C}_{19} \mathrm{H}_{13} \mathrm{Br}_{2} \mathrm{NO}_{2} \mathrm{~S}: \mathrm{C}, 47.62 ; \mathrm{H}, 2.73 ; \mathrm{N}, 2.92 ; \mathrm{S}, 6.69$. Found: C, 47.66; H, 2.70; N, 2.91; S, 6.66. 

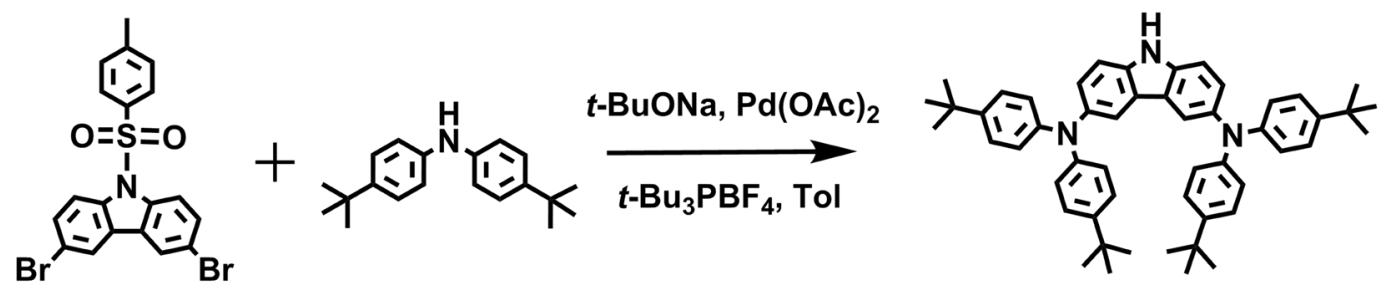

The mixture of 1 (3.83 g, $8 \mathrm{mmol})$, bis(4-(tert-butyl)phenyl)amine (4.73 g, 16.8 mmol), sodium tert-butoxide $(3.1 \mathrm{~g}, 32 \mathrm{mmol})$, palladium diacetate $(225 \mathrm{mg}, 1 \mathrm{mmol})$, and tri-tert-butylphosphonium tetrafluoroborate (144 mg, $0.5 \mathrm{mmol})$ in $100 \mathrm{~mL}$ toluene was refluxed under nitrogen for $12 \mathrm{~h}$. After cooling to room temperature, the resulting product was diluted with chloroform and washed with water. The combined organic extracts were dried over $\mathrm{Na}_{2} \mathrm{SO}_{4}$ and concentrated by rotary evaporation. The crude product was purified by column chromatography with dichloromethane/petroleum (1:3) as eluent to afford a white solid (3.7 g, 64\%). ${ }^{1} \mathrm{H}$ NMR (500 MHz, Methylene Chloride$\left.d_{2}\right) \delta 7.87-6.33(\mathrm{~m}, 23 \mathrm{H}), 1.28(\mathrm{~s}, 36 \mathrm{H})$. ESI-MS $(\mathrm{M}): \mathrm{m} / \mathrm{z}: 725.44[\mathrm{M}]+$ (calcd: 726.07). Anal. Calcd for $\mathrm{C}_{52} \mathrm{H}_{59} \mathrm{~N}_{3}$ : C, 86.02; H, 8.19; N, 5.79. Found: C, 85.95; H, 8.26; $\mathrm{N}, 5.77$.

9,9'-(2-bromo-1,3-phenylene)bis $\left(N^{3}, N^{3}, N^{6}, N^{6}\right.$-tetrakis(4-(tert-butyl)phenyl)-9Hcarbazole-3,6-diamine) (3)

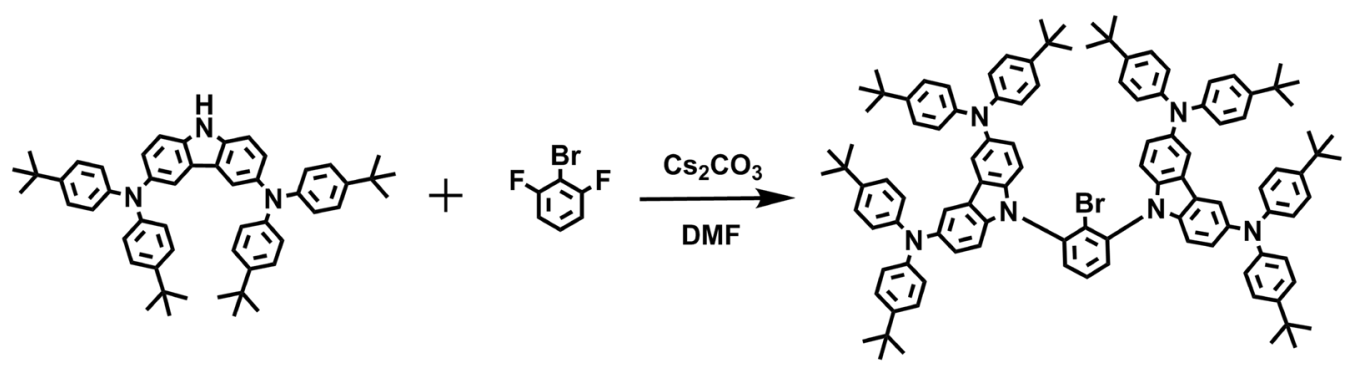

The mixture of 2 (2.98 g, 4.1 mmol), 2-bromo-1,3-difluorobenzene (386 mg, $2 \mathrm{mmol}$ ) and cesium carbonate $(2.6 \mathrm{~g}, 8 \mathrm{mmol})$ in $25 \mathrm{~mL}$ DMF was refluxed for $12 \mathrm{~h}$ under nitrogen. After cooling to room temperature, the resulting product was diluted with 
chloroform and washed with water. The combined organic extracts were dried over $\mathrm{Na}_{2} \mathrm{SO}_{4}$ and concentrated under reduced pressure. The crude product was purified by column chromatography with dichloromethane/petroleum (1:4) as eluent to afford a white solid (2.89 g, 90\%). ${ }^{1} \mathrm{H}$ NMR (500 MHz, Methylene Chloride- $\left.d_{2}\right) \delta 7.72(\mathrm{~s}, 5 \mathrm{H})$, 7.08 (d, $J=130.7 \mathrm{~Hz}, 42 \mathrm{H}), 1.27$ (s, 72H). MALDI: m/z: 1604.86 [M]+ (calcd: 1605.11). Anal. Calcd for $\mathrm{C}_{110} \mathrm{H}_{119} \mathrm{BrN}_{6}$ : C, 82.31; H, 7.47; N, 5.24. Found: C, 82.33; H, 7.50; N, 5.22.

\section{BN-1}

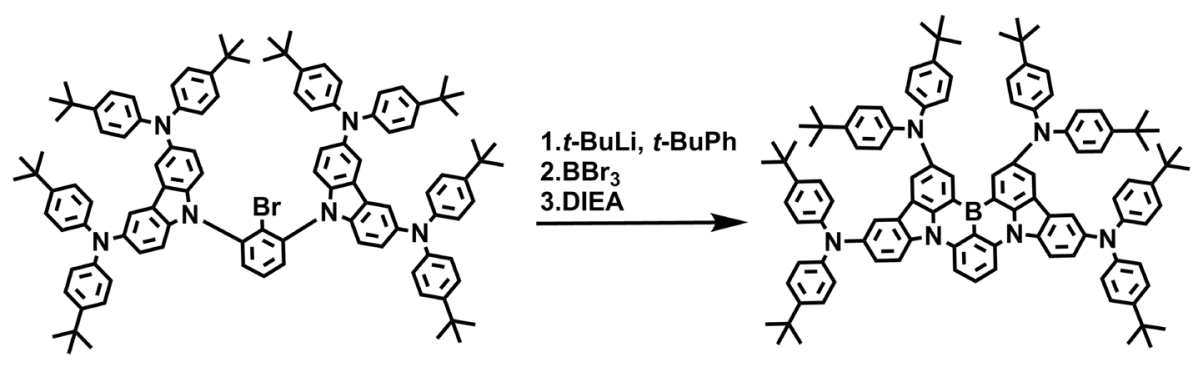

The solution of tert-butyllithium in pentane $(2.77 \mathrm{~mL}, 1.30 \mathrm{M}, 3.6 \mathrm{mmol})$ was added slowly to a solution of $3(2.89 \mathrm{~g}, 1.8 \mathrm{mmol})$ in tert-butylbenzene $(30 \mathrm{~mL})$ at $-78{ }^{\circ} \mathrm{C}$ under nitrogen atmosphere. After stirring at $40^{\circ} \mathrm{C}$ for $2 \mathrm{~h}$, pentane was distilled at $60{ }^{\circ} \mathrm{C}$. After addition of boron tribromide $(501 \mathrm{mg}, 2 \mathrm{mmol})$ at $-30^{\circ} \mathrm{C}$, the reaction mixture was stirred at room temperature for $0.5 \mathrm{~h} . \mathrm{N}, \mathrm{N}$-Diisopropylethylamine (517 $\mathrm{mg}, 4 \mathrm{mmol})$ was added at $0{ }^{\circ} \mathrm{C}$ and then the reaction mixture was heated to room temperature. After stirring at $120{ }^{\circ} \mathrm{C}$ for $8 \mathrm{~h}$, the reaction mixture was cooled to room temperature. The resulting product was diluted with chloroform and washed with water. The combined organic extracts were dried over $\mathrm{Na}_{2} \mathrm{SO}_{4}$ and concentrated under reduced pressure. The crude product was purified by column chromatography with dichloromethane/petroleum (1: 4) as eluent to afford an orange solid (1.24 g, 45\%). ${ }^{1} \mathrm{H}$ 
NMR (500 MHz, Methylene Chloride- $\left.d_{2}\right) \delta 8.34(\mathrm{~s}, 6 \mathrm{H}), 8.03(\mathrm{~s}, 2 \mathrm{H}), 7.82(\mathrm{~s}, 2 \mathrm{H}), 7.34$ (dd, $J=9.0,2.4 \mathrm{~Hz}, 3 \mathrm{H}), 7.27(\mathrm{~d}, J=8.2 \mathrm{~Hz}, 9 \mathrm{H}), 7.20(\mathrm{~s}, 8 \mathrm{H}), 6.98$ (d, $J=54.6 \mathrm{~Hz}$, 15H), 1.30 (s, 36H), 1.22 (s, 36H). MALDI: m/z:1533.90 [M]+ (calcd: 1534.00). Anal. Calcd for $\mathrm{C}_{110} \mathrm{H}_{117} \mathrm{BN}_{6}: \mathrm{C}, 86.13 ; \mathrm{H}, 7.69 ; \mathrm{N}, 5.48$. Found: C, 85.98; H, 7.72; N, 5.45.

\section{BN-1-Bpin}

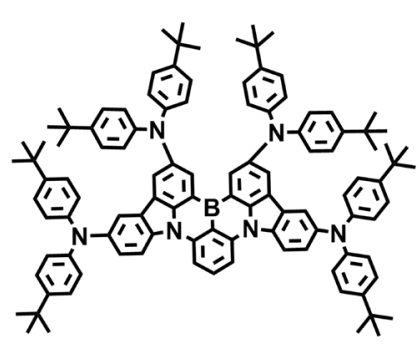

4,4'-di-tert-butyl-2,2'-bipyridine (dtbpy)

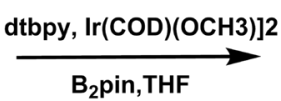

$B_{2}$ pin, THF

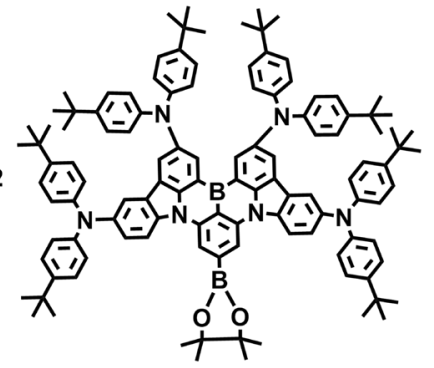

(34.9 $\mathrm{mg}, \quad 0.13 \mathrm{mmol}$ ) and di-mu-

methoxobis(1,5-cyclooctadiene)diiridium(I) $\left(\left[\operatorname{Ir}(\mathrm{COD})\left(\mathrm{OCH}_{3}\right)\right]_{2}\right) \quad(43.1 \mathrm{mg}, \quad 0.065$ mmol) were added to the suspension of $\mathrm{BN}-1$ (9.97 $\mathrm{g}, 6.5 \mathrm{mmol})$ and bis(pinacolato)diboron $\left(\mathrm{B}_{2} \mathrm{Pin}\right)(1.68 \mathrm{~g}, 6.6 \mathrm{mmol})$ in extra dry tetrahydrofuran (THF) $(150 \mathrm{~mL})$ at room temperature. Then the mixture was bubbled with nitrogen for further 5 minutes and heated to reflux and stirred for 12 hours. After cooling to room temperature, the reaction mixture was directly concentrated under reduced pressure and purified by column chromatography with using a mixture eluent of dichloromethane/petroleum ether $(1: 2)$ to afford a red solid $(9.7 \mathrm{~g})$. Yield: $90 \% .{ }^{1} \mathrm{H}$ NMR (500 MHz, Methylene Chloride- $\left.d_{2}\right) \delta 7.34(\mathrm{~d}, J=37.5 \mathrm{~Hz}, 44 \mathrm{H}), 1.44(\mathrm{~s}, 12 \mathrm{H})$, 1.31 (s, 36H), 1.23 (s, 36H). MALDI: m/z:1660.34 [M]+ (calcd:1659.96). Anal. Calcd for $\mathrm{C}_{116} \mathrm{H}_{128} \mathrm{~B}_{2} \mathrm{~N}_{6} \mathrm{O}_{2}$ : C, 83.93; H, 7.77; N, 5.06. Found: C, 83.98; H, 7.72; N, 5.05.

\section{BN-2}




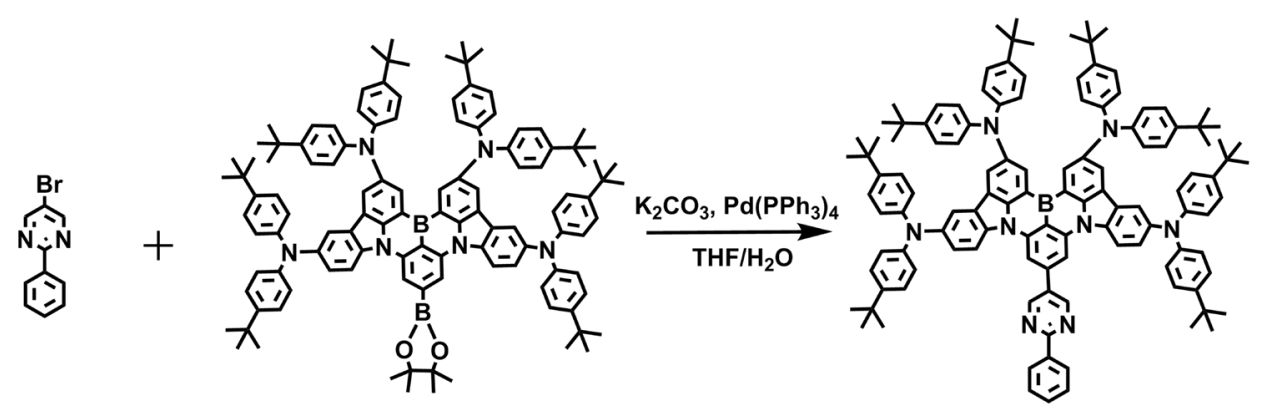

The mixture of 5-bromo-2-phenylpyrimidine (235 mg, $1 \mathrm{mmol}$ ), BN-1-Bpin (1.66 g, 1 mmol$)$, potassium carbonate $(277 \quad \mathrm{mg}, \quad 2 \quad \mathrm{mmol})$ and tetrakis(triphenylphosphine)palladium (25 mg, $0.05 \mathrm{mmol})$ in $50 \mathrm{~mL}$ THF and $10 \mathrm{~mL}$ water under nitrogen was refluxed for $8 \mathrm{~h}$. After cooling to room temperature, the resulting product was diluted with dichloromethane and washed with water. The combined organic extracts were dried over $\mathrm{Na}_{2} \mathrm{SO}_{4}$ and concentrated by rotary evaporation. The crude product was purified by column chromatography with dichloromethane/petroleum (1: 3) as eluent to afford an orange solid (1.35 g, 80\%). ${ }^{1} \mathrm{H}$ NMR (500 MHz, Methylene Chloride- $\left.d_{2}\right) \delta 7.58-7.52(\mathrm{~m}, 6 \mathrm{H}), 7.35(\mathrm{dd}, J=9.1,2.3$ $\mathrm{Hz}, 2 \mathrm{H}), 7.29(\mathrm{~d}, J=8.4 \mathrm{~Hz}, 5 \mathrm{H}), 7.24(\mathrm{~d}, J=8.8 \mathrm{~Hz}, 20 \mathrm{H}), 7.06(\mathrm{~d}, J=8.1 \mathrm{~Hz}, 6 \mathrm{H})$, $7.00(\mathrm{~d}, J=8.7 \mathrm{~Hz}, 4 \mathrm{H}), 6.94(\mathrm{~s}, 8 \mathrm{H}), 1.28(\mathrm{~s}, 72 \mathrm{H})$. MALDI: m/z:1688.00 [M]+ (calcd:1688.17). Anal. Calcd for $\mathrm{C}_{120} \mathrm{H}_{123} \mathrm{BN}_{8}$ : C, 85.38; H, 7.34; N, 6.64. Found: C, 85.33; H, 7.32; N, 6.55.

\section{BN-3}

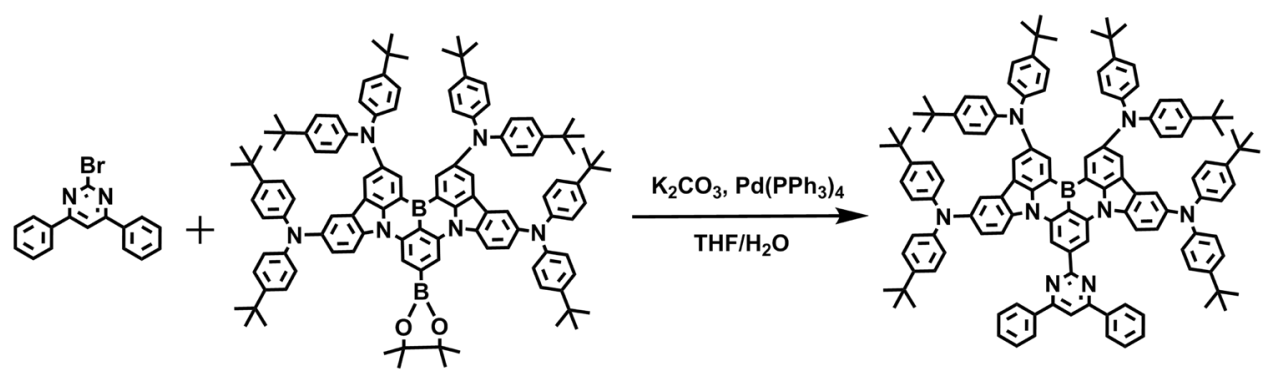


BN-3 was synthesized by replacing 5-bromo-2-phenylpyrimidine with 2-bromo-4,6diphenylpyrimidine $(311 \mathrm{mg}, 1 \mathrm{mmol})$ according to the same procedure. The crude product was purified by column chromatography with dichloromethane/petroleum (1:

3) as eluent to afford a red solid (1.5 g, 85\%). ${ }^{1} \mathrm{H}$ NMR (500 MHz, Methylene Chloride$\left.d_{2}\right) \delta 8.42(\mathrm{~s}, 6 \mathrm{H}), 8.20(\mathrm{~s}, 2 \mathrm{H}), 7.52(\mathrm{~s}, 9 \mathrm{H}), 7.38(\mathrm{~d}, J=45.1 \mathrm{~Hz}, 38 \mathrm{H}), 1.33(\mathrm{~s}, 36 \mathrm{H})$, 1.25 (s, 36H). MALDI: m/z: 1764.37 [M]+ (calcd:1764.27). Anal. Calcd for $\mathrm{C}_{126} \mathrm{H}_{127} \mathrm{BN}_{8}: \mathrm{C}, 85.78 ; \mathrm{H}, 7.26 ; \mathrm{N}, 6.35$. Found: $\mathrm{C}, 85.73 ; \mathrm{H}, 7.32 ; \mathrm{N}, 6.35$.

\section{BN-4}

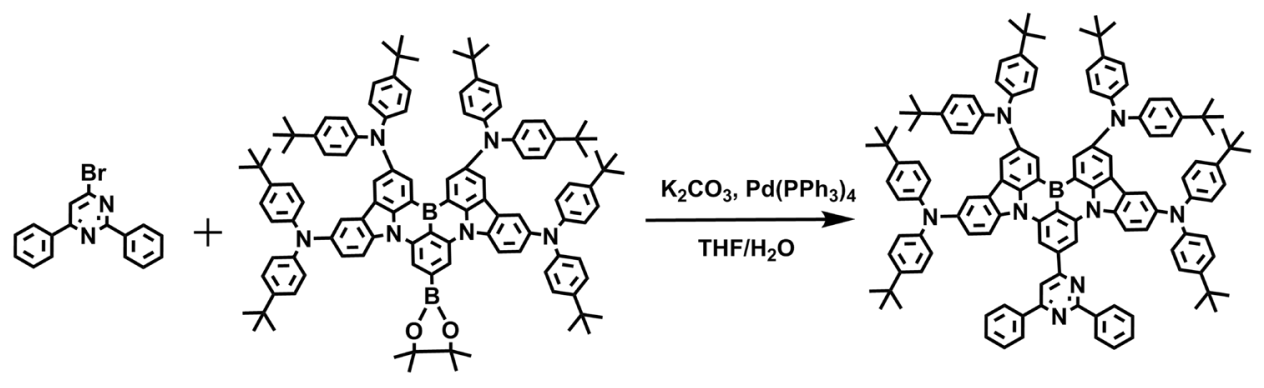

BN-4 was synthesized by replacing 5-bromo-2-phenylpyrimidine with 4-bromo-2,6diphenylpyrimidine $(311 \mathrm{mg}, 1 \mathrm{mmol})$ according to the same procedure. The crude product was purified by column chromatography with dichloromethane/petroleum (1:3) as eluent to afford a red solid (1.37 g, 78\%). ${ }^{1} \mathrm{H}$ NMR (500 MHz, Methylene Chloride$\left.d_{2}\right) \delta 8.83(\mathrm{~s}, 2 \mathrm{H}), 8.60(\mathrm{~s}, 3 \mathrm{H}), 8.39-8.33(\mathrm{~m}, 4 \mathrm{H}), 7.60(\mathrm{~d}, J=6.7 \mathrm{~Hz}, 3 \mathrm{H}), 7.50(\mathrm{~s}$, 3H), $7.43(\mathrm{~d}, J=8.9 \mathrm{~Hz}, 3 \mathrm{H}), 7.30(\mathrm{~s}, 37 \mathrm{H}), 1.32(\mathrm{~s}, 36 \mathrm{H}), 1.24$ (s, 36H). MALDI: m/z: 1764.38 [M]+ (calcd:1764.27). Anal. Calcd for $\mathrm{C}_{126} \mathrm{H}_{127} \mathrm{BN}_{8}: \mathrm{C}, 85.78 ; \mathrm{H}, 7.26 ; \mathrm{N}, 6.35$. Found: C, 85.69; H, 7.30; N, 6.31.

\section{BN-5}



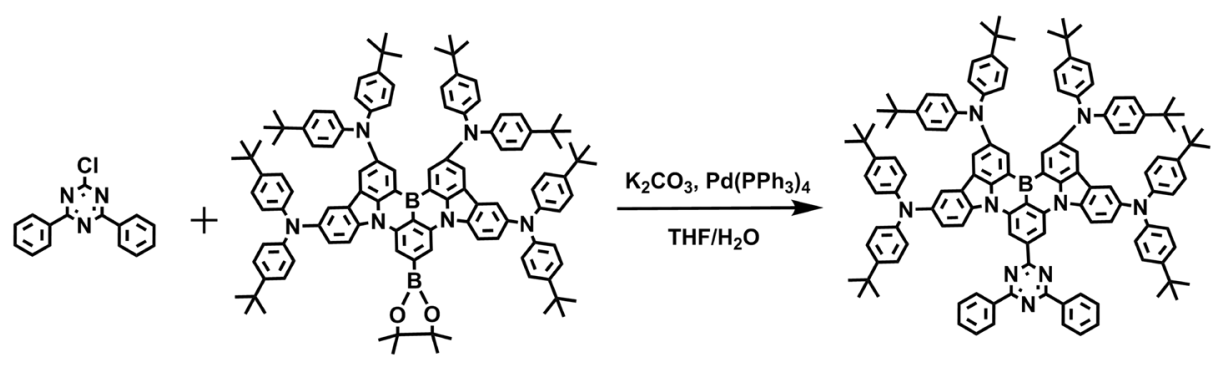

BN-5 was synthesized by replacing 5-bromo-2-phenylpyrimidine with 2-chloro-4,6diphenyl-1,3,5-triazine (268 $\mathrm{mg}, 1 \mathrm{mmol}$ ) according to the same procedure. The crude product was purified by column chromatography with dichloromethane/petroleum (1:3) as eluent to afford a black solid (1.32 g, 75\%). ${ }^{1} \mathrm{H}$ NMR (500 MHz, Methylene Chloride- $\left.d_{2}\right) \delta 8.79-8.73(\mathrm{~m}, 1 \mathrm{H}), 7.55-7.48(\mathrm{~m}, 1 \mathrm{H}), 7.48-7.37(\mathrm{~m}, 2 \mathrm{H}), 7.19(\mathrm{~d}$, $J=111.4 \mathrm{~Hz}, 6 \mathrm{H}), 1.32(\mathrm{~s}, 7 \mathrm{H}), 1.24(\mathrm{~s}, 7 \mathrm{H})$. MALDI: m/z: $1764.97[\mathrm{M}]+$ (calcd:1765.26). Anal. Calcd for $\mathrm{C}_{125} \mathrm{H}_{126} \mathrm{BN}_{9}$ : C, 85.05; H, 7.19; N, 7.14. Found: $\mathrm{C}$, 85.09; H, 7.20; N, 6.11.

\section{2-chloro-4,6-bis(4-((2-ethylhexyl)oxy)phenyl)-1,3,5-triazine (4)}

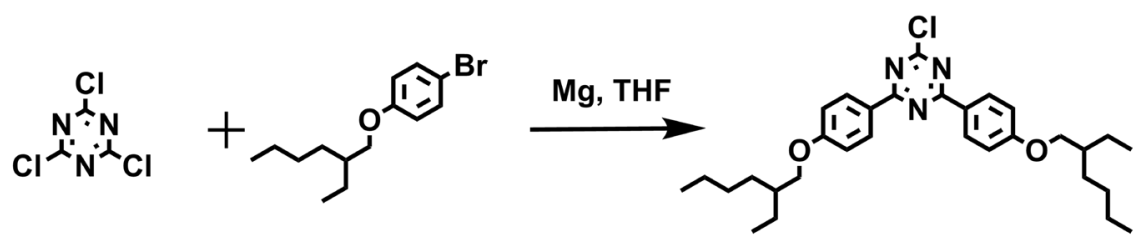

1-bromo-4-((2-ethylhexyl)oxy)benzene was synthesized from 4-bromophenol and 3(bromomethyl)heptane via nucleophilic substitution reaction under alkaline conditions. ${ }^{[6]}$ The solution of 1-bromo-4-((2-ethylhexyl)oxy)benzene in THF (5 ml, 0.2 M, $1 \mathrm{mmol})$ was slowly added to magnesium ribbon $(2.40 \mathrm{~g}, 100 \mathrm{mmol})$ and iodine particles in $10 \mathrm{ml} \mathrm{THF}$ at $30^{\circ} \mathrm{C}$ under nitrogen atmosphere. The reaction mixture turned grey, the remaining solution of 1-bromo-4-((2-ethylhexyl)oxy)benzene in THF (145 ml, $0.2 \mathrm{M}, 29 \mathrm{mmol}$ ) was slowly added to the reaction mixture at $0{ }^{\circ} \mathrm{C}$ and stirred at $0^{\circ} \mathrm{C}$ 
for 2 hours. The prepared grignard reagent was slowly added to the mixture of 2,4,6trichloro-1,3,5-triazine $(1.84 \mathrm{~g}, 10 \mathrm{mmol})$ in $100 \mathrm{ml}$ THF under nitrogen atmosphere at $0{ }^{\circ} \mathrm{C}$ and stirred at $35^{\circ} \mathrm{C}$ for 12 hours. After the reaction was completed, the solution of $\mathrm{NH}_{4} \mathrm{Cl}$ was added to the reaction mixture to adjust $\mathrm{pH}=7$. The resulting product was diluted with dichloromethane and washed with water. The combined organic extracts were dried over $\mathrm{Na}_{2} \mathrm{SO}_{4}$ and concentrated by rotary evaporation. The crude product was purified by column chromatography with dichloromethane/petroleum (1:3) as eluent to afford a white solid (3.66 g, 70\%). ${ }^{1} \mathrm{H}$ NMR (500 MHz, DMSO- $\left.d_{6}\right) \delta 8.11$ (d, $J=9.0$ Hz, 4H), 7.09 (d, $J=8.9 \mathrm{~Hz}, 4 \mathrm{H}), 3.97$ (d, $J=5.8 \mathrm{~Hz}, 4 \mathrm{H}), 1.70$ (q, $J=6.1 \mathrm{~Hz}, 2 \mathrm{H})$, $1.42(\mathrm{dtq}, J=21.9,14.4,6.9 \mathrm{~Hz}, 10 \mathrm{H}), 1.32-1.27(\mathrm{~m}, 8 \mathrm{H}), 0.91(\mathrm{~s}, 2 \mathrm{H}), 0.90(\mathrm{~s}, 4 \mathrm{H})$, $0.88(\mathrm{~d}, J=2.2 \mathrm{~Hz}, 4 \mathrm{H})$. ESI-MS (M): m/z: $523.33[\mathrm{M}]+$ (calcd: 524.15). Anal. Calcd for $\mathrm{C}_{31} \mathrm{H}_{42} \mathrm{ClN}_{3} \mathrm{O}_{2}$ : C, 71.04; H, 8.08; N, 8.02. Found: C, 71.20; H, 8.12; N, 8.08.

\section{BN-6}
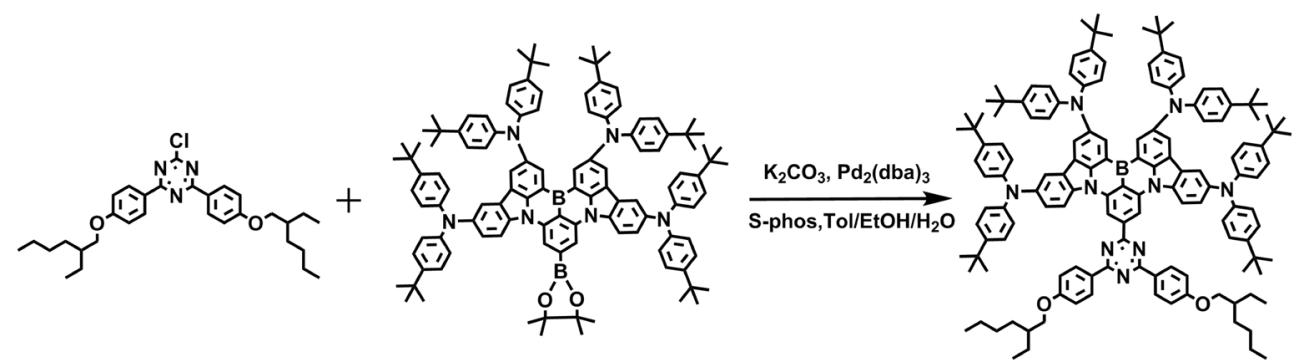

The mixture of 4 (524 mg, $1 \mathrm{mmol})$, BN-1-Bpin (1.66 g, $1 \mathrm{mmol})$, 2dicyclohexylphosphino-2',6'-dimethoxybiphenyl

(41 $\mathrm{mg}, \quad 0.1 \quad \mathrm{mmol})$, potassiumcarbonate ( $277 \mathrm{mg}, 2 \mathrm{mmol})$, and tris(dibenzylideneacetone)dipalladium (25 $\mathrm{mg}, 0.05 \mathrm{mmol}$ ) in $50 \mathrm{~mL}$ toluene, $10 \mathrm{ml}$ water and $10 \mathrm{ml}$ ethanol under nitrogen was refluxed for $12 \mathrm{~h}$. After cooling to room temperature, the resulting product was diluted with dichloromethane and washed with water. The combined organic extracts were 
dried over $\mathrm{Na}_{2} \mathrm{SO}_{4}$ and concentrated by rotary evaporation. The crude product was purified by column chromatography with dichloromethane/petroleum $(1: 3)$ as eluent to afford a black solid (1.07 g, 53\%). ${ }^{1} \mathrm{H}$ NMR (500 MHz, Methylene Chloride- $\left.d_{2}\right) \delta 8.59$ (dd, $J=48.0,8.6 \mathrm{~Hz}, 4 \mathrm{H}), 8.36(\mathrm{~s}, 2 \mathrm{H}), 7.96(\mathrm{~d}, J=103.6 \mathrm{~Hz}, 4 \mathrm{H}), 7.44-7.40(\mathrm{~m}, 2 \mathrm{H})$, $7.31-6.91(\mathrm{~m}, 40 \mathrm{H}), 3.94(\mathrm{~d}, J=30.7 \mathrm{~Hz}, 4 \mathrm{H}), 1.56(\mathrm{t}, J=7.1 \mathrm{~Hz}, 4 \mathrm{H}), 1.31(\mathrm{~s}, 36 \mathrm{H})$, $1.28(\mathrm{~s}, 16 \mathrm{H}), 1.23(\mathrm{~s}, 36 \mathrm{H}), 0.97-0.90(\mathrm{~m}, 10 \mathrm{H})$. MALDI: m/z: $2021.68[\mathrm{M}]+$ (calcd:2021.69). Anal. Calcd for $\mathrm{C}_{141} \mathrm{H}_{158} \mathrm{BN}_{9} \mathrm{O}_{2}$ : C, 83.77; H, 7.88; N, 6.24. Found: C, 83.79; H, 7.90; N, 6.21 .

\section{2-chloro-4,6-bis(3-((2-ethylhexyl)oxy)phenyl)-1,3,5-triazine (5)}

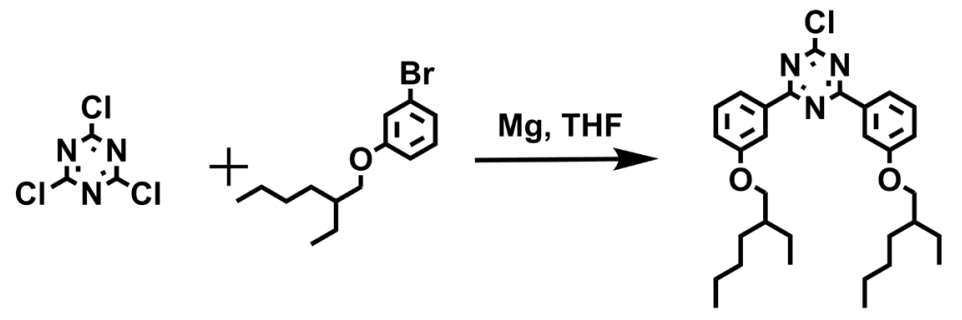

5 was synthesized by replacing 1-bromo-3-((2-ethylhexyl)oxy)benzene (8.55 g, 30 mmol) with 1-bromo-4-((2-ethylhexyl)oxy)benzene according to the same procedure for 4. The crude product was purified by column chromatography with dichloromethane/petroleum (1:3) as eluent to afford a colorless oil $(4.08 \mathrm{~g}, 78 \%) .{ }^{1} \mathrm{H}$ NMR (500 MHz, DMSO- $\left.d_{6}\right) \delta 8.13(\mathrm{~d}, J=7.7 \mathrm{~Hz}, 2 \mathrm{H}), 8.01(\mathrm{t}, J=2.0 \mathrm{~Hz}, 2 \mathrm{H}), 7.55$ $(\mathrm{t}, J=8.0 \mathrm{~Hz}, 2 \mathrm{H}), 7.32(\mathrm{dd}, J=8.1,2.6 \mathrm{~Hz}, 2 \mathrm{H}), 4.00(\mathrm{~d}, J=5.7 \mathrm{~Hz}, 4 \mathrm{H}), 1.77-1.72$ $(\mathrm{m}, 2 \mathrm{H}), 1.51-1.44(\mathrm{~m}, 6 \mathrm{H}), 1.40(\mathrm{~s}, 4 \mathrm{H}), 1.34-1.30(\mathrm{~m}, 6 \mathrm{H}), 1.23(\mathrm{~s}, 2 \mathrm{H}), 0.93-$ $0.88(\mathrm{~m}, 10 \mathrm{H})$. ESI-MS (M): m/z: $525.22[\mathrm{M}]+$ (calcd: 524.15). Anal. Calcd for $\mathrm{C}_{31} \mathrm{H}_{42} \mathrm{ClN}_{3} \mathrm{O}_{2}: \mathrm{C}, 71.04 ; \mathrm{H}, 8.08 ; \mathrm{N}, 8.02$. Found: $\mathrm{C}, 71.20 ; \mathrm{H}, 8.12 ; \mathrm{N}, 8.08$.

\section{BN-7}




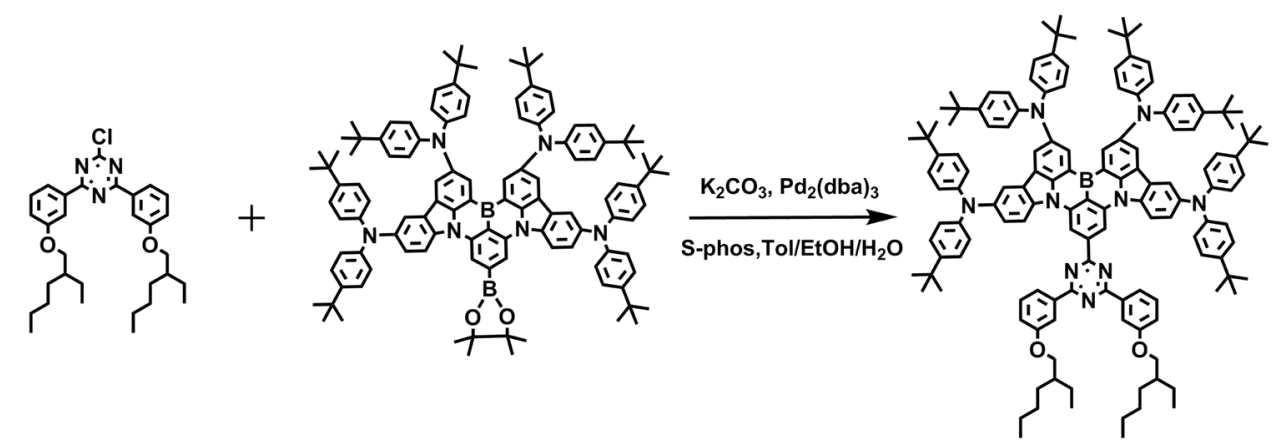

BN-7 was synthesized by replacing 4 with $5(524 \mathrm{mg}, 1 \mathrm{mmol})$ according to the same procedure for BN-6. The crude product was purified by column chromatography with dichloromethane/petroleum (1:3) as eluent to afford a black solid $(1.37 \mathrm{~g}, 68 \%) .{ }^{1} \mathrm{H}$ NMR (500 MHz, Methylene Chloride- $\left.d_{2}\right) \delta 8.45(\mathrm{dt}, J=7.6,1.2 \mathrm{~Hz}, 3 \mathrm{H}), 8.39(\mathrm{t}, J=$ $2.0 \mathrm{~Hz}, 3 \mathrm{H}), 7.52-7.41(\mathrm{~m}, 6 \mathrm{H}), 7.40-6.79(\mathrm{~m}, 40 \mathrm{H}), 4.00(\mathrm{dd}, J=5.5,2.3 \mathrm{~Hz}, 4 \mathrm{H})$, $1.77-1.73(\mathrm{~m}, 2 \mathrm{H}), 1.55-1.51(\mathrm{~m}, 2 \mathrm{H}), 1.50-1.39(\mathrm{~m}, 8 \mathrm{H}), 1.31(\mathrm{~s}, 40 \mathrm{H}), 1.24(\mathrm{~s}$, 36H), 0.88 (dt, $J=20.1,7.3 \mathrm{~Hz}, 14 \mathrm{H})$. MALDI: m/z: 2021.68 [M]+ (calcd:2021.69). Anal. Calcd for $\mathrm{C}_{141} \mathrm{H}_{158} \mathrm{BN}_{9} \mathrm{O}_{2}$ : C, 83.77; H, 7.88; N, 6.24. Found: C, 83.82; H, 7.92; N, 6.23.

\section{$N^{3}, N^{3}, N^{6}, N^{6}$-tetrakis(4-(2-phenylpropan-2-yl)phenyl)-9H-carbazole-3,6-}

\section{diamine (6)}

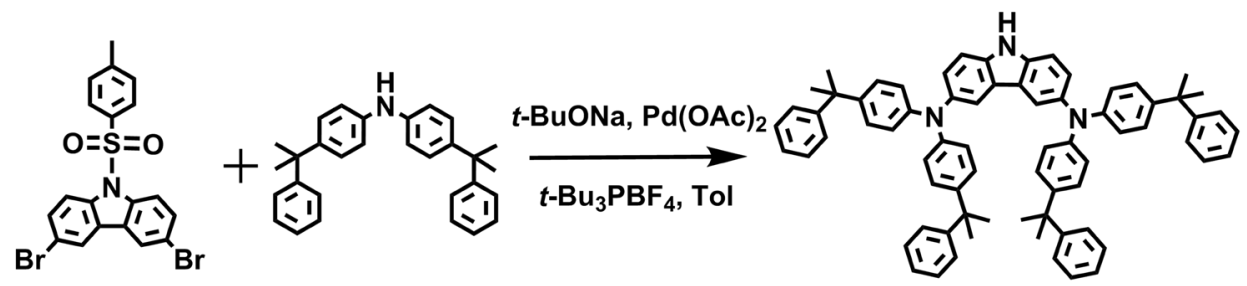

6 was synthesized by replacing bis(4-(tert-butyl)phenyl)amine with bis(4-(2phenylpropan-2-yl)phenyl)amine (2.15 g, $1 \mathrm{mmol})$ according to the same procedure for 2. The crude product was purified by column chromatography with dichloromethane/petroleum (1:3) as eluent to afford a white solid (5.07 g, 65\%). ${ }^{1} \mathrm{H}$ 
NMR (500 MHz, Methylene Chloride- $\left.d_{2}\right) \delta 7.65-6.24(\mathrm{~m}, 43 \mathrm{H}), 1.64$ (s, 24H). ESIMS (M): m/z: 973.53 [M]+ (calcd: 974.35). Anal. Calcd for $\mathrm{C}_{72} \mathrm{H}_{67} \mathrm{~N}_{3}: \mathrm{C}, 88.76 ; \mathrm{H}$, 6.93; N, 4.31. Found: C, 88.82; H, 6.91; N, 4.19.

\section{9,9'-(2-bromo-1,3-phenylene)bis $\left(N^{3}, N^{3}, N^{6}, N^{6}\right.$-tetrakis(4-(2-phenylpropan-2-}

\section{yl)phenyl)-9H-carbazole-3,6-diamine) (7)}
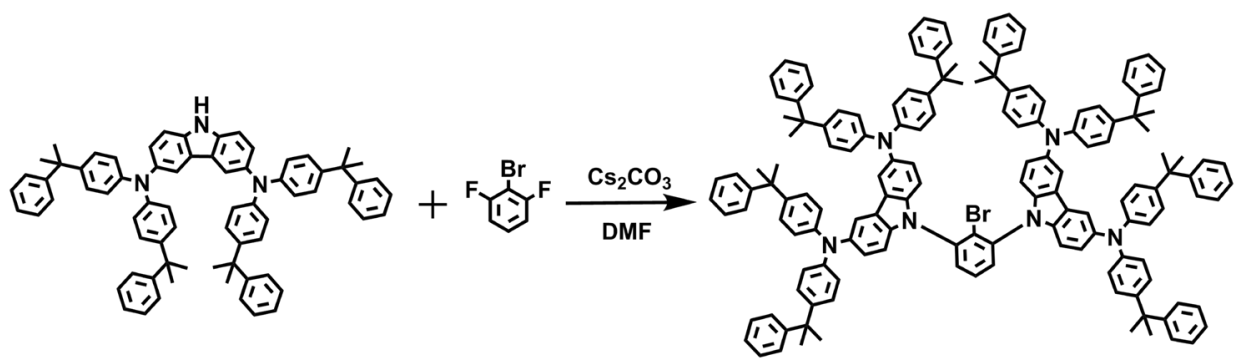

7 was synthesized by replacing 2 with $6(2.15 \mathrm{~g}, 1 \mathrm{mmol})$ according to the same procedure for 3 . The crude product was purified by column chromatography with dichloromethane/petroleum (1:4) as eluent to afford a white solid (3.95 g, 94\%). ${ }^{1} \mathrm{H}$ NMR (500 MHz, Methylene Chloride- $\left.d_{2}\right) \delta 7.69(\mathrm{~s}, 6 \mathrm{H}), 7.30-7.19(\mathrm{~m}, 38 \mathrm{H}), 7.19-$ $6.70(\mathrm{~m}, 43 \mathrm{H}), 1.63(\mathrm{~s}, 48 \mathrm{H})$. MALDI: m/z: $2101.44[\mathrm{M}]+(\mathrm{calcd}: 2101.68)$. Anal. Calcd for $\mathrm{C}_{150} \mathrm{H}_{135} \mathrm{BrN}_{6}$ : C, 85.72; H, 6.47; N, 4.00. Found: C, 85.82; H, 6.41; N, 4.09.

\section{BN-8}

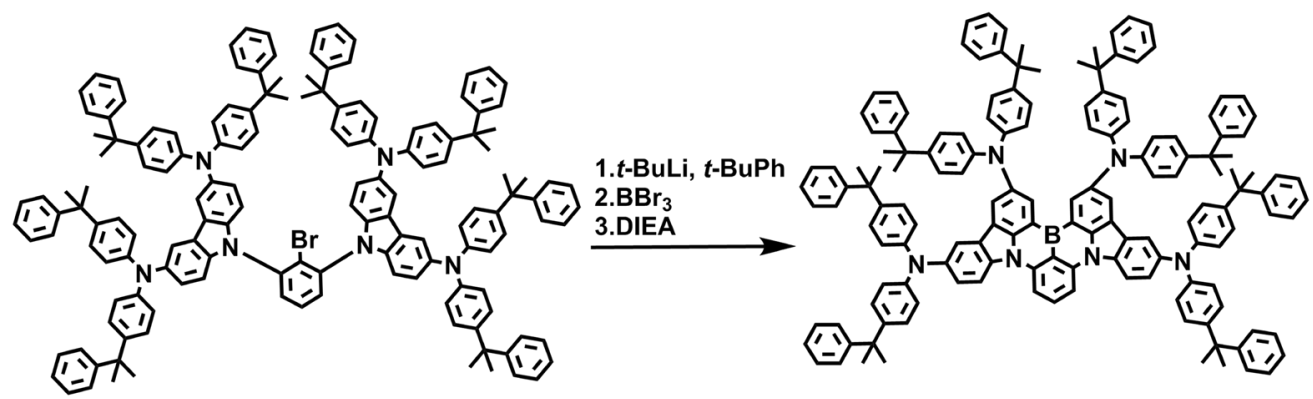

BN-8 was synthesized by replacing 3 with $7(2.15 \mathrm{~g}, 1 \mathrm{mmol})$ according to the same procedure for $\mathrm{BN}-1$. The crude product was purified by column chromatography with dichloromethane/petroleum (1:4) as eluent to afford an orange solid $(3.18 \mathrm{~g}, 87 \%) .{ }^{1} \mathrm{H}$ 
NMR (500 MHz, Methylene Chloride- $\left.d_{2}\right) \delta 7.34(\mathrm{dd}, J=9.0,2.4 \mathrm{~Hz}, 2 \mathrm{H}), 7.29-7.19$ (m, 34H), $7.18-6.86(\mathrm{~m}, 49 \mathrm{H}), 1.66$ (s, 24H), 1.56 (s, 24H). MALDI: m/z: 2030.47 $[\mathrm{M}]+$ (calcd:2030.57). Anal. Calcd for $\mathrm{C}_{150} \mathrm{H}_{133} \mathrm{BN}_{6}: \mathrm{C}, 88.73 ; \mathrm{H}, 6.60 ; \mathrm{N}, 4.14$. Found: C, 88.72; H, 6.61; N, 4.09.

\section{BN-8-Bpin}
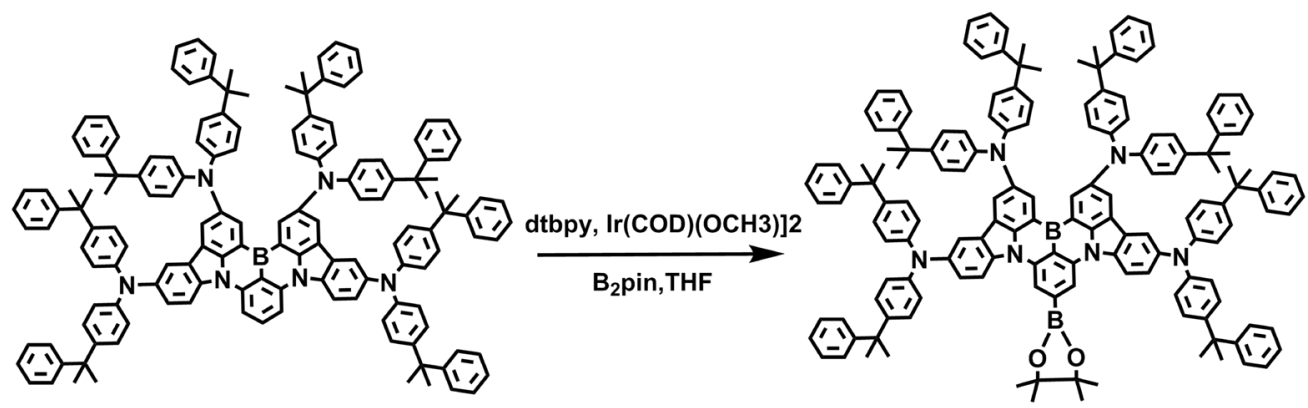

4,4'-di-tert-butyl-2,2'-bipyridine (dtbpy) (34.9 $\mathrm{mg}, 0.13 \mathrm{mmol})$ and di-mumethoxobis(1,5-cyclooctadiene)diiridium(I) $\quad\left(\left[\operatorname{Ir}(\mathrm{COD})\left(\mathrm{OCH}_{3}\right)\right]_{2}\right) \quad(43.1 \mathrm{mg}, \quad 0.065$ mmol) were added to the suspension of $\mathrm{BN}-8$ (9.97 g, $6.5 \mathrm{mmol})$ and bis(pinacolato)diboron $\left(\mathrm{B}_{2}\right.$ Pin) $(1.1 \mathrm{~g}, 4.3 \mathrm{mmol})$ in extra dry $\mathrm{THF}(150 \mathrm{~mL})$ at room temperature. Then the mixture was bubbled with nitrogen for further 5 minutes and heated to reflux and stirred for 1 hours. After cooling to room temperature, the reaction mixture was directly concentrated under reduced pressure and purified by column chromatography with using a mixture eluent of dichloromethane/petroleum ether $(2: 3)$ to afford a red solid (5.88 g). Yield: 42\%. ${ }^{1} \mathrm{H}$ NMR (500 MHz, Methylene Chloride- $d_{2}$ ) $\delta 7.39(\mathrm{~d}, J=7.3 \mathrm{~Hz}, 2 \mathrm{H}), 7.30-7.19(\mathrm{~m}, 35 \mathrm{H}), 7.19-7.01(\mathrm{~m}, 47 \mathrm{H}), 1.68(\mathrm{~s}, 24 \mathrm{H})$, 1.58 (s, 24H), 1.45 (s, 12H). MALDI: m/z: 2156.60 [M]+ (calcd:2156.53). Anal. Calcd for $\mathrm{C}_{156} \mathrm{H}_{144} \mathrm{~B}_{2} \mathrm{~N}_{6} \mathrm{O}_{2}: \mathrm{C}, 86.89 ; \mathrm{H}, 6.73 ; \mathrm{N}, 3.90$. Found: $\mathrm{C}, 86.82 ; \mathrm{H}, 6.69 ; \mathrm{N}, 3.95$.

\section{BN-9}




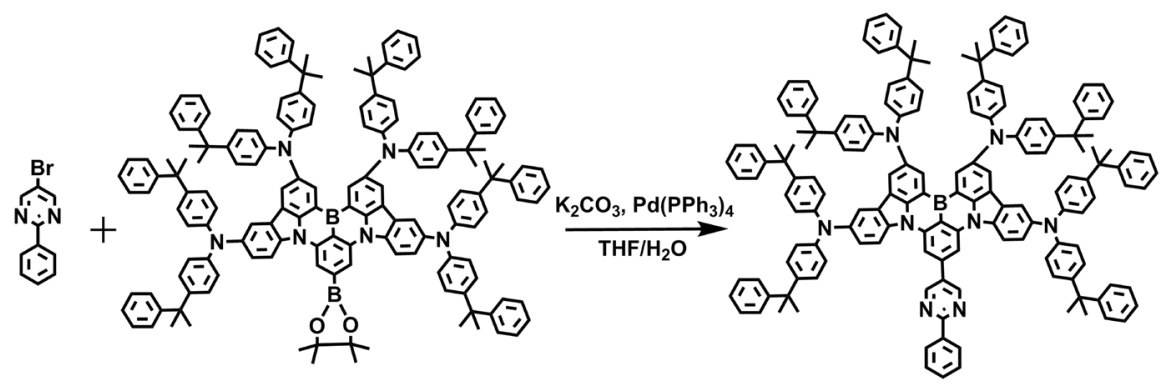

BN-9 was synthesized by replacing BN-1-Bpin with BN-8-Bpin (2.15 g, $1 \mathrm{mmol})$ according to the same procedure for $\mathrm{BN}-2$. The crude product was purified by column chromatography with dichloromethane/petroleum (1:4) as eluent to afford an orange solid (1.75 g, 80\%). ${ }^{1} \mathrm{H}$ NMR (500 MHz, Methylene Chloride- $\left.d_{2}\right) \delta 7.57$ (dt, $J=4.7$, $1.8 \mathrm{~Hz}, 3 \mathrm{H}), 7.53(\mathrm{dd}, J=5.1,2.0 \mathrm{~Hz}, 2 \mathrm{H}), 7.37(\mathrm{~d}, J=2.3 \mathrm{~Hz}, 1 \mathrm{H}), 7.35(\mathrm{~d}, J=2.4$ Hz, 1H), $7.30-7.21(\mathrm{~m}, 39 \mathrm{H}), 7.19-6.97(\mathrm{~m}, 45 \mathrm{H}), 1.67(\mathrm{~s}, 24 \mathrm{H}), 1.58(\mathrm{~s}, 24 \mathrm{H})$. MALDI: m/z: 2184.56 [M]+ (calcd:2184.74). Anal. Calcd for $\mathrm{C}_{160} \mathrm{H}_{139} \mathrm{BN}_{8}: \mathrm{C}, 87.96$; H, 6.41; N, 5.13. Found: C, 87.92; H, 6.39; N, 5.15.

\section{BN-10}

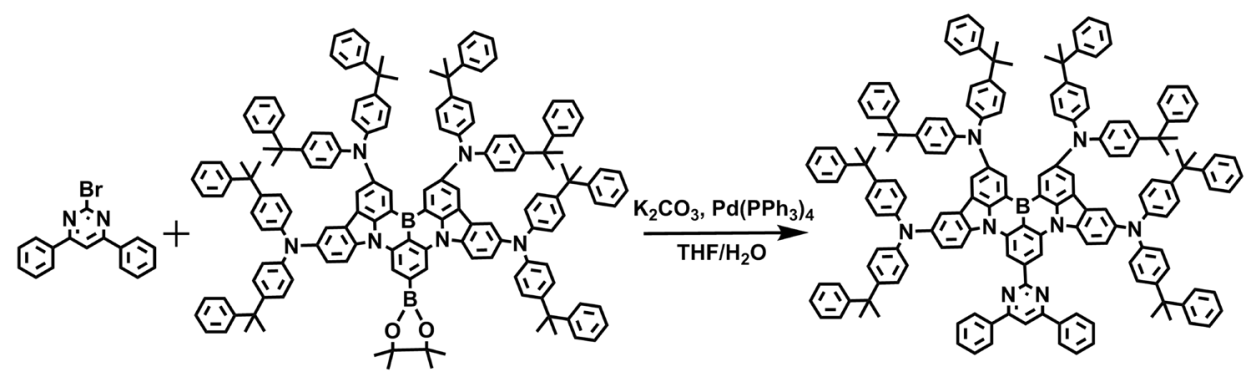

$\mathrm{BN}-10$ was synthesized by replacing $\mathrm{BN}-1-\mathrm{Bpin}$ with $\mathrm{BN}-8$-Bpin (2.15 g, $1 \mathrm{mmol})$ according to the same procedure for BN-4. The crude product was purified by column chromatography with dichloromethane/petroleum (1:4) as eluent to afford a red solid (1.72 g, 76\%). ${ }^{1} \mathrm{H}$ NMR (500 MHz, Methylene Chloride- $\left.d_{2}\right) \delta 8.39(\mathrm{dd}, J=6.6,2.9 \mathrm{~Hz}$, 5H), $8.16(\mathrm{~s}, 1 \mathrm{H}), 7.51(\mathrm{q}, J=2.9 \mathrm{~Hz}, 8 \mathrm{H}), 7.43(\mathrm{~d}, J=9.1 \mathrm{~Hz}, 3 \mathrm{H}), 7.35-7.21(\mathrm{~m}$, 34H), $7.20-6.86(\mathrm{~m}, 43 \mathrm{H}), 1.68(\mathrm{~s}, 24 \mathrm{H}), 1.59$ (s, 24H). MALDI: m/z: 2260.16 [M]+ 
(calcd:2260.84). Anal. Calcd for $\mathrm{C}_{166} \mathrm{H}_{143} \mathrm{BN}_{8}$ : C, 88.19; H, 6.38; N, 4.96. Found: C, 88.12; H, 6.39; N, 5.02.

\section{BN-11}

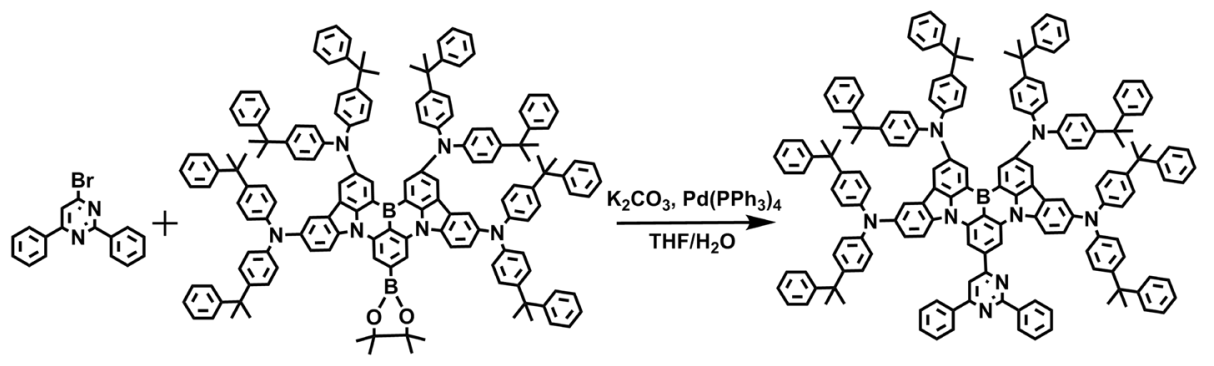

BN-11 was synthesized by replacing BN-1-Bpin with BN-8-Bpin (2.15 g, 1 mmol) according to the same procedure for BN-4. The crude product was purified by column chromatography with dichloromethane/petroleum (1:4) as eluent to afford a red solid (1.76 g, 78\%). ${ }^{1} \mathrm{H}$ NMR (500 MHz, Methylene Chloride- $\left.d_{2}\right) \delta 7.62(\mathrm{dd}, J=5.0,1.9 \mathrm{~Hz}$, 4H), $7.58-7.42(\mathrm{~m}, 12 \mathrm{H}), 7.32-7.21(\mathrm{~m}, 42 \mathrm{H}), 7.21-7.15(\mathrm{~m}, 13 \mathrm{H}), 7.15-7.11(\mathrm{~m}$, 12H), $7.11-7.05(\mathrm{~m}, 12 \mathrm{H}), 1.68(\mathrm{~s}, 24 \mathrm{H}), 1.59$ (s, 24H). MALDI: m/z: 2260.16 [M]+ (calcd:2260.84). Anal. Calcd for $\mathrm{C}_{166} \mathrm{H}_{143} \mathrm{BN}_{8}$ : C, 88.19; H, 6.38; N, 4.96. Found: $\mathrm{C}$, 88.25; H, 6.30; N, 5.08.

\section{BN-12}

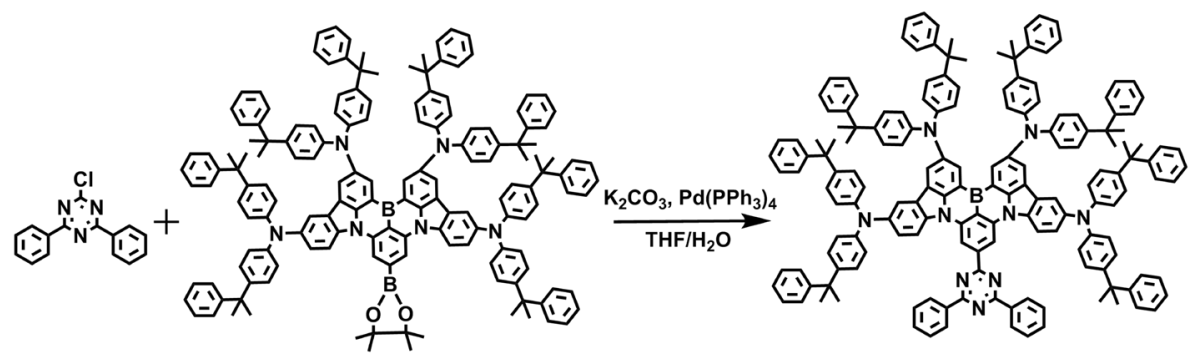

BN-12 was synthesized by replacing BN-1-Bpin with BN-8-Bpin (2.15 g, 1 mmol) according to the same procedure for BN-5. The crude product was purified by column chromatography with dichloromethane/petroleum (1:4) as eluent to afford a black solid 
(1.65 g, 73\%). ${ }^{1} \mathrm{H}$ NMR (500 MHz, Methylene Chloride- $\left.d_{2}\right) \delta 8.77(\mathrm{~d}, J=7.5 \mathrm{~Hz}, 4 \mathrm{H})$, $7.57-7.42(\mathrm{~m}, 10 \mathrm{H}), 7.31-7.21(\mathrm{~m}, 30 \mathrm{H}), 7.21-6.93(\mathrm{~m}, 50 \mathrm{H}), 1.68(\mathrm{~s}, 24 \mathrm{H}), 1.59$ (s, 24H). MALDI: m/z: 2261.10 [M]+ (calcd:2261.82). Anal. Calcd for $\mathrm{C}_{165} \mathrm{H}_{142} \mathrm{BN}_{9}$ : C, 87.62; H, 6.33; N, 5.57. Found: C, 87.55; H, 6.30; N, 5.58.

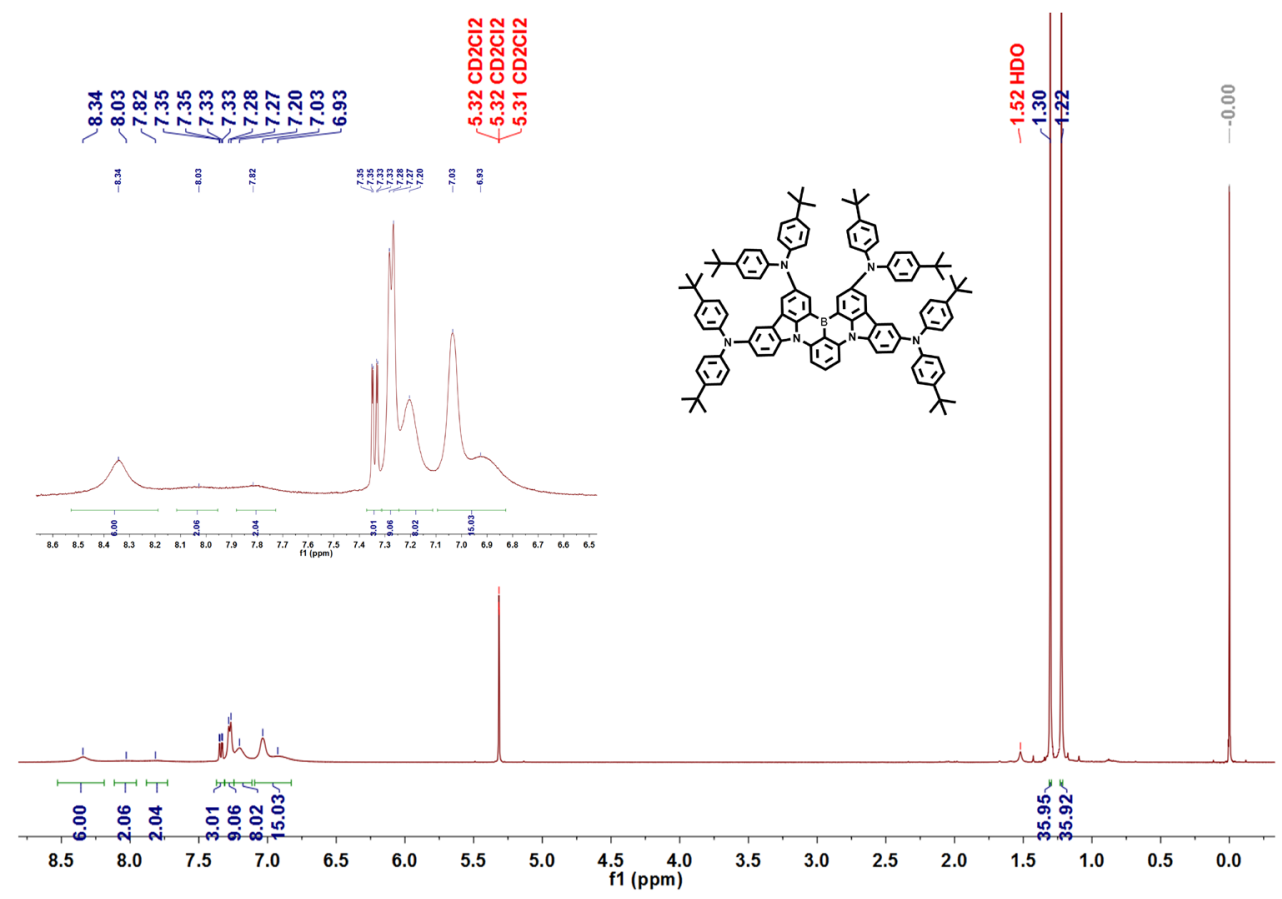

Figure S1. ${ }^{1} \mathrm{H}$ NMR spectrum $\left(500 \mathrm{MHz}, \mathrm{CD}_{2} \mathrm{Cl}_{2}\right)$ of $\mathrm{BN}-1$. 


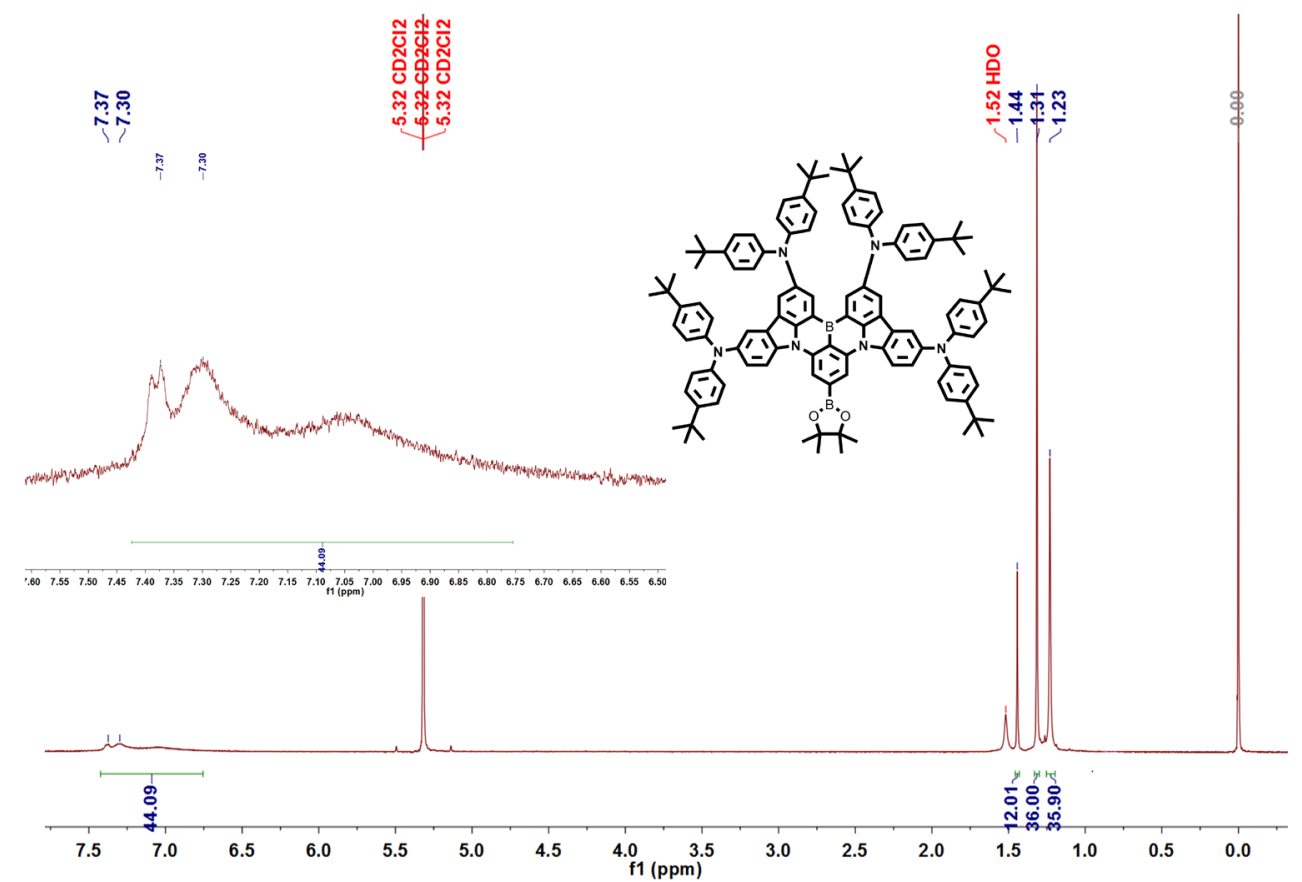

Figure S2. ${ }^{1} \mathrm{H}$ NMR spectrum $\left(500 \mathrm{MHz}, \mathrm{CD}_{2} \mathrm{Cl}_{2}\right)$ of $\mathrm{BN}-1-\mathrm{Bpin}$.

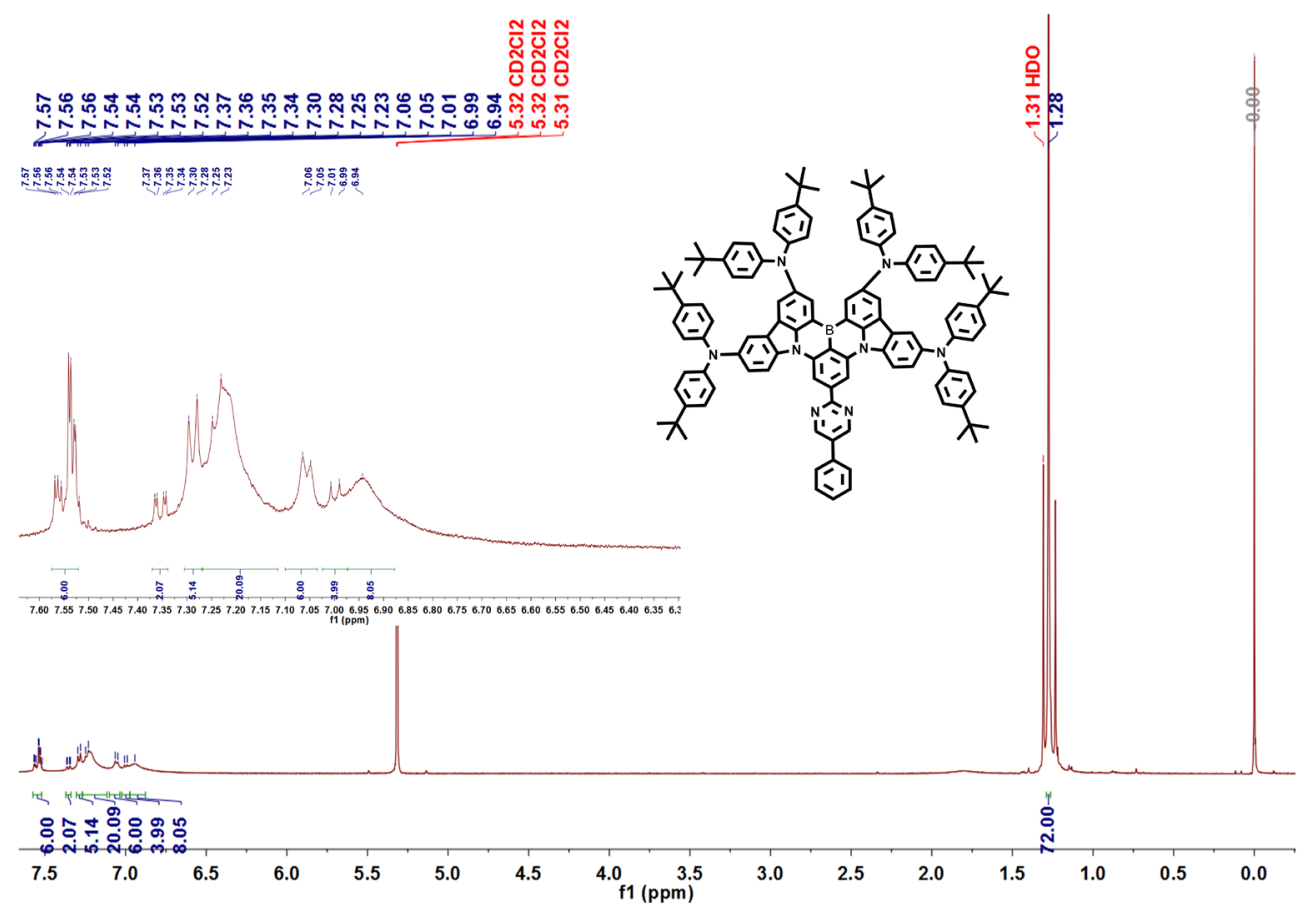

Figure S3. ${ }^{1} \mathrm{H}$ NMR spectrum $\left(500 \mathrm{MHz}, \mathrm{CD}_{2} \mathrm{Cl}_{2}\right)$ of $\mathrm{BN}-2$. 


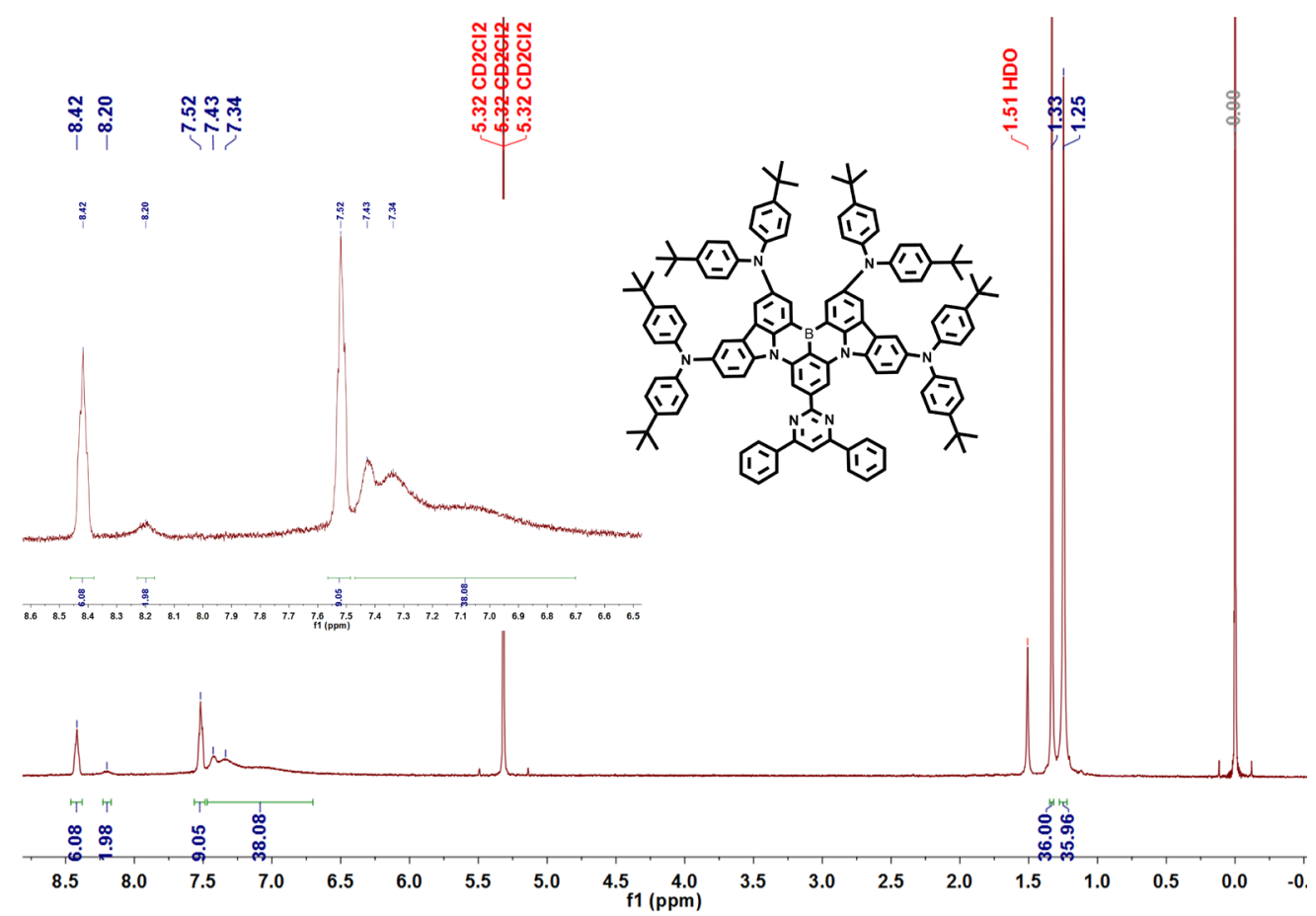

Figure S4. ${ }^{1} \mathrm{H}$ NMR spectrum $\left(500 \mathrm{MHz}, \mathrm{CD}_{2} \mathrm{Cl}_{2}\right)$ of $\mathrm{BN}-3$.

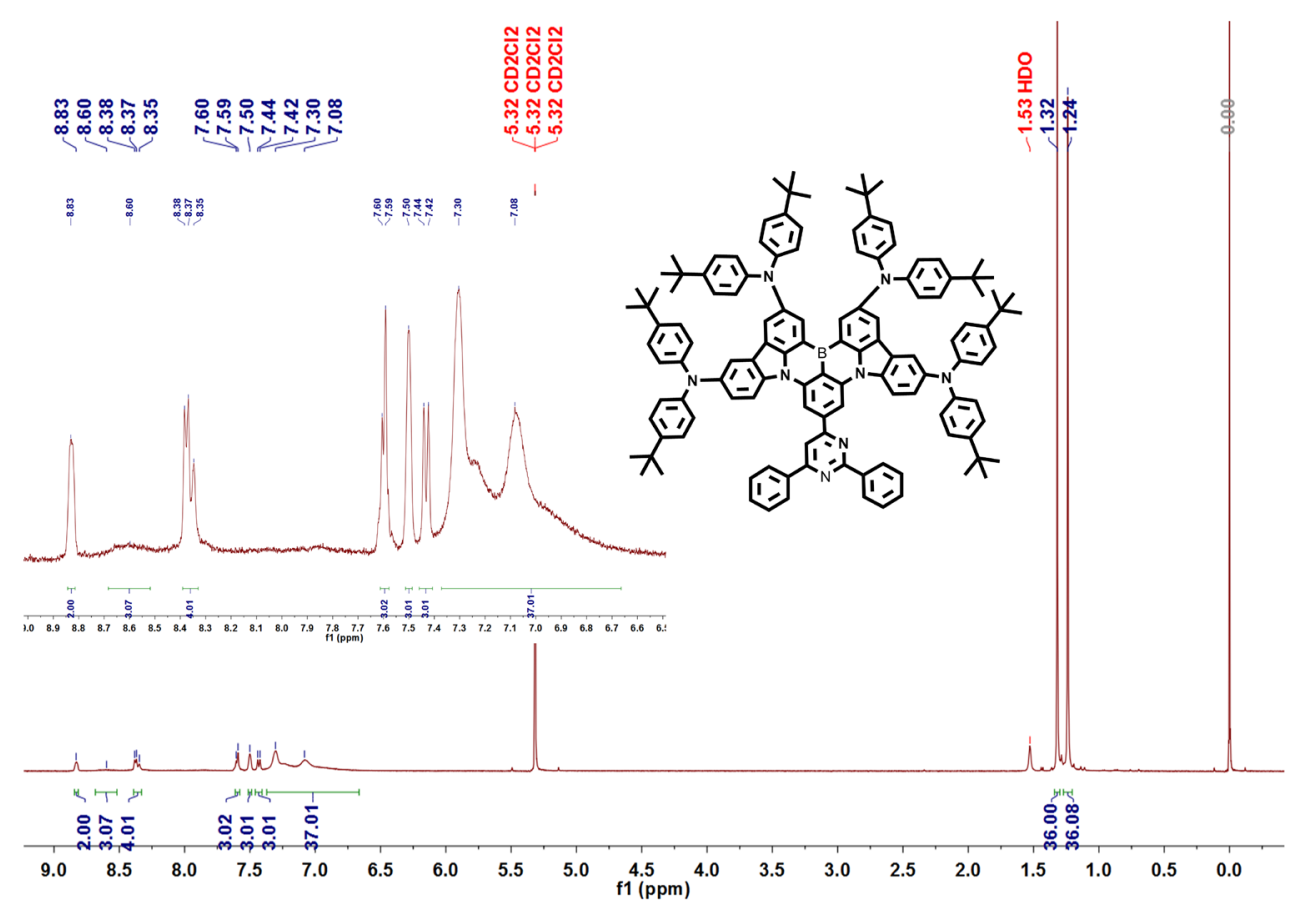

Figure S5. ${ }^{1} \mathrm{H}$ NMR spectrum $\left(500 \mathrm{MHz}, \mathrm{CD}_{2} \mathrm{Cl}_{2}\right)$ of $\mathrm{BN}-4$. 


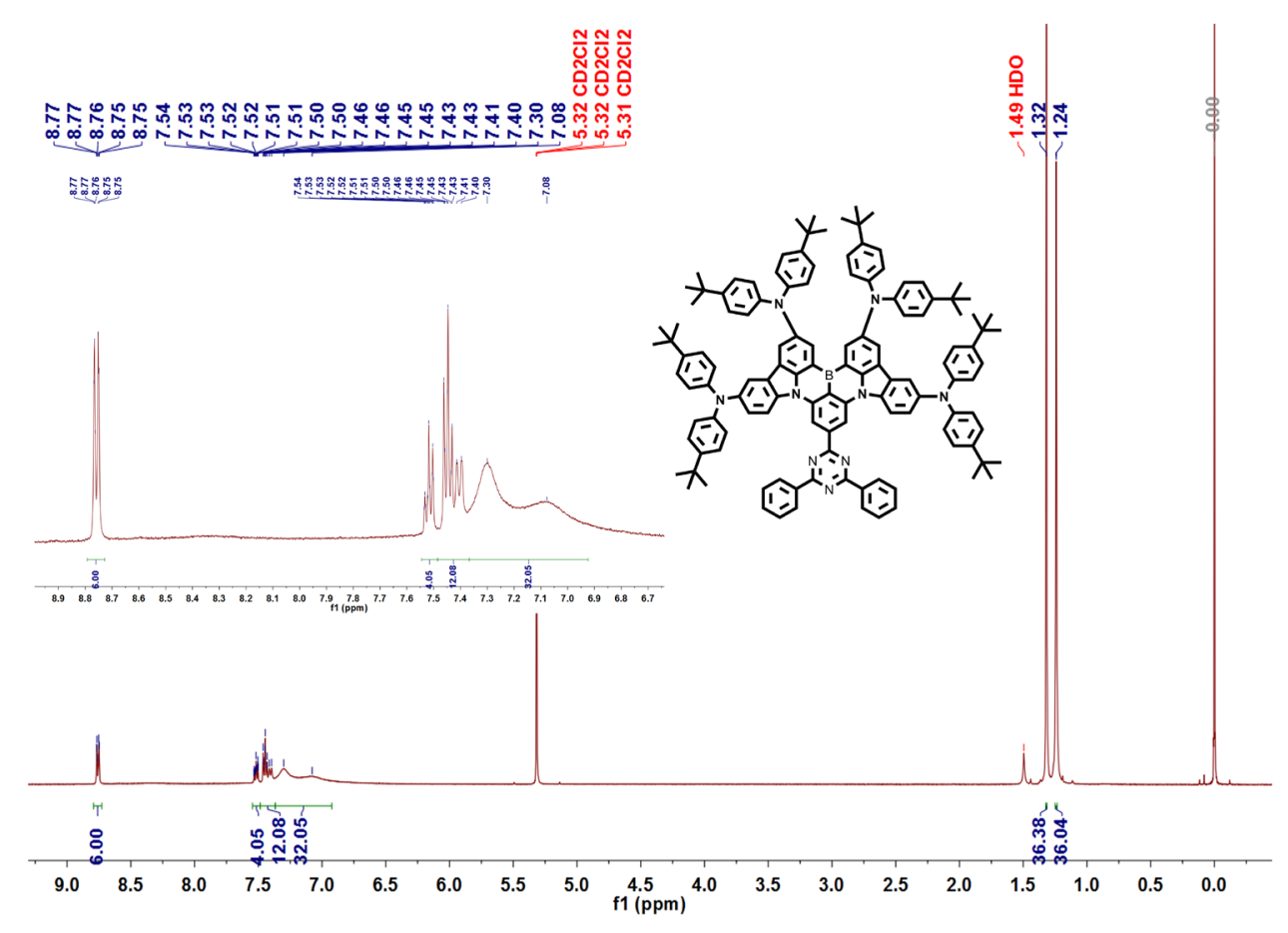

Figure S6. ${ }^{1} \mathrm{H}$ NMR spectrum $\left(500 \mathrm{MHz}, \mathrm{CD}_{2} \mathrm{Cl}_{2}\right)$ of $\mathrm{BN}-5$.

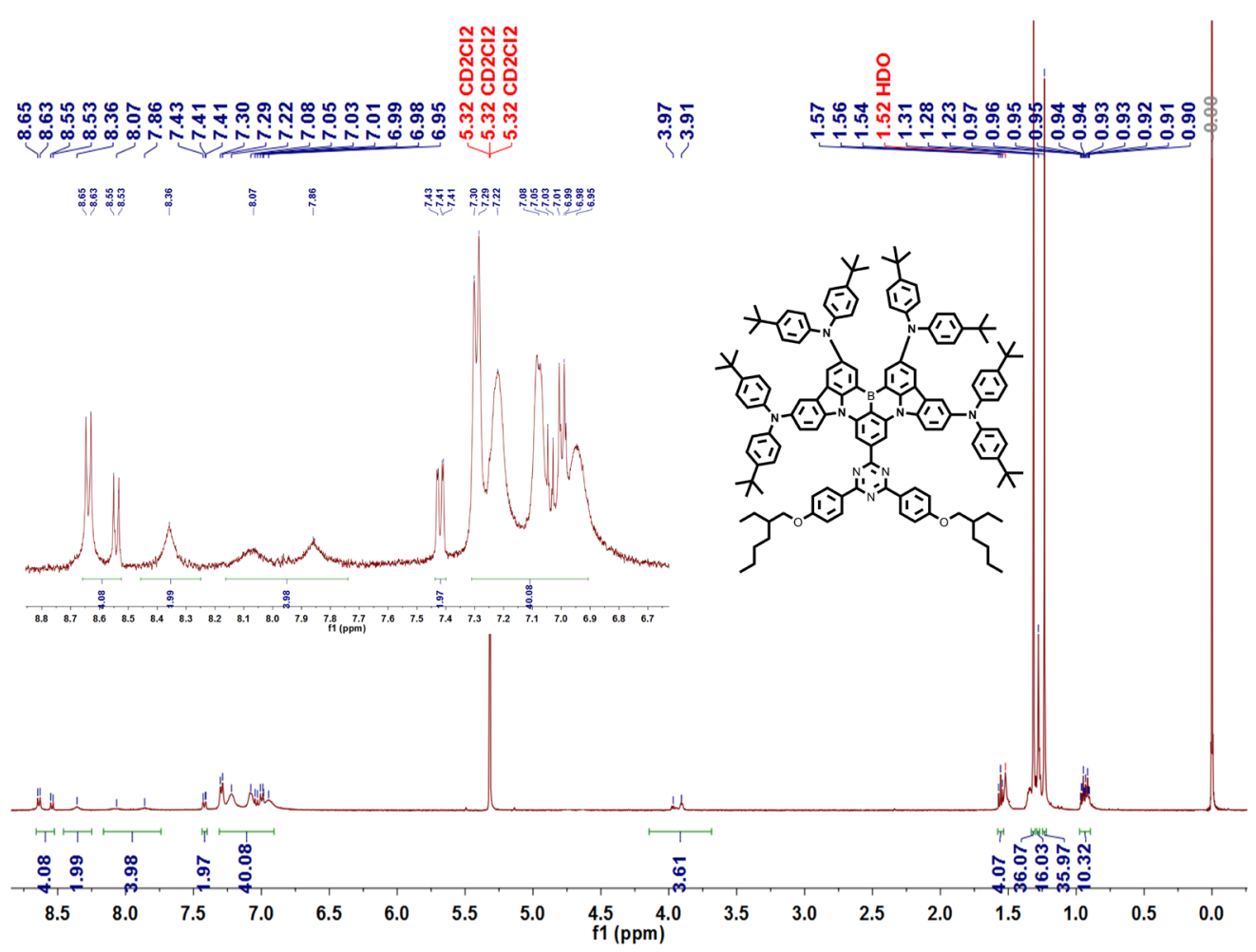

Figure S7. ${ }^{1} \mathrm{H}$ NMR spectrum $\left(500 \mathrm{MHz}, \mathrm{CD}_{2} \mathrm{Cl}_{2}\right)$ of $\mathrm{BN}-6$. 


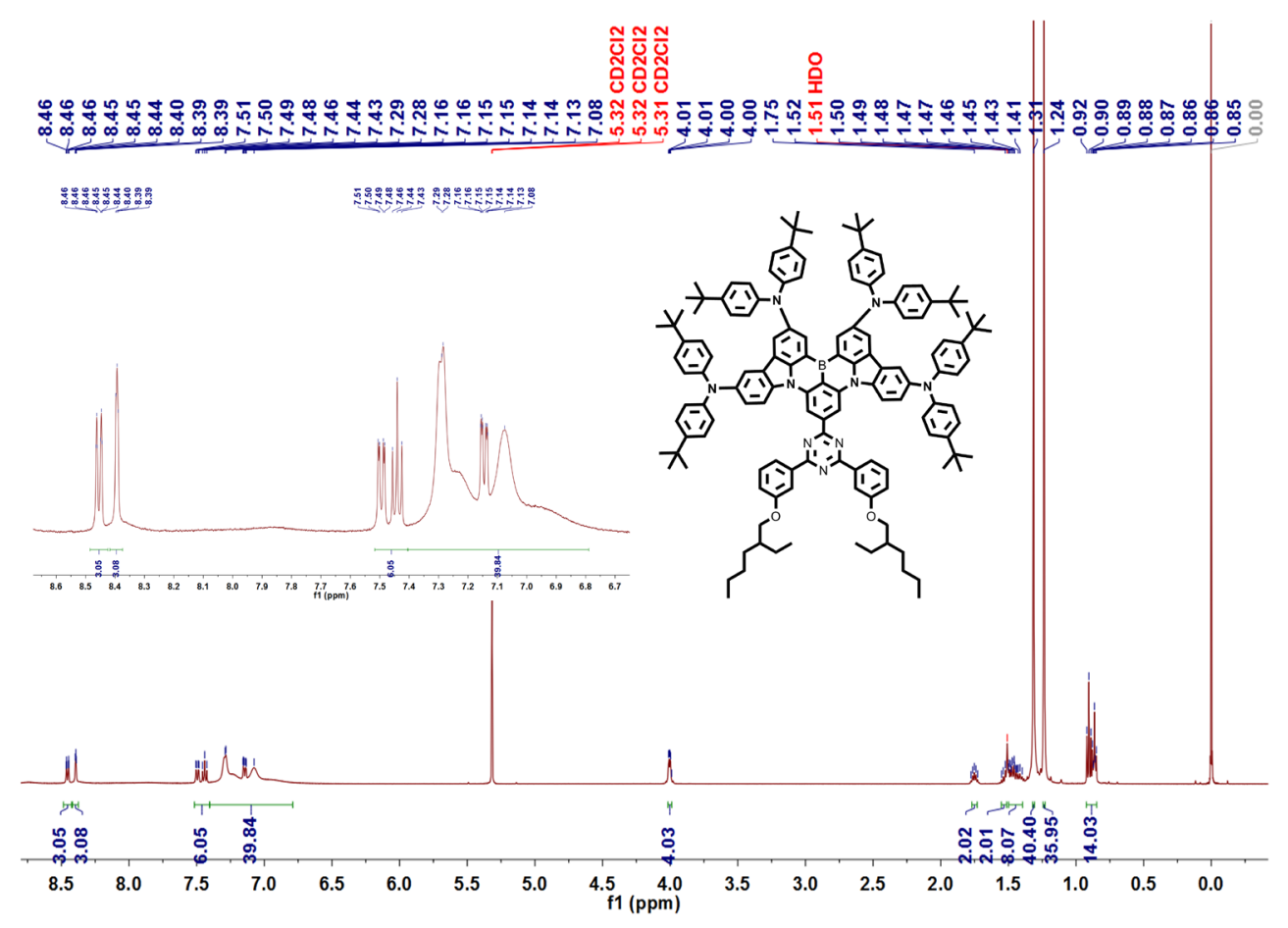

Figure S8. ${ }^{1} \mathrm{H}$ NMR spectrum $\left(500 \mathrm{MHz}, \mathrm{CD}_{2} \mathrm{Cl}_{2}\right)$ of $\mathrm{BN}-7$.

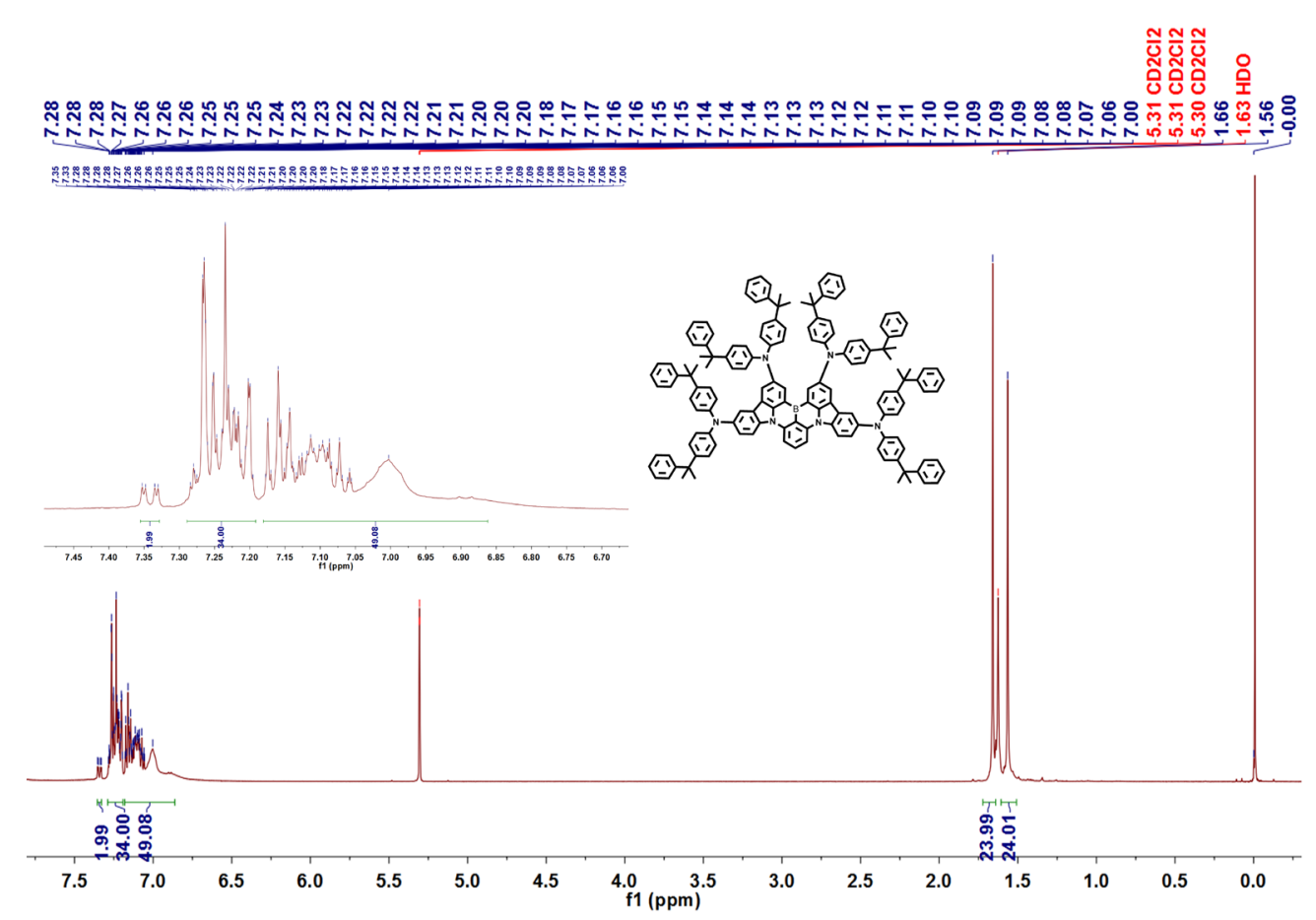

Figure S9. ${ }^{1} \mathrm{H}$ NMR spectrum $\left(500 \mathrm{MHz}, \mathrm{CD}_{2} \mathrm{Cl}_{2}\right)$ of $\mathrm{BN}-8$. 


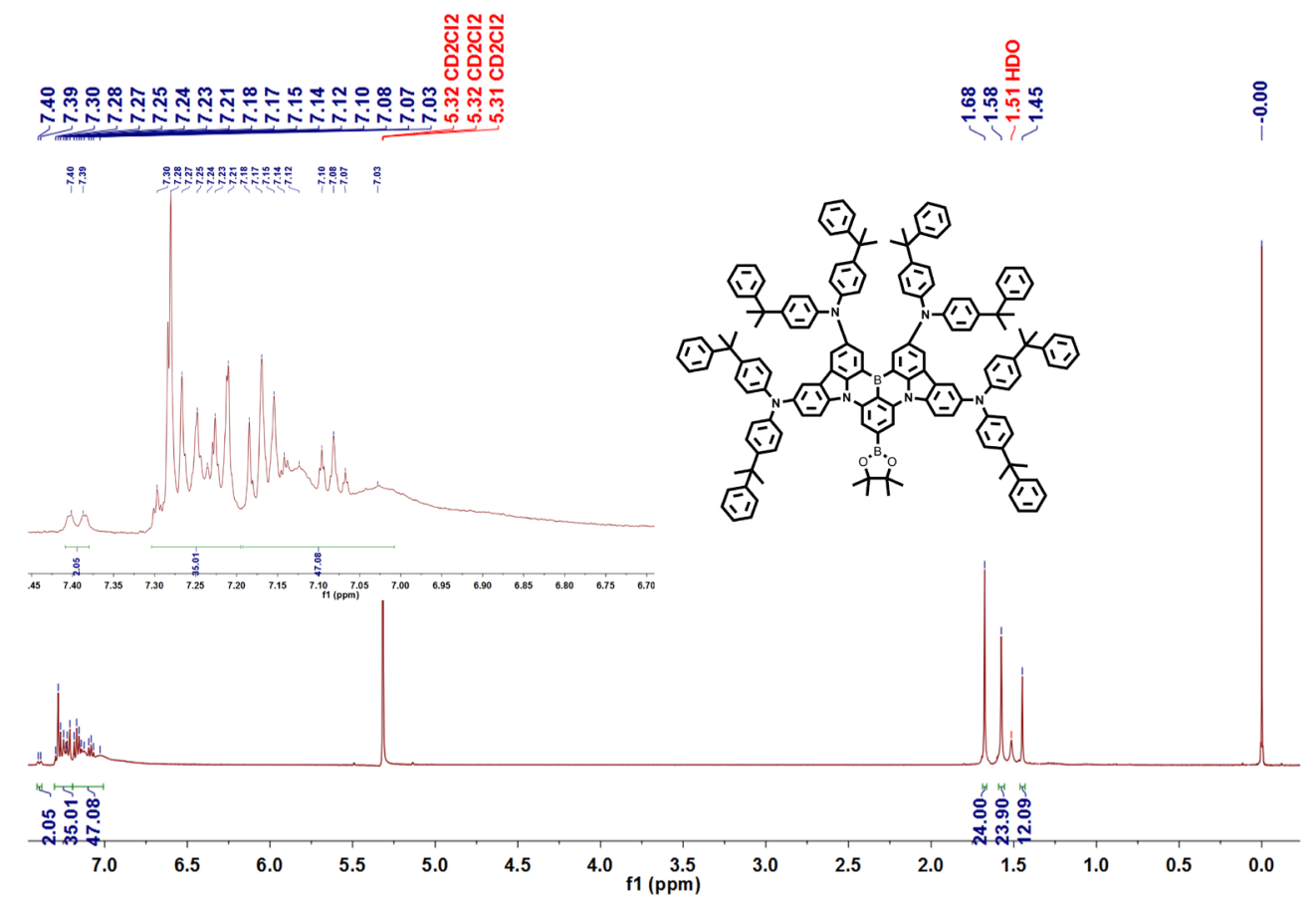

Figure S10. ${ }^{1} \mathrm{H}$ NMR spectrum $\left(500 \mathrm{MHz}, \mathrm{CD}_{2} \mathrm{Cl}_{2}\right)$ of $\mathrm{BN}-8$-Bpin.

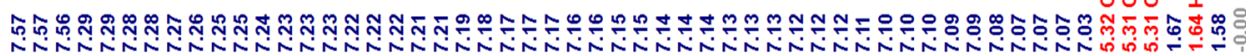

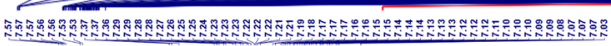

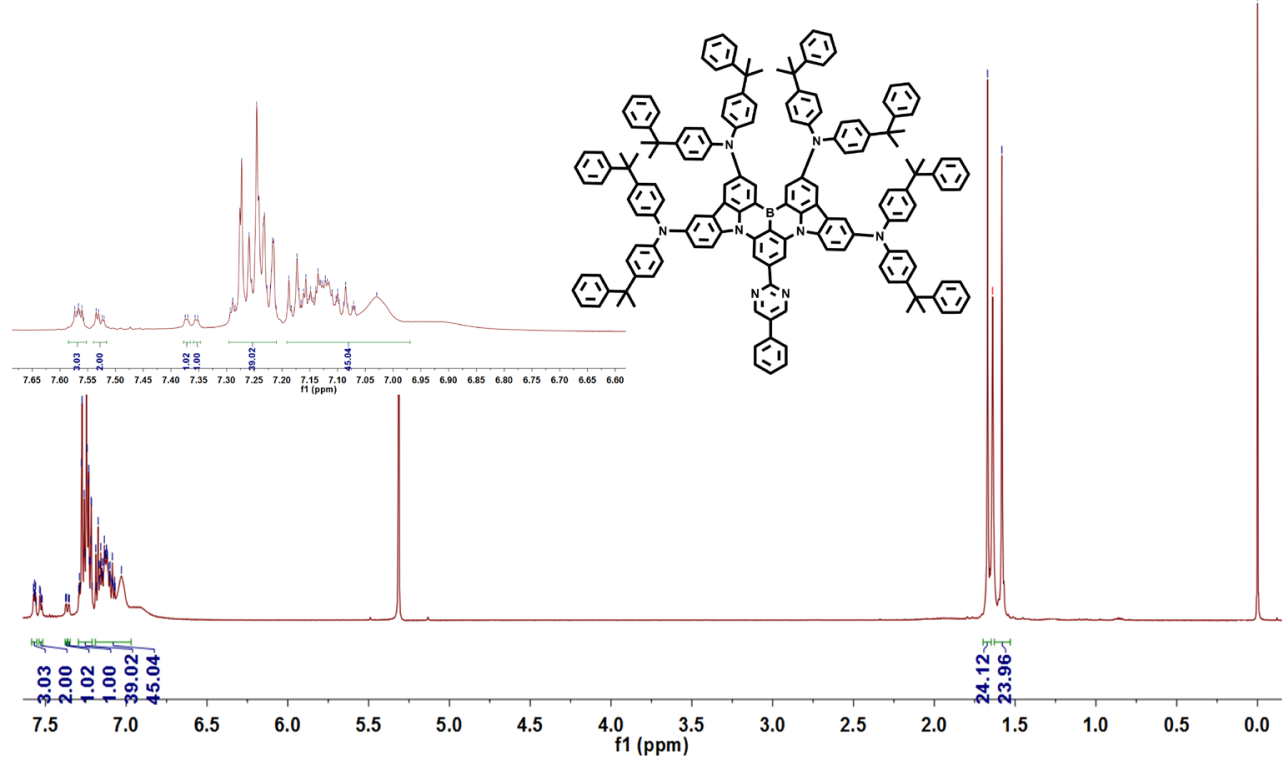

Figure S11. ${ }^{1} \mathrm{H}$ NMR spectrum $\left(500 \mathrm{MHz}, \mathrm{CD}_{2} \mathrm{Cl}_{2}\right)$ of $\mathrm{BN}-9$. 


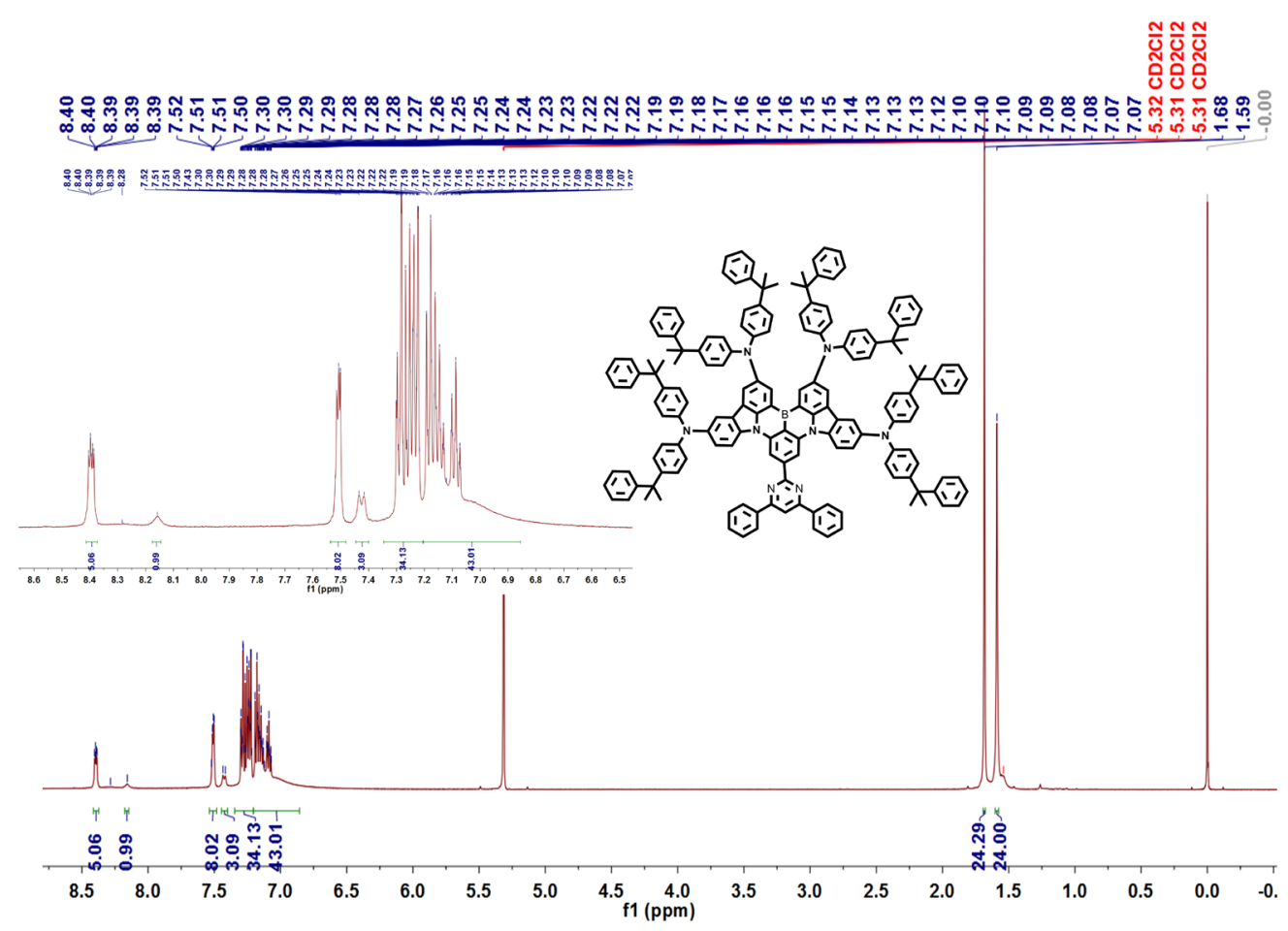

Figure S12. ${ }^{1} \mathrm{H}$ NMR spectrum $\left(500 \mathrm{MHz}, \mathrm{CD}_{2} \mathrm{Cl}_{2}\right)$ of $\mathrm{BN}-10$.

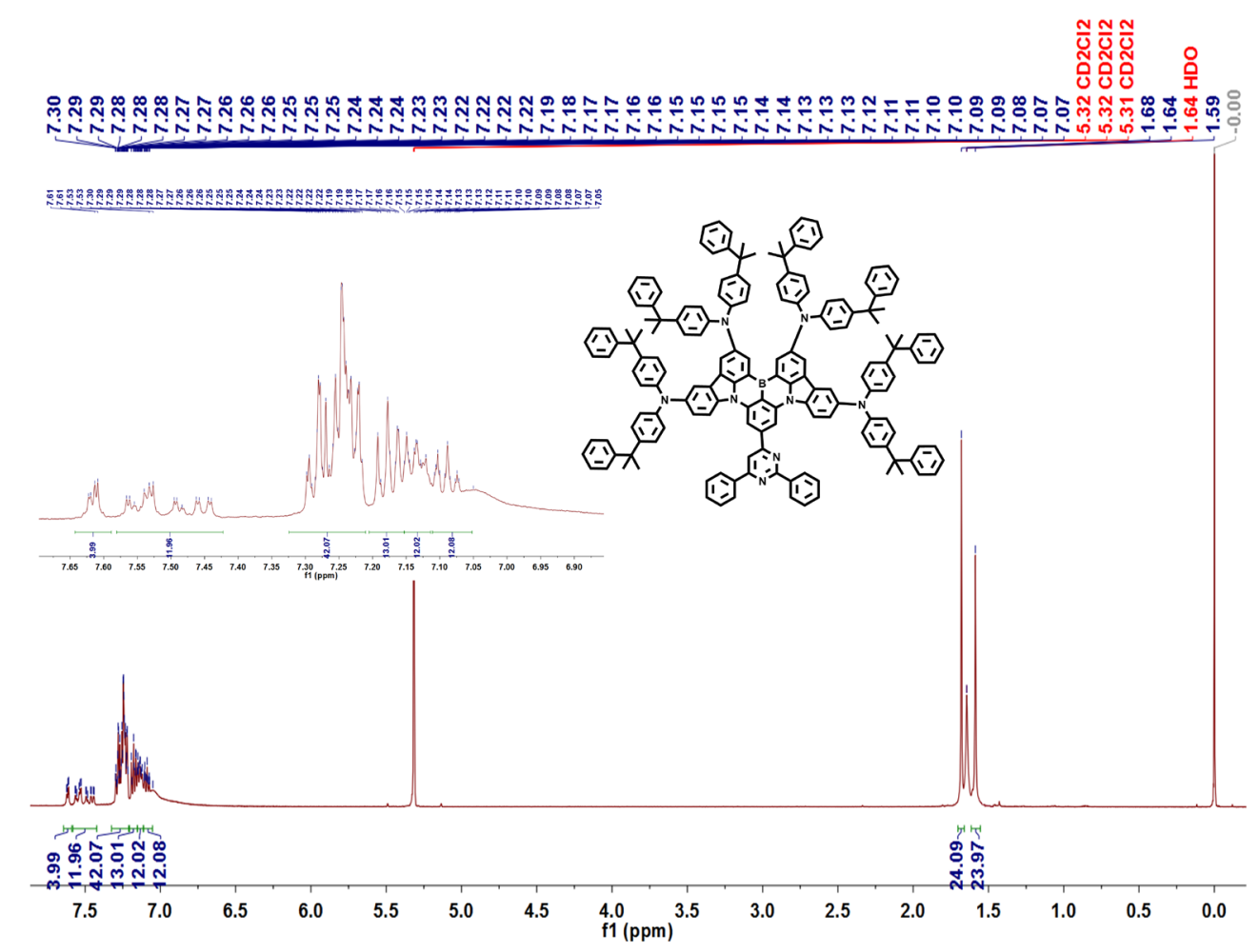

Figure S13. ${ }^{1} \mathrm{H}$ NMR spectrum $\left(500 \mathrm{MHz}, \mathrm{CD}_{2} \mathrm{Cl}_{2}\right)$ of $\mathrm{BN}-11$. 


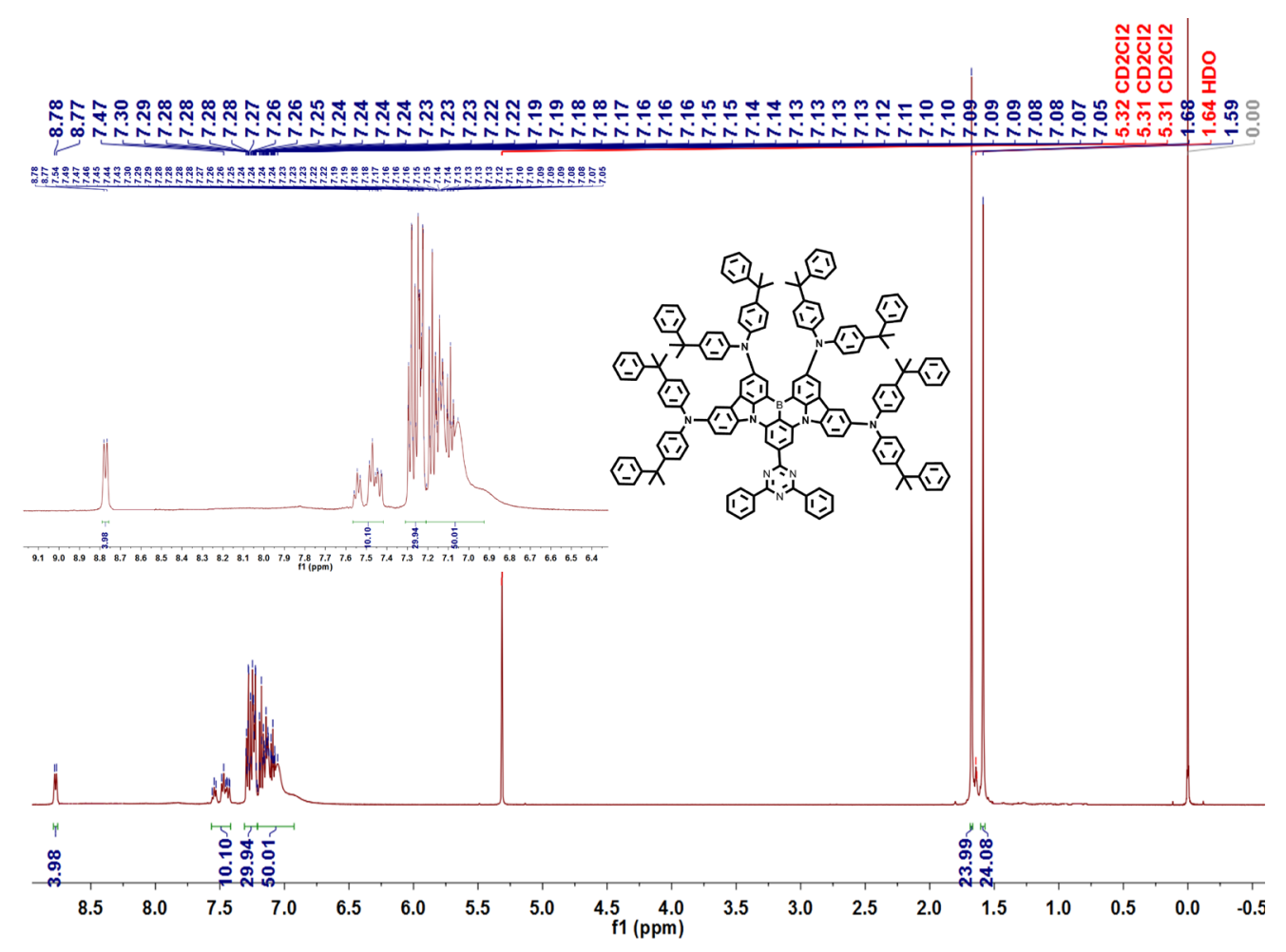

Figure S14. ${ }^{1} \mathrm{H}$ NMR spectrum $\left(500 \mathrm{MHz}, \mathrm{CD}_{2} \mathrm{Cl}_{2}\right)$ of $\mathrm{BN}-12$.

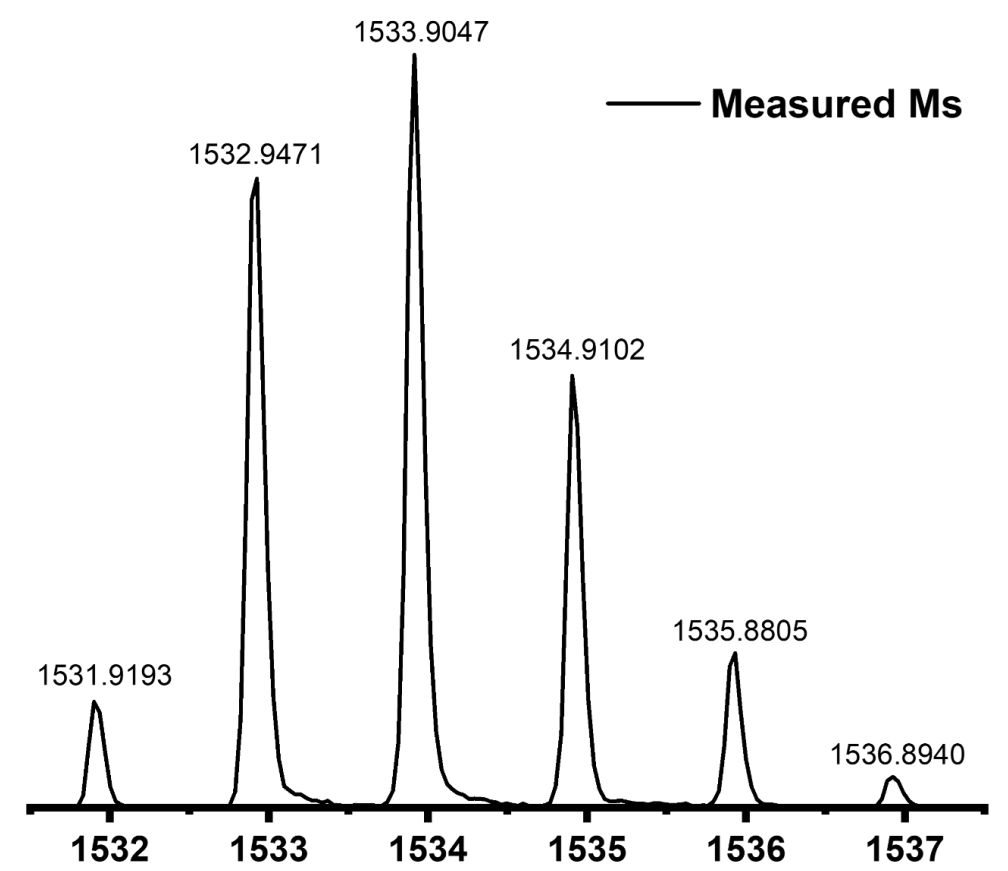

Figure S15. MALDI spectrum of BN-1. 


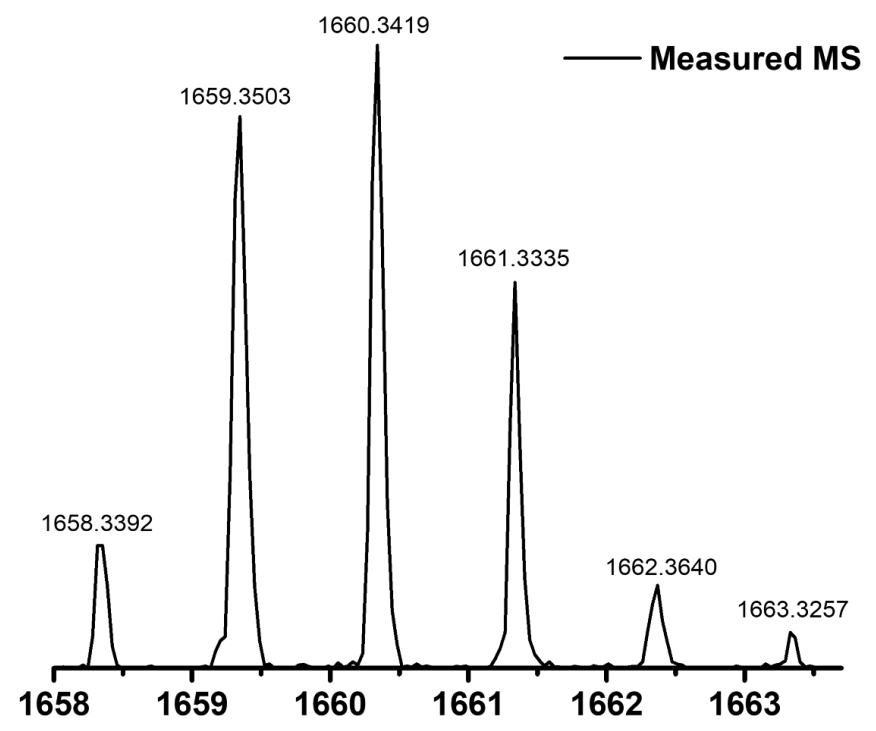

Figure S16. MALDI spectrum of BN-1-Bpin.

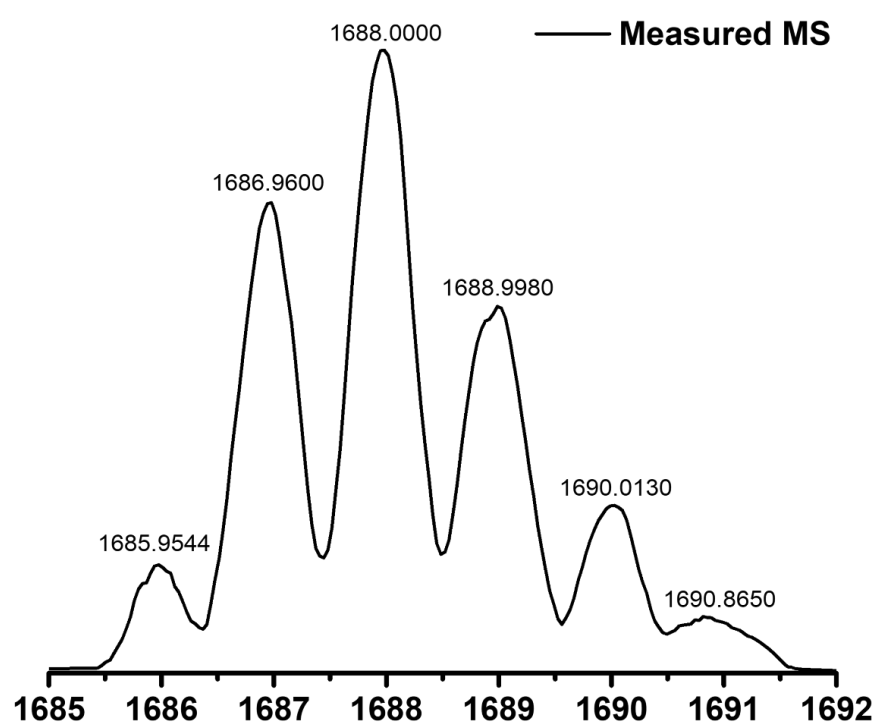

Figure S17. MALDI spectrum of BN-2. 


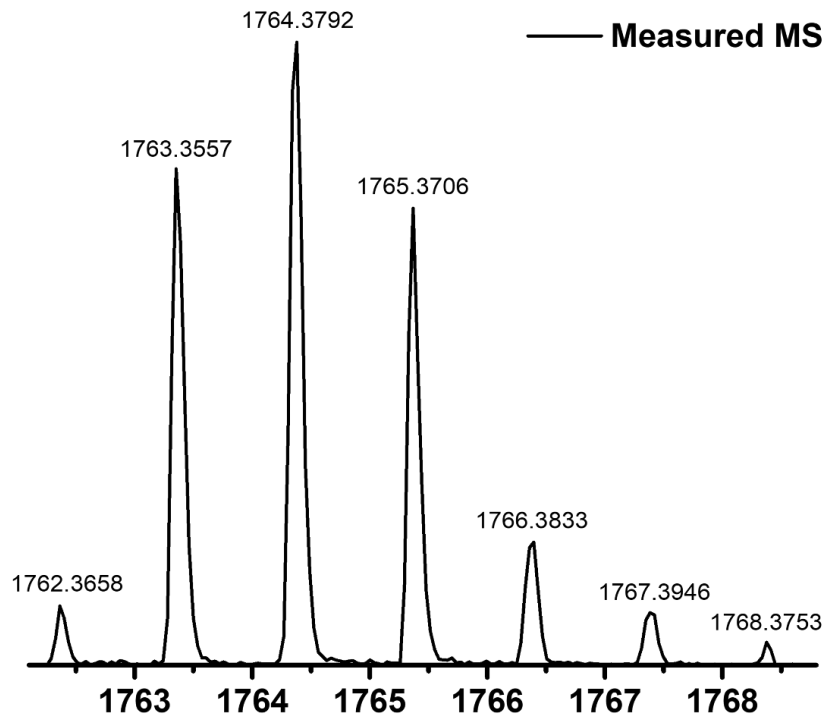

Figure S18. MALDI spectrum of BN-3.

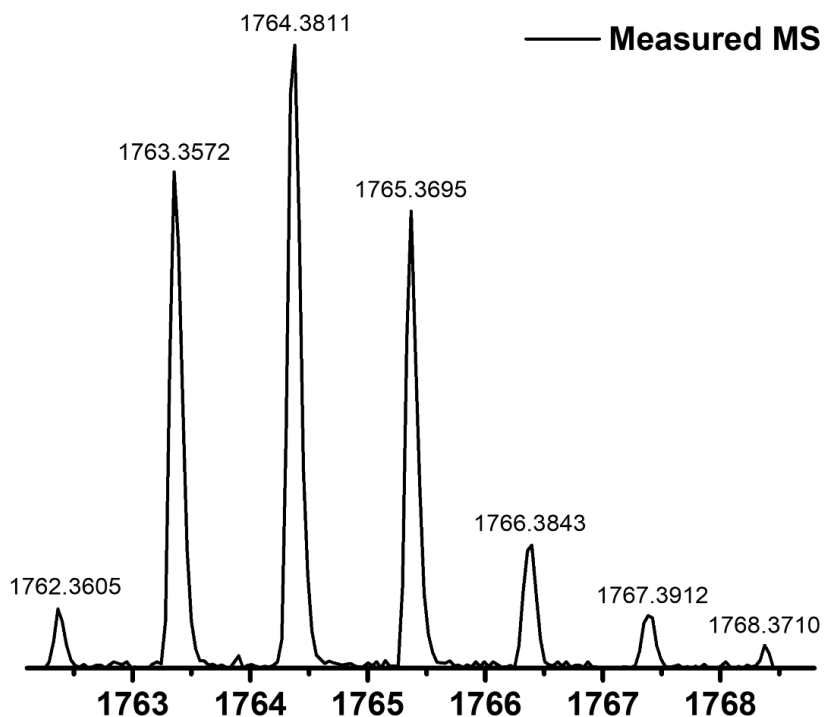

Figure S19. MALDI spectrum of BN-4. 


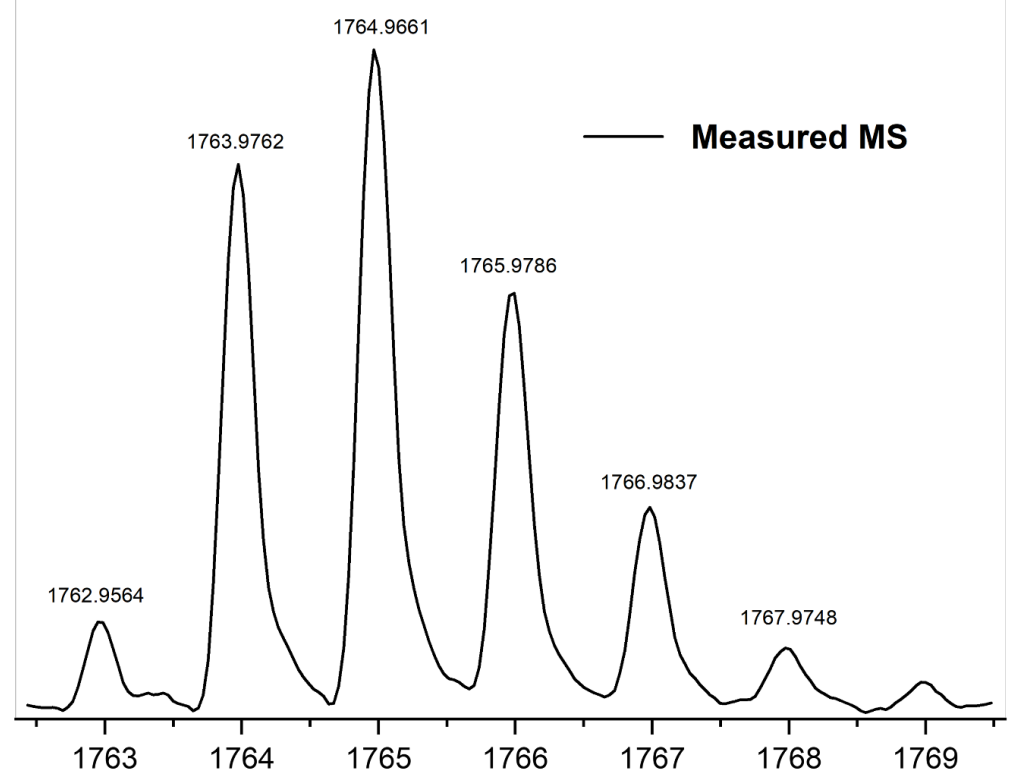

Figure S20. MALDI spectrum of BN-5.

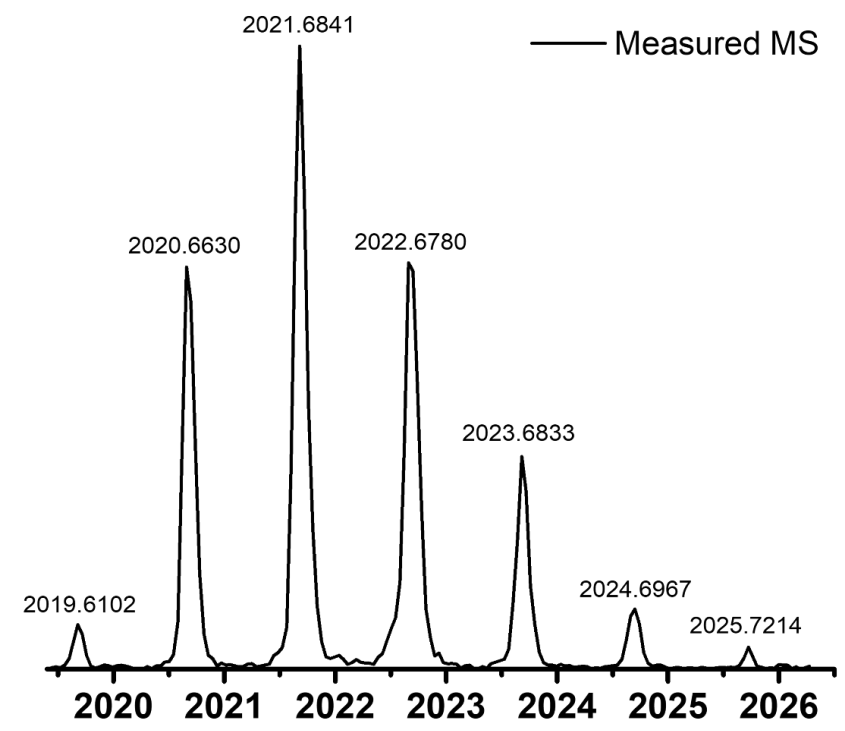

Figure S21. MALDI spectrum of BN-6. 


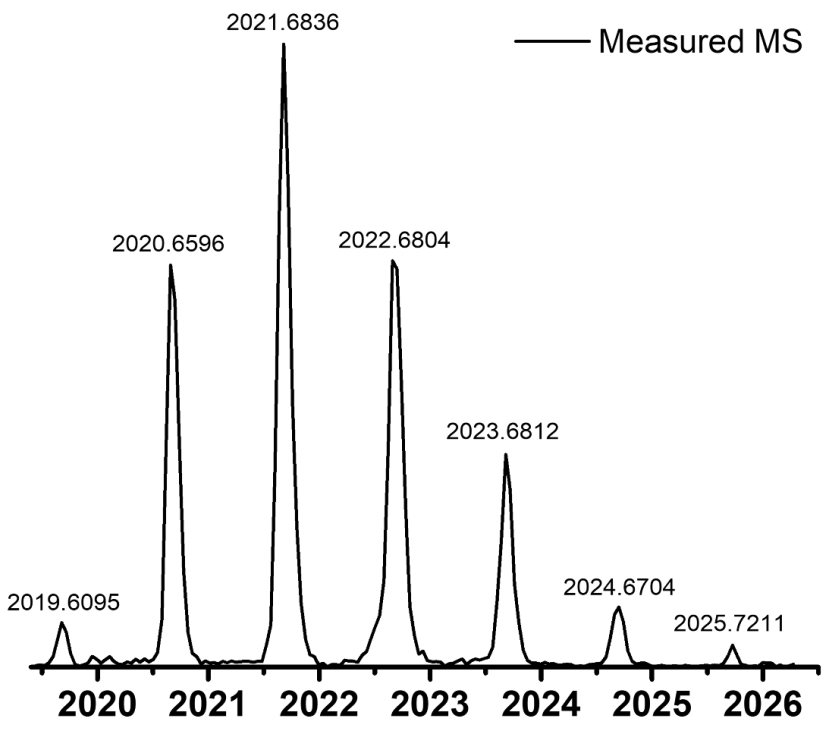

Figure S22. MALDI spectrum of BN-7.

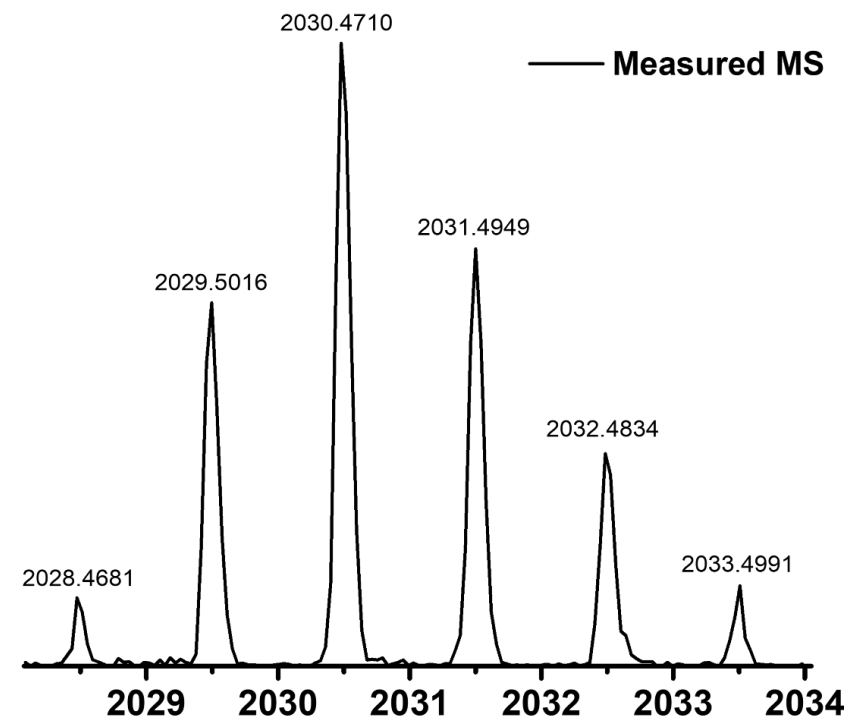

Figure S23. MALDI spectrum of BN-8. 


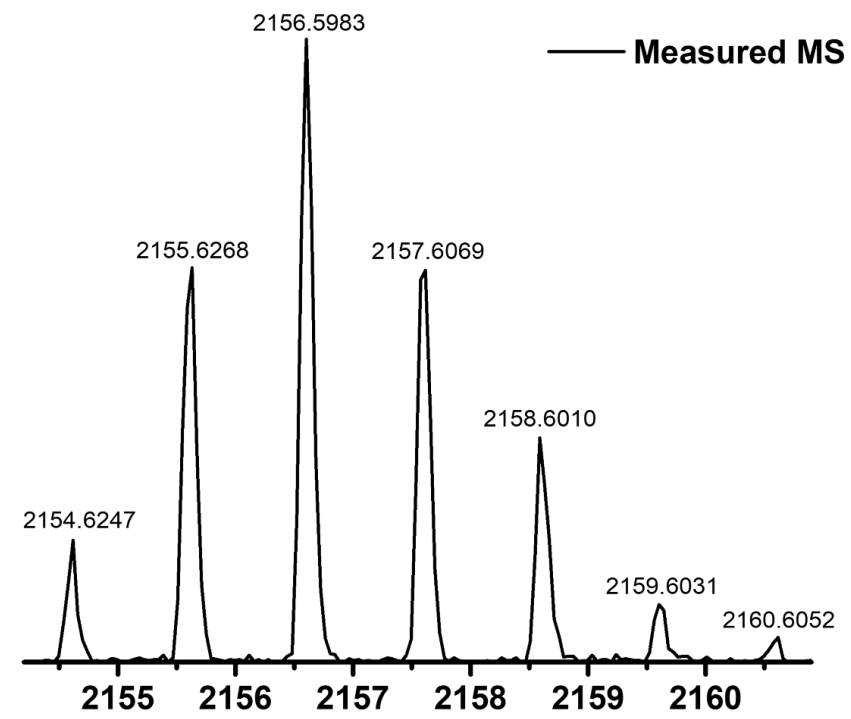

Figure S24. MALDI spectrum of BN-8-Bpin.

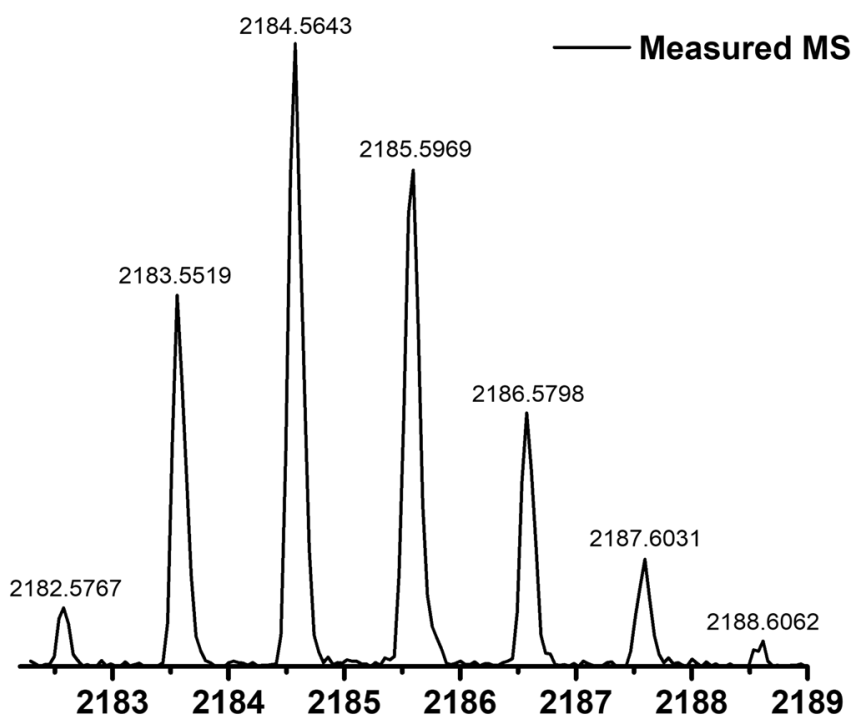

Figure S25. MALDI spectrum of BN-9. 


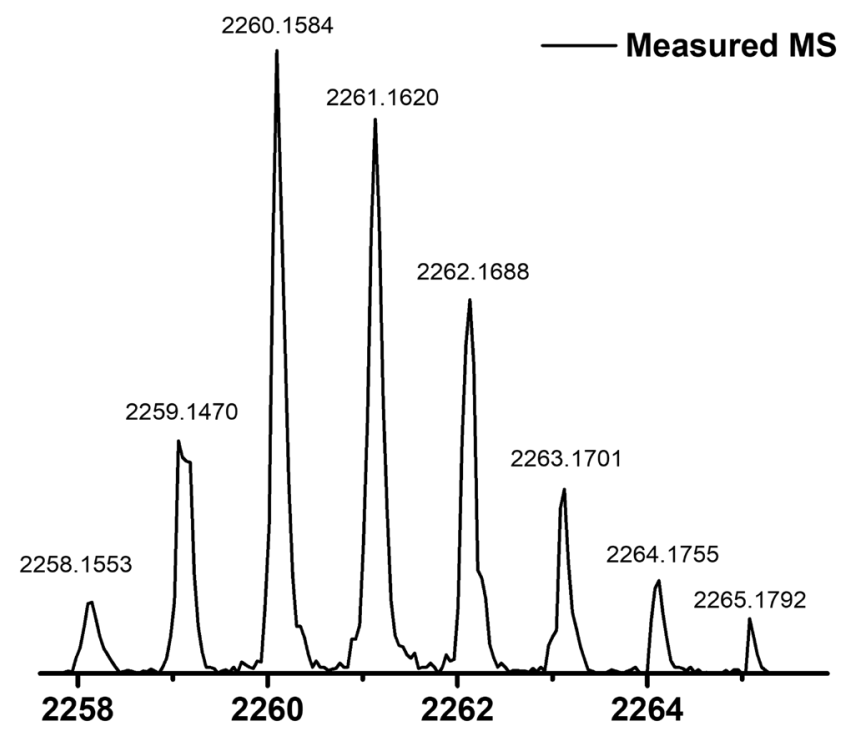

Figure S26. MALDI spectrum of BN-10.

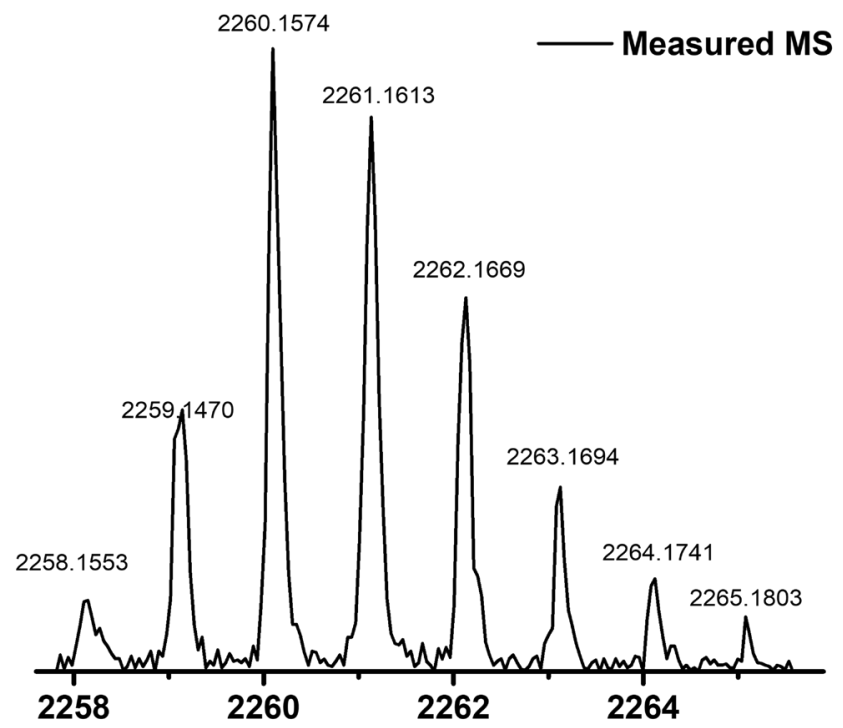

Figure S27. MALDI spectrum of BN-11. 


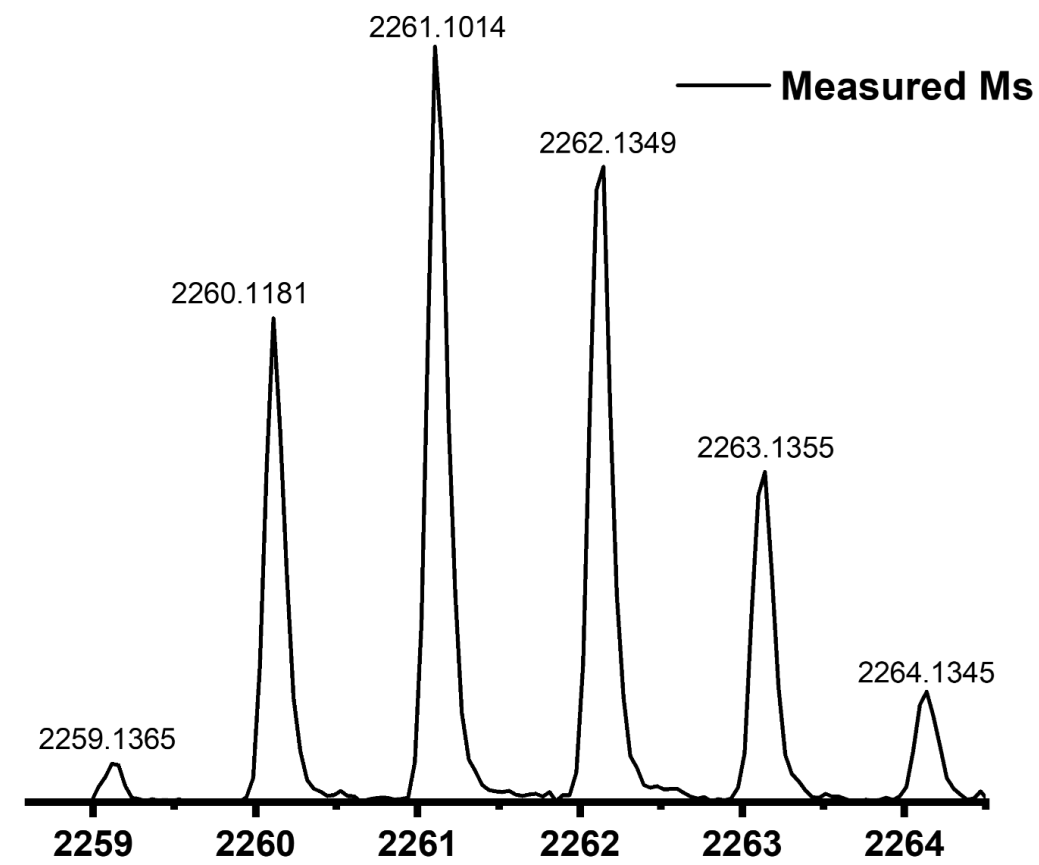

Figure S28. MALDI spectrum of BN-12.

(a)

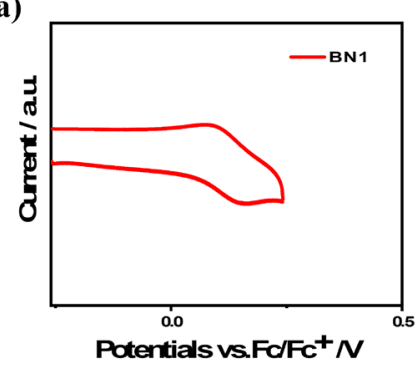

(c)

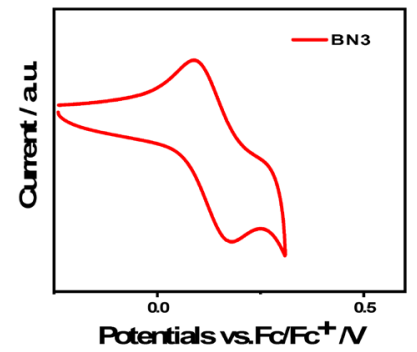

(b)

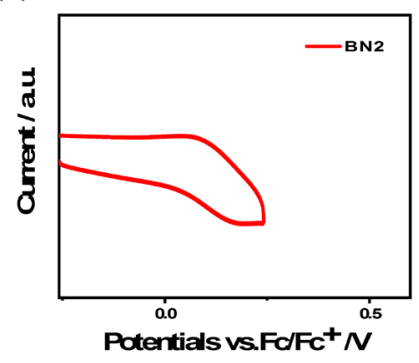

(d)

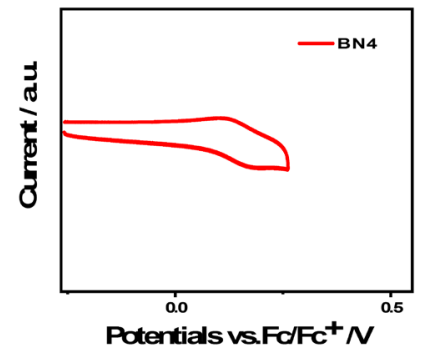

Figure S29. CV curves of BN-1 (a), BN-2 (b), BN-3 (c) and BN-4 (d). 
(a)

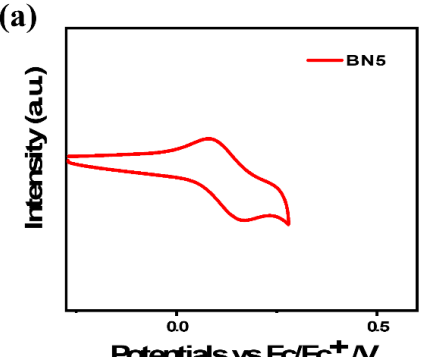

(c)

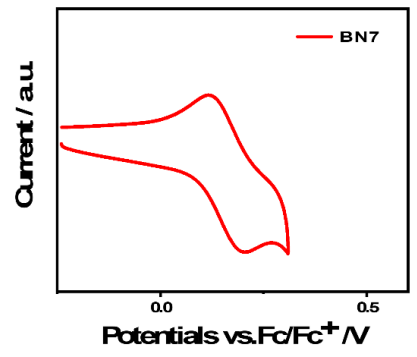

(b)

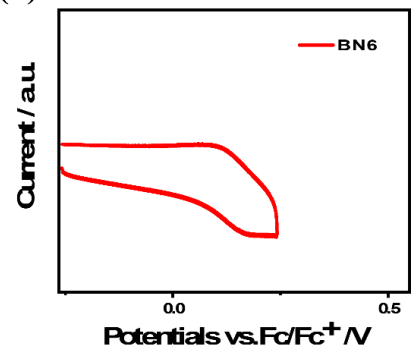

(d)

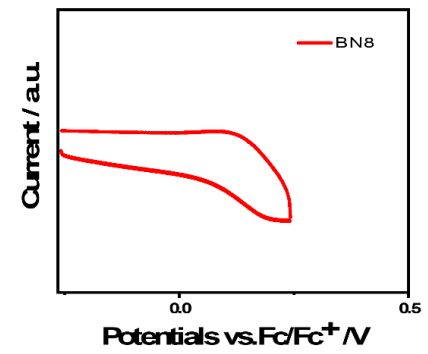

Figure S30. CV curves of BN-5 (a), BN-6 (b), BN-7 (c) and BN-8 (d).

(a)

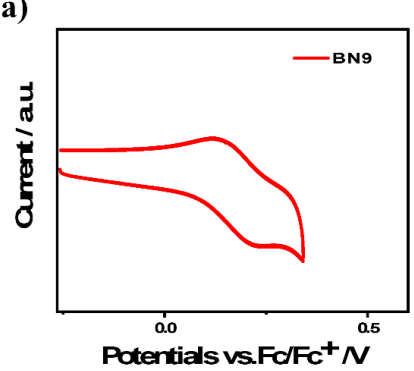

(c)

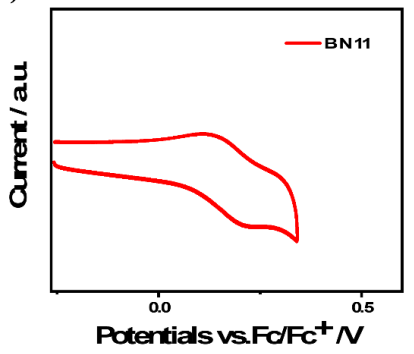

(b)

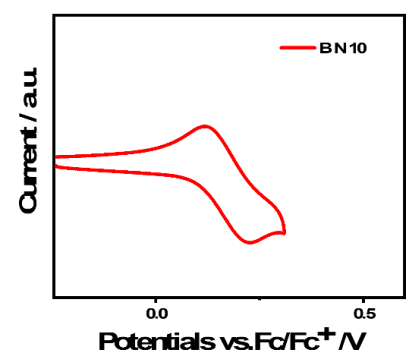

(d)

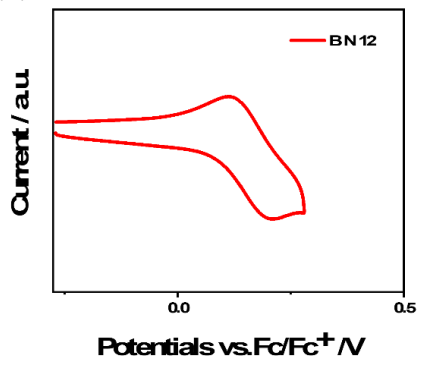

Figure S31. CV curves of BN-9 (a), BN-10 (b), BN-11 (c) and BN-12 (d). 
(a)

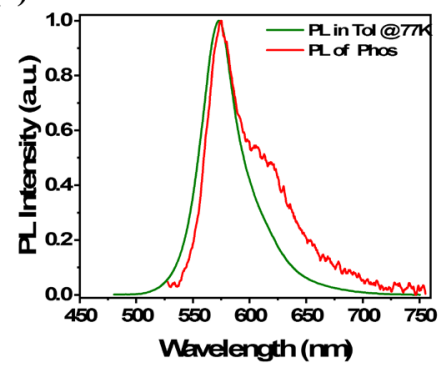

(c)

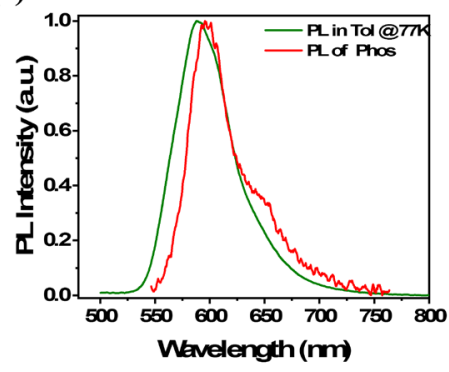

(b)

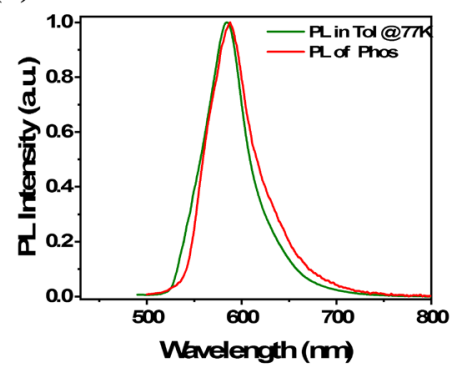

(d)

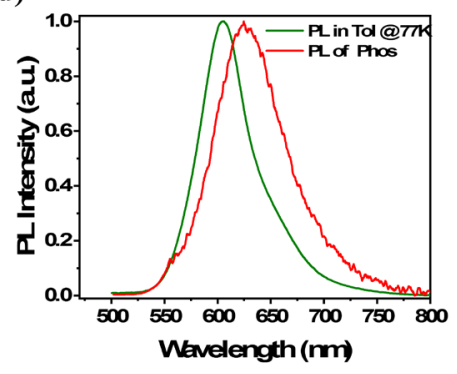

Figure S32. Normalized fluorescence and phosphorescence spectra of BN-1 (a), BN-

2 (b), BN-3 (c) and BN-4 (d) measured in toluene solution $\left(1 \times 10^{-5} \mathrm{M}, 77 \mathrm{~K}\right)$.

(a)

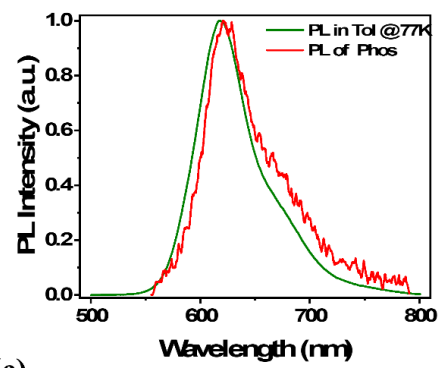

(c)

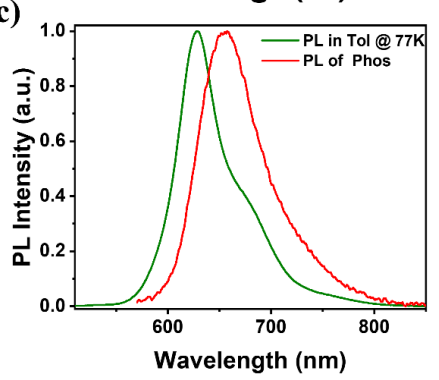

(b)
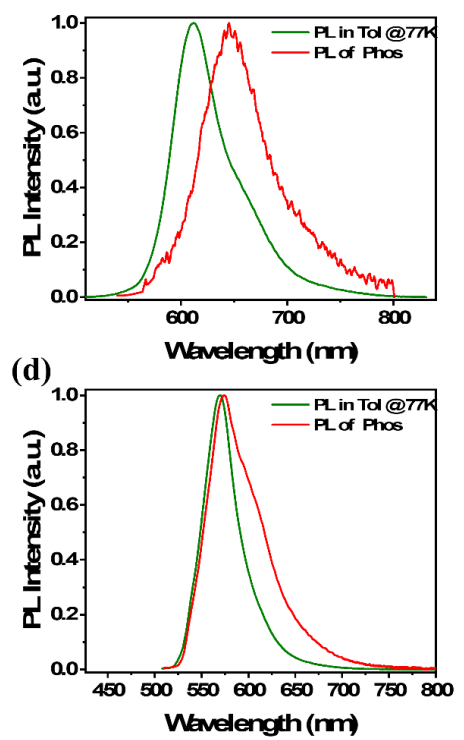

Figure S33. Normalized fluorescence and phosphorescence spectra of BN-5 (a), BN-

6 (b), BN-7 (c) and BN-8 (d) measured in toluene solution $\left(1 \times 10^{-5} \mathrm{M}, 77 \mathrm{~K}\right)$. 
(a)

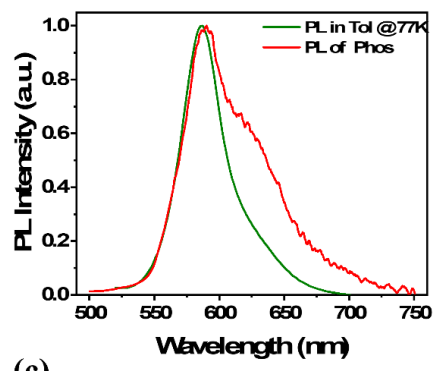

(c)

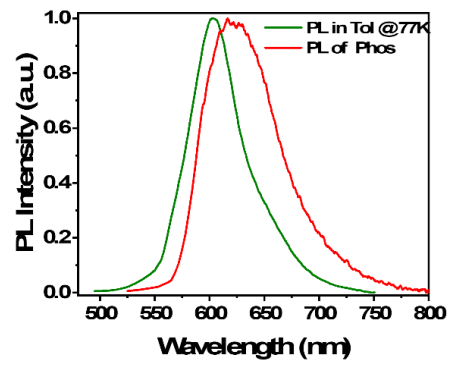

(b)

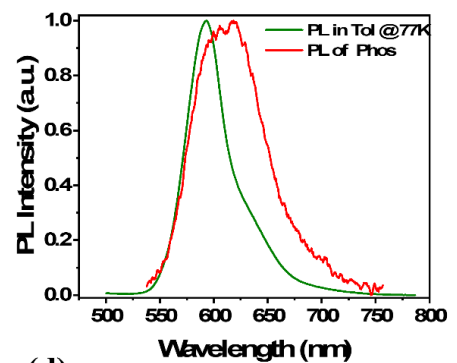

(d)

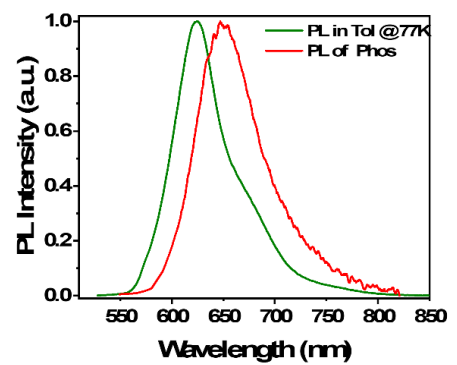

Figure S34. Normalized fluorescence and phosphorescence spectra of BN-9 (a), BN-

10 (b), BN-11 (c) and BN-12 (d) measured in toluene solution $\left(1 \times 10^{-5} \mathrm{M}, 77 \mathrm{~K}\right)$.

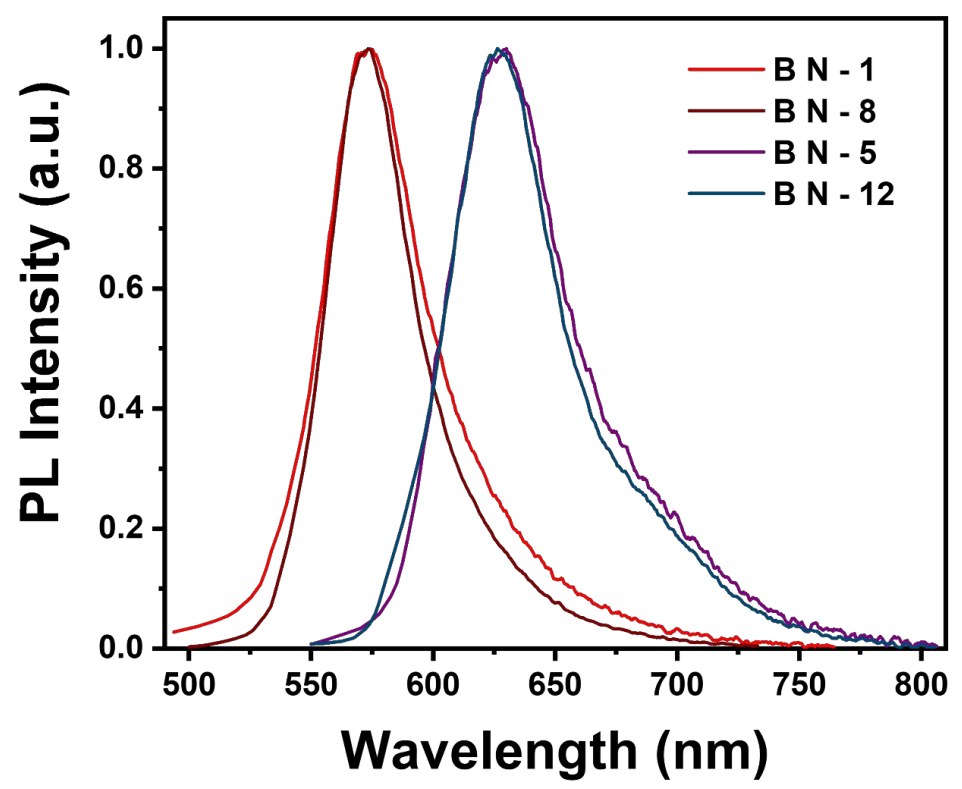

Figure S35. PL spectra of 3 wt $\%$ doping concentration of BN-1 (a), BN-5 (b), BN-8

(c) and BN-12 (d) in mCP deposited films. 
(a)
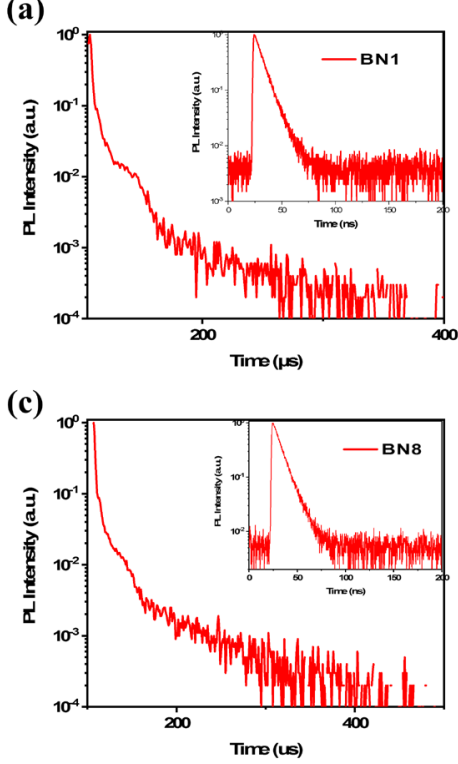

(b)

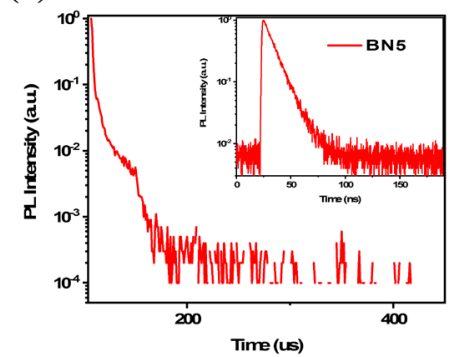

(d)

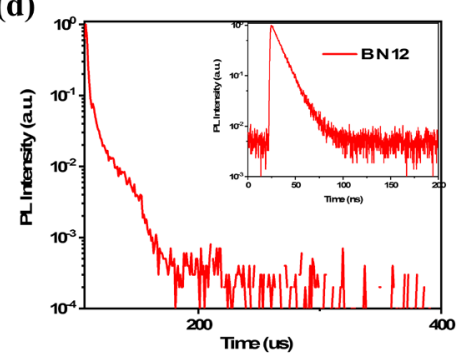

Figure S36. Transient PL decay spectra in film of BN-1 (a), BN-5 (b), BN-8 (c) and $\mathrm{BN}-12(\mathrm{~d})$.

\section{References}

(1) A. D. Becke, J. Chem. Phys. 1993, 98, 5648-5652.

(2) C. Lee, W. Yang, R. G. Parr, Phys. Rev. B 1988, 37, 785-789.

(3) R. Krishnan, J. S. Binkley, R. Seeger, J. Pople, J. Chem. Phys. 1980, 72, 650-654.

(4) S. Grimme, J. Antony, S. Ehrlich, H. Krieg, J. Chem. Phys. 2010, 132, 154104.

(5) Gaussian 09, Revision D.01, M. J. Frisch, G. W. Trucks, H. B. Schlegel, G. E. Scuseria, M. A. Robb, J. R. Cheeseman, G. Scalmani, V. Barone, B. Mennucci, G. A. Petersson, H. Nakatsuji, M. Caricato, X. Li, H. P. Hratchian, A. F. Izmaylov, J. Bloino, G. Zheng, J. L. Sonnenberg, M. Hada, M. Ehara, K. Toyota, R. Fukuda, J. Hasegawa, M. Ishida, T. Nakajima, Y. Honda, O. Kitao, H. Nakai, T. Vreven, J. A. Montgomery, Jr., J. E. Peralta, F. Ogliaro, M. Bearpark, J. J. Heyd, E. Brothers, K. N. Kudin, V. N. 
Staroverov, T. Keith, R. Kobayashi, J. Normand, K. Raghavachari, A. Rendell, J. C. Burant, S. S. Iyengar, J. Tomasi, M. Cossi, N. Rega, J. M. Millam, M. Klene, J. E. Knox, J. B. Cross, V. Bakken, C. Adamo, J. Jaramillo, R. Gomperts, R. E. Stratmann, O. Yazyev, A. J. Austin, R. Cammi, C. Pomelli, J. W. Ochterski, R. L. Martin, K. Morokuma, V. G. Zakrzewski, G. A. Voth, P. Salvador, J. J. Dannenberg, S. Dapprich, A. D. Daniels, O. Farkas, J. B. Foresman, J. V. Ortiz, J. Cioslowski, and D. J. Fox, Gaussian, Inc., Wallingford CT, 2013.

[6] C. Jiang, M. Zhao, X. Chen, X. Li, H. Wang, Dyes and Pigments 2020, 174, 108044 